UNIVERSIDADE DE BRASÍLIA

FACULDADE DE CIÊNCIAS DA SAÚDE

DEPARTAMENTO DE ENFERMAGEM

PROGRAMA DE PÓS-GRADUAÇÃO EM ENFERMAGEM

SAMUEL RIOS TEIXEIRA

PREVALÊNCIA DO USO DE ÁLCOOL E DE TABACO ENTRE ALUNOS DO CURSO DE ENFERMAGEM EM DUAS FACULDADES PRIVADAS DO DISTRITO FEDERAL.

BRASÍLIA 


\author{
UNIVERSIDADE DE BRASÍLIA \\ FACULDADE DE CIÊNCIAS DA SAÚDE \\ DEPARTAMENTO DE ENFERMAGEM \\ PROGRAMA DE PÓS-GRADUAÇÃO EM ENFERMAGEM
}

SAMUEL RIOS TEIXEIRA

PREVALÊNCIA DO USO DE ÁLCOOL E DE TABACO ENTRE ALUNOS DO CURSO DE ENFERMAGEM EM DUAS FACULDADES PRIVADAS DO DISTRITO FEDERAL.

\begin{abstract}
Dissertação apresentada ao Programa de Pós-Graduação em Enfermagem, como requisito parcial para a obtenção do Grau de Mestre em Enfermagem pela Universidade de Brasília.
\end{abstract}

Área de Concentração: Gestão de Sistemas e de Serviços em Saúde e Enfermagem Linha de Pesquisa: Epidemiologia Orientador: Prof. Dr. Pedro Sadi Monteiro

BRASÍLIA 
Ficha catalográfica elaborada automaticamente, com os dados fornecidos pelo(a) autor(a)

REN56p TEIXEIRA, SAMUEL

Prevalência do uso de álcool e de tabaco entre alunos do curso de enfermagem em duas faculdades privadas do Distrito Federal. / SAMUEL RIOS TEIXEIRA; orientador PEDRO SADI MONTEIRO. -Brasilia, 2017.

$101 \mathrm{p}$.

Dissertação (Mestrado - Mestrado em Enfermagem) -Universidade de Brasilia, 2017.

1. Prevalência. 2. Consumo de bebidas alcólicas. 3. Tabagismo. 4. Bstudantes de enfermagem. I. SADI MONTEIRO, PEDRO, orient. II. Título. 


\section{PREVALÊNCIA DO USO DE ÁLCOOL E DE TABACO ENTRE ALUNOS DO CURSO DE ENFERMAGEM EM DUAS FACULDADES PRIVADAS DO DISTRITO FEDERAL.}

Dissertação apresentada ao Programa de Pós-Graduação em Enfermagem, como requisito parcial para a obtenção do Grau de Mestre em Enfermagem pela Universidade de Brasília.

Brasília, 29 de março de 2017.

BANCA EXAMINADORA

Prof. Dr. Pedro Sadi Monteiro

Universidade de Brasília

Presidente

Profa. Dra. Ana Karina Bezerra Pinheiro

Universidade Federal do Ceará

Membro

Profa. Dra. Gisele Martins

Universidade de Brasília

Membro

Prof. Dra. Dirce Guilhem

Suplente

Universidade de Brasília 


\section{AGRADECIMENTOS}

A Deus, pelas portas abertas e por todas as bênçãos enviadas.

Ao meu orientador, Prof. Dr. Pedro Sadi Monteiro, pelo apoio prestado na execução da dissertação, por todo o conhecimento compartilhado, pela compreensão nos momentos difíceis e pela prontidão com que tratou todas as minhas solicitações e dúvidas.

Às Profas. Dra. Dirce Guilhem e Dra. Gisele Martins pela gentileza de aceitarem o convite para composição da banca examinadora e pelas contribuições valiosas para o aprimoramento do trabalho.

À Profa. Dra. Ana Karina Bezerra Pinheiro que tão gentil e prontamente deslocou-se de Fortaleza à Brasília, mesmo com sua atribulada rotina de trabalho, para participar deste momento tão importante em minha carreira e por todos os ensinamentos durante a graduação na Universidade Federal do Ceará.

À minha querida mãe por todo o amor, incentivo e esforço imprimidos de maneira batalhadora e incansável em prol da minha formação.

À minha esposa, Alexandra, pelo companheirismo e incentivo desde o primeiro momento desta caminhada e por compartilhar comigo todas as angústias, medos e alegrias dando-me força e coragem a todo o momento.

À minha pequena Sofia, filha tão amada e razão da minha vida, que a cada "papai" proferido, a cada olhar dirigido e pela ternura dos momentos ao seu lado, me fez relaxar e me encheu de motivação e força para concluir este projeto.

A todos os meus familiares a amigos que vibraram comigo e torceram pelo sucesso deste projeto.

Ao Programa de Pós-Graduação em Enfermagem da Universidade de Brasília que de maneira profissional e responsável possibilitou a materialização deste sonho.

Ao amigo e colega de profissão Vinícius pela parceria e apoio na coleta de dados.

Às colegas, Analy, Anaely, Denise, Karla. Renata e Ana Carolina, pela parceria durante toda essa caminhada.

Aos colegas Suderlan e Patrícia e às Coordenações de Curso de Enfermagem das faculdades pelas portas abertas para a efetivação da coleta de dados.

Por fim, aos acadêmicos de enfermagem que aceitaram participar da pesquisa e assim possibilitar a construção do conhecimento científico. 
“A tarefa não é tanto ver aquilo que ninguém viu, mas pensar o que ninguém ainda pensou sobre aquilo que todo mundo vê." 


\section{RESUMO}

Introdução: O consumo excessivo de álcool e de tabaco é um problema recorrente na população mundial. Nesse contexto, o público universitário constitui um grupo vulnerável a práticas de risco para a saúde envolvendo o abuso e a dependência dessas substâncias. Objetivo: Analisar a prevalência e o padrão de risco do consumo de álcool e de tabaco entre alunos de enfermagem em duas faculdades privadas do Distrito Federal. Metodologia: Tratase de um estudo epidemiológico transversal descritivo e analítico. A coleta dos dados ocorreu entre março e maio de 2016, aplicando-se questionário com 179 estudantes de enfermagem. Utilizou-se um questionário fechado baseado na ferramenta Alcool, Smoking and Substance Involvement Screening Test - ASSIST, elaborado pela Organização Mundial de Saúde, com versão autoaplicável validada no Brasil. Para a análise das associações entre variáveis, utilizou-se o teste de Qui-Quadrado com correção de Yates. Foram considerados significantes os resultados cujo valor $\mathrm{p}$ foi inferior ou igual a 5\%. Resultados: A população estudada foi predominantemente feminina, com idade igual ou superior a 22 anos, solteira, de etnia parda, cursando até o $4^{\circ}$ semestre. Um estudante que já usou álcool na vida tem 18,86 vezes mais chances de também ter usado tabaco do que aquele que nunca usou álcool. As prevalências de uso atual de álcool e tabaco foram respectivamente 50,2\% e 7,3\%. A faixa de consumo de baixo risco prevaleceu para ambas as drogas. Dirigir veículo e falta à escola ou trabalho foram as situações mais vivenciadas após o consumo do álcool. Conclusão: O consumo de álcool associou-se significativamente ao consumo de tabaco e a classificação do grau de risco de consumo para ambas as drogas também demonstrou ser estatisticamente significante. Estudantes que experimentaram o álcool por curiosidade e influência de amigos tiveram mais chances de serem classificados em consumo de alto risco. Quanto ao tabaco, estudantes que o experimentaram com idades mais precoces tiveram mais chances de serem classificados nesta mesma faixa de risco.

Descritores: Prevalência. Consumo de bebidas alcoólicas. Tabagismo. Estudantes de enfermagem. 


\begin{abstract}
Introduction: The dependent use of alcohol and tobacco is an increasing problem around the world. University students are considered to be extremely vulnerable to unhealthy practices that might damage their health, especially becoming dependent to these substances. Objective: Analyze the prevalence and pattern of risk of alcohol and tobacco use among nursing students from two private universities in the Federal District, Brazil. Method: To do so, a descriptive and cross-sectional epidemiological study was conducted. Data was collected between March and May, 2016, from 179 nursing students. Based on the tool Alcohol, Smoking and Substance Involvement Screening Test - ASSIST, created by the World Health Organization, a questionnaire from the Brazilian version of the tool was applied. In the analysis of possible associations of variables, the chi-squared test with Yates correction was used. Values $\mathrm{p}<0.05$ were considered significant. Results: The majority of the studied population were female, aged 22 years or over, single, dark skinned, up to the fourth semester. Students that have already consumed alcohol in their lives are 18.86 times more likely to use tobacco than students that have never consumed alcohol. The prevalence of alcohol and tobacco use was of $50.2 \%$ and $7.6 \%$ respectively. The low risk consumption line was the same for both drugs. Driving a vehicle, truancy and missing work were the most common situations experienced after consuming alcohol. Conclusion: Alcohol consumption was significantly associated with tobacco consumption. Furthermore, the classification of the degree of consumption risk for both drugs was statistically significant. Students who experimented with alcohol out of curiosity and influence from friends were more likely to be classified as high-risk drinkers. Students who tried tobacco at an earlier age were more likely to be classified in this same group.
\end{abstract}

Keywords: Prevalence; Alcohol use; Tobacco use; Nursing Students. 


\section{RESUMEN}

Introducción: el consumo excesivo de alcohol y de tabaco es un problema recurrente en la población mundial. En este contexto, los estudiantes unversitarios son un grupo vulnerable a prácticas de riesgo para salud relacionadas al abuso y la dependencia de estas sustancias. Objetivo: analisar la prevalencia del consumo de alcohol y tabaco por estudiantes de enfermería en dos instituciones de enseñanza superior privadas en el Distrito Federal. Metodología: se trata de un estudio epidemiológico transversal descriptivo y analítico. La recolección de datos ocurrió entre marzo y mayo de 2016, basado em un cuetionario respondidos por 179 estudiantes. Se utilizó un cuestionario basado en la herramienta Alcool, Smoking and Substance Involvement Screening Test (ASSIST), elaborada por la Organización Mundial de la Salud, con versión validada en Brasil. Para el análisis de posibles asociaciones entre variables, se utilizó la prueba chi-cuadrado con corrección de Yates. Los resultados con valores de P inferiores a 5\% fueron considerados significativos. Resultados: La población de estudio fue predominantemente femenina, con edad igual o superior a 22 años, soltera, parda, estudiando hasta el $4^{\circ}$ semestre. Es más probable un estudiante que ya ha utilizado alcohol en vida también ya tener usado el tabaco que los que nunca utilizaron el alcohol. La prevalencia de uso actual de alcohol fue de 50,2\% y la prevalencia para el tabaco fue $7.6 \%$. La mayoría de los entrevistado fueron clasificados em la categoría de bajo riesgo para el consumo de las dos sustancias. Conducir vehículos y faltar a la escuela o el trabajo fueron las situaciones más observadas después del consumo de alcohol. Conclusión El consumo de alcohol es significativamente asociado al consumo de tabaco y la clasificación del grado de riesgo del consumo de las drogas también es estadísticamente significativa. Los estudiantes que han experimentado el alcohol por curiosidad e influencia de amigos presentaron mayor probabilidad de ser clasificado en consumo de alto riesgo. Sobre el tabaco, los estudiantes que experimentaron la sustancia con edades más tempranas eran más propensos a ser clasificados en este mismo grupo de riesgo.

Descriptores: Prevalencia; Consumo de Bebidas Alcohólicas; Consumo de Productos Derivados del Tabaco. Estudiantes de enfermería. 


\section{LISTA DE FIGURAS}

Figura 1 - Distribuição das faixas etárias de experimentação de álcool e de tabaco pela população estudada - DF, 2016. 


\section{LISTA DE TABELAS}

Tabela 1 - Perfil sociodemográfico dos estudantes por sexo - DF, 2016.

Tabela 2 - Distribuição dos estudantes conforme semestre e sexo, por faculdade- DF, 2016.42

Tabela 3 - Distribuição do comportamento de consumo de álcool e de tabaco na população estudada - DF, 2016.

Tabela 4 - Teste de independência de Qui-Quadrado e razão de chances para o uso de álcool e tabaco - DF, 2016

Tabela 5 - Distribuição do comportamento de consumo na vida e consumo atual de álcool e de tabaco por sexo na população estudada - DF 2016.

Tabela 6 - Distribuição das prevalências de relato e fatores associados ao uso de álcool na população estudada - DF, 2016.

Tabela 7 - Distribuição das prevalências de relato e fatores associados ao uso de tabaco na população estudada - DF, 2016.

Tabela 8 - Distribuição dos estudantes de acordo com as opções de resposta às questões do ASSIST na população estudada para ambas as drogas - DF, 2016

Tabela 9 - Porcentagem de participantes que pontuaram em cada questão do ASSIST segundo a droga na população estudada - DF, 2016.

Tabela 10 - Perfil dos estudantes por faixa de risco do ASSIST para o álcool na população estudada - DF, 2016.

Tabela 11 - Teste Qui-Quadrado entre o perfil dos estudantes e as faixas de risco do ASSIST para o uso de álcool - DF, 2016.

Tabela 12 - Distribuição dos estudantes que já utilizaram álcool na vida por semestre e faixa de risco do ASSIST para a droga na população estudada- DF, 2016.

Tabela 13 - Perfil dos estudantes por faixa de risco do ASSIST para o tabaco na população estudada - DF, 2016.

Tabela 14 - Teste Qui-Quadrado entre as variáveis do perfil dos estudantes e as faixas de risco do ASSIST para o uso de derivados do tabaco - DF, 2016. 66

Tabela 15 - Distribuição dos estudantes que já utilizaram tabaco na vida por semestre e faixa de risco do ASSIST para a droga na população estudada- DF, 2016.

Tabela 16 - Distribuição das situações vivenciadas após o consumo do álcool por faixa de risco do ASSIST - DF, 2016. 
Tabela 17 - Teste de independência de Qui-Quadrado entre as classificações de risco do

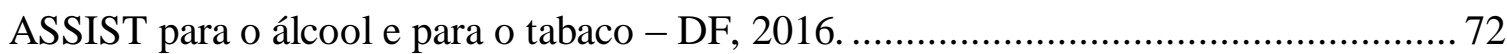




\section{LISTA DE SIGLAS}

AMS

ANVISA

ASSIST

BAT

CAPS

CAPS AD

CEP/FS

CID-10

CQCT

IBGE

INCA

INPAD

OMS

PNCT

RAPS

SPSS

SUS

TCLE
Assembleia Mundial de Saúde

Agência Nacional de Vigilância Sanitária

Alcool, Smoking and Substance Involvement Screening Test

British American Tobacco

Centros de Atenção Psicossocial

Centros de Atenção Psicossocial Álcool e Drogas

Comitê de Ética em Pesquisa da Faculdade de Ciências da Saúde

Classificação Estatística Internacional de Doenças e Problemas

Relacionados à Saúde

Convenção Quadro para Controle do Tabaco

Instituto Brasileiro de Geografia e Estatística

Instituto Nacional do Câncer

Instituto Nacional de Ciência e Tecnologia para Políticas

Públicas de Álcool e Outras Drogas

Organização Mundial de Saúde

Programa Nacional de Controle do Tabagismo

Rede de Atenção Psicossocial

Statistical Package for the Social Sciences

Sistema Único de Saúde

Termo de Consentimento Livre e Esclarecido 


\section{SUMÁRIO}

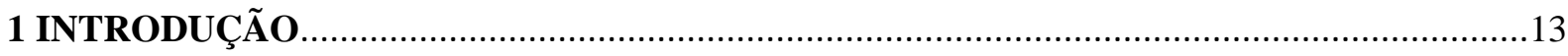

2 ASPECTOS CONCEITUAIS DA TEMÁTICA INVESTIGADA ..........................................22

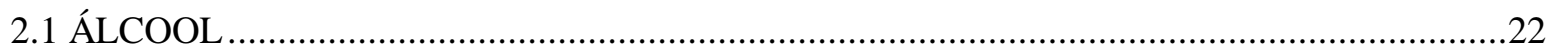

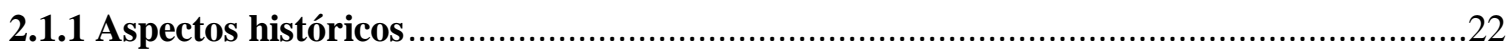

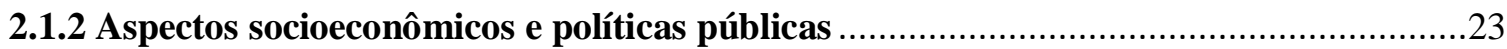

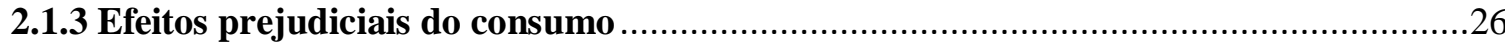

2.2 TABACO

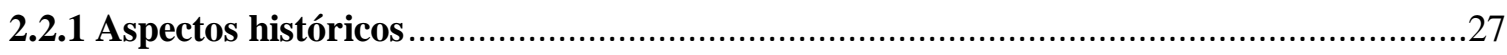

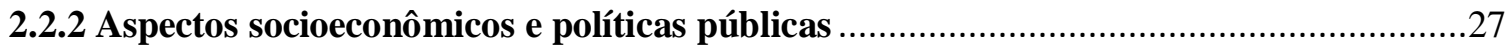

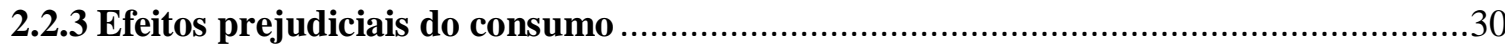

3 OBJETIVOS

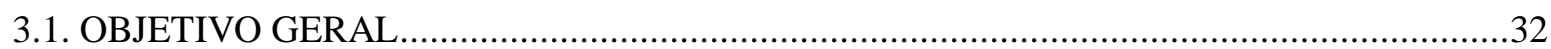

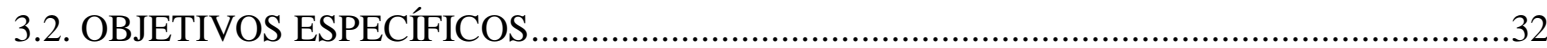

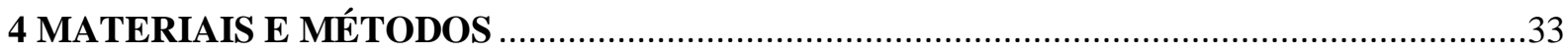

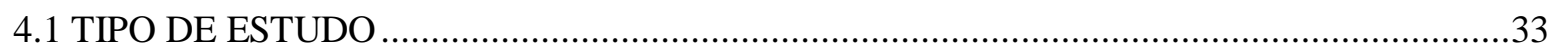

4.2 LOCAL DE REALIZAÇÃO DA PESQUISA E POPULAÇÃO ESTUDADA …........................33

4.3 TAMANHO DA AMOSTRA E SELEÇÃO DOS ESTUDANTES ...........................................33

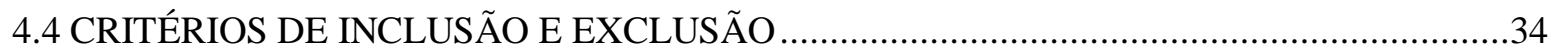

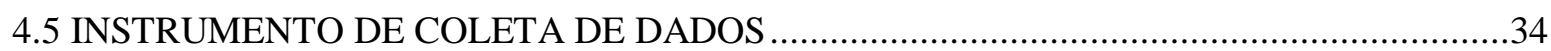

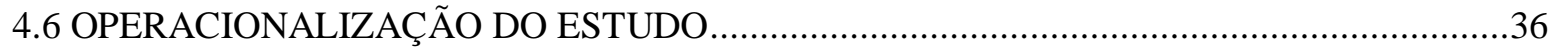

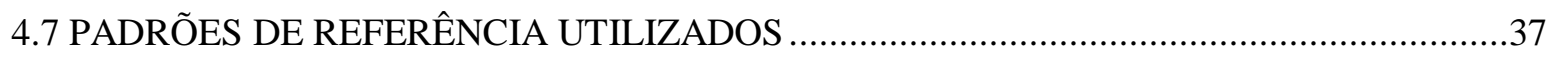

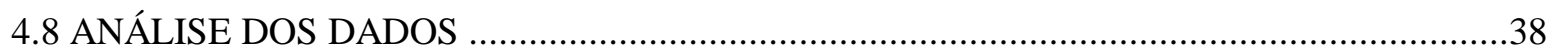

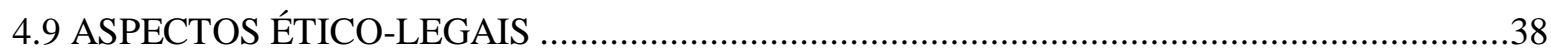

5 RESULTADOS E DISCUSSÃO

7 CONCLUSÃO

8 REFERÊNCIAS

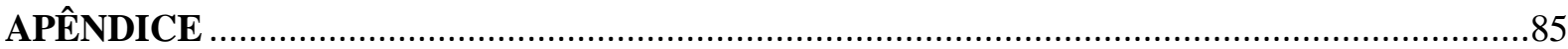


APÊNDICE A - Questionário de investigação do uso de álcool e tabaco.

ANEXO A - Questionário ASSIST - Versão Original - Entrevista .90

ANEXO B - Questionário ASSIST - Versão Adaptada - Autopreenchimento .92

ANEXO C - Tabela de Pontuação da Versão Adaptada para Autopreenchimento do ASSIST .99 ANEXO D - Parecer do Comitê de Ética em Pesquisa. 100 ANEXO E - Termo de Consentimento Livre e Esclarecido - TCLE. 101 


\section{INTRODUÇÃO}

O consumo excessivo de álcool e o tabagismo são problemas crescentes no mundo, ocasionando inúmeras mortes a cada ano, especialmente entre pessoas de 15 a 35 anos (WHO, 2011). Não obstante, ambos fazem parte da lista dos 10 mais importantes riscos de morbidade evitáveis a nível mundial e regional (OMS, 2002).

Donati et al. (2012) afirmam que nos últimos anos o álcool é a droga mais consumida entre o público jovem no Brasil e que sua experimentação ocorre cada vez mais cedo. Mundialmente, mais de 50\% dos adolescentes de até 18 anos já fumaram pelo menos uma vez na vida (MANDIL et al., 2010).

Estatística da Organização Mundial de Saúde (OMS) apontou que, em 2010, o consumo per capita de álcool no Brasil, estimado em 8,7 litros por pessoa, superou o consumo per capita do continente americano e perdeu apenas para o continente europeu, onde foi registrado um consumo de 10,9 litros per capita (WHO, 2014).

A nível nacional, a pesquisa de Carlini et al (2007) revelou que 74,6\% dos brasileiros já experimentaram álcool e que o consumo dessa substância predomina na população masculina em todas as faixas etárias, com destaque para adultos jovens. Inclusive, pessoas de 18 a 24 anos consomem álcool uma vez ou mais por semana e bebem 5 ou mais doses por ocasião, indicando que esse grupo compõe a faixa etária em que há o maior consumo da substância (CARLINI et al., 2007). O II Levantamento Nacional de Álcool e Drogas, realizado pelo Instituto Nacional de Ciência e Tecnologia para Políticas Públicas de Álcool e Outras Drogas (INPAD) em 2012, revelou que 50\% da população brasileira consome álcool e que, desses, $17 \%$ fazem uso abusivo e/ou são dependentes. Na mesma pesquisa, ficou evidente um aumento considerável no consumo de álcool pela população feminina brasileira (LARANJEIRA et al., 2014).

Por outro lado, estima-se que aproximadamente 1,3 bilhões de pessoas são fumantes de cigarros ou consomem outros produtos compostos pelo tabaco, em todo o mundo (GUIDON; BOISCLAIR, 2003). No Brasil, um levantamento domiciliar realizado em 2007 mostrou que $44 \%$ das pessoas já experimentaram o tabaco, 19,2\% consumiram a substância pelo menos uma vez nos últimos 12 meses antes da pesquisa e 18,4\% consumiram pelo menos uma vez 30 dias antes do inquérito (CARLINI et al., 2007). Ademais, constata-se que quase metade dos universitários brasileiros entre 18 e 24 anos já fizeram uso do tabaco pelo menos uma vez na vida (ANDRADE; DUARTE; OLIVEIRA, 2010). 
No entanto, em 2008, a Pesquisa Especial de Tabagismo no Brasil, conduzida pelo Instituto Nacional do Câncer (INCA), apontou que, em comparação a estudos anteriores de prevalência do tabagismo, há uma tendência de redução gradativa desse hábito no país. Sobre isso, o estudo identificou que o percentual de consumo de cigarros caiu de 33,4\% para 18,1\% em indivíduos com idade igual ou superior a 18 anos no período entre 1989 e 2008 (INCA, 2011).

Considerando os vários tipos de bebidas alcoólicas, em pesquisa recente, a OMS apontou que as bebidas destiladas são as mais consumidas no mundo (50\%), seguidas da cerveja $(35 \%)$ e do vinho $(8 \%)$. No continente americano, porém, a bebida mais consumida é a cerveja (55\%), seguida das destiladas $(32,6 \%)$ e do vinho $(11,7 \%)$ (WHO, 2014).

Em relação aos derivados do tabaco, há uma variedade de produtos no mercado nacional e internacional que são usados de diversas maneiras, como por exemplo: fumado/inalado (cigarro, cachimbo, charuto, cigarro de palha, cigarrete, narguillé); aspirado (rapé); mascado (fumo-de-rolo, snuff); absorvido pela mucosa oral (snus). Em todos esses tipos a nicotina está presente, o que pode causar dependência e um maior risco de se adquirir doenças crônicas não transmissíveis. Os cigarros manufaturados representam a principal forma de tabaco fumado a nível mundial (SHAFEY et al., 2009). No Brasil, esta é também a forma predominante de uso do tabaco (BRASIL, 2003).

O padrão de consumo do álcool é estudado sob vários aspectos, dentre eles, a frequência e a quantidade de uso em doses. Dose é, na média, uma lata de cerveja ou chope de $350 \mathrm{ml}$, uma taça de vinho de $90 \mathrm{ml}$, uma dose de destilado de $30 \mathrm{ml}$, uma lata ou uma garrafa pequena de qualquer bebida "ice". Em levantamento nacional sobre padrões de consumo de álcool a Secretaria Nacional Antidrogas estratificou entre os consumidores de álcool a frequência de consumo da seguinte forma: muito frequente - beber todos os dias; frequente de uma a quatro vezes por semana; ocasional - de uma a três vezes por mês; raramente menos de uma vez por mês e abstinente - menos de uma vez por ano ou nunca bebeu. A quantidade de uso foi estratificada da seguinte forma: até duas doses; de 3 a 4 doses; 5 a 11 doses e 12 doses ou mais. Nesta pesquisa identificou-se que $22 \%$ dos usuários de álcool com idade entre 18 e 24 anos bebem frequentemente e $33 \%$ na mesma faixa etária bebem em "binge" - termo definido pela OMS como a ingestão de 5 ou mais doses para homens e 4 ou mais doses para mulheres em uma única ocasião pelo menos uma vez no último mês (LARANJEIRA et al., 2007). 
O consumo do cigarro também já foi medido em diversos estudos no país e com diversas populações diferentes. Embora a Pesquisa Especial de Tabagismo no Brasil tenha apontado uma tendência de redução no consumo de cigarros no país, uma situação que preocupa é que dados brasileiros do Projeto Internacional de Avaliação das Políticas de Controle do Tabaco Projeto revelaram que os fumantes brasileiros consomem, em média, 15,4 cigarros por dia e $92 \%$ dos fumantes relataram fumar diariamente. Aproximadamente, $91 \%$ dos fumantes afirmaram ser dependentes do cigarro e $52 \%$ deles "muito dependentes". O curioso é que a mesma pesquisa aponta que $91 \%$ dos fumantes pesquisados se arrependem de terem começado a fumar e admitem preocupação com possíveis problemas de saúde futuros decorrentes do tabagismo (MCNALLY et al., 2013).

O II Levantamento Domiciliar sobre o uso de drogas psicotrópicas no Brasil, realizado em 2005, mostrou a quantidade de cigarro fumada e a frequência de consumo nos últimos 12 meses que antecederam a pesquisa. Os dados revelaram que $85,8 \%$ dos fumantes consumiam cigarro todos os dias do ano e que $55 \%$ deles fumavam mais de 10 cigarros diariamente. $\mathrm{O}$ mesmo inquérito revelou que $56 \%$ dos fumantes aguardam no máximo 30 minutos após acordar para fumar o primeiro cigarro do dia (CARLINI et al., 2007).

A OMS estabeleceu em 2004 que o consumo aceitável de álcool correspondia a até 15 doses/semana para homens e 10 para mulheres (WHO, 2004). Já em relação aos produtos fumígenos derivados do tabaco, não há consumo aceitável, pois não existem níveis seguros de uso, conforme afirma a Agência Nacional de Vigilância Sanitária (ANVISA). A Agência, inclusive, exige, por meio de resolução, que esta informação seja claramente explicitada nos rótulos de produtos que contenham tabaco (ANVISA, 2015).

Ambos, álcool e tabaco, são produtos amplamente comercializados e publicizados. Estudo realizado em São Paulo com alunos de escolas públicas de São Bernardo do Campo revelou uma associação positiva das propagandas de bebidas alcoólicas ao consumo recente de cerveja. O consumo de álcool nos últimos 30 dias foi associado a fatores como a similaridade das festas em que os jovens participavam com as festas mostradas nos comerciais, o fato de prestarem muita atenção às propagandas comerciais e por acreditarem que os comerciais falam a verdade (FARIA et al., 2011).

O consumo de bebida alcoólica é estimulado pelas propagandas, que geralmente atrela o consumo da substância a liberdade, sexualidade, poder e inclusão social. Nesse cenário, devido a características como inexperiência e impulsividade, adolescentes e jovens adultos têm mais chances de desenvolver problemas relacionados ao álcool (CUFFA, 2012). 
Em relação ao tabaco, as estratégias de marketing dos fabricantes do setor, motivadas por interesses econômicos, contribuem para a criação de um contexto social de aceitação do hábito de fumar, gerando uma atmosfera propícia ao aumento do tabagismo, ainda que os efeitos nocivos do consumo dos derivados do tabaco sejam amplamente reconhecidos (PAHO, 2002; CAMPAIGN FOR TOBACCO FREE KIDS, 2001).

De modo complementar, alguns estudos demonstram que o consumo exacerbado de álcool e tabaco pode ocorrer concomitantemente. Adicionalmente, esses trabalhos constatam que o tabaco é a droga mais comumente associada ao consumo de álcool (ANDRADE; DUARTE; OLIVEIRA, 2010; CUNHA, 2010).

Dados da OMS a respeito do início do hábito tabágico estimam que, por dia, cerca de 100.000 jovens começam a fumar. Desses, em torno de $80 \%$ são adolescentes com idade média de 15 anos em países em desenvolvimento (WHO, 2001).

Estudo feito com acadêmicos de cursos da área de saúde da Universidade de Brasília apontou que a influência de amigos foi o principal motivo para o uso de tabaco nos últimos 30 dias que antecederam a pesquisa (RUBIO, 2008). Corroborando com esse resultado, estão os achados de Paduani et al. (2008) e de Andrade et al. (2006) que relataram a vontade própria e a influência de amigos como principais gatilhos para o início do tabagismo entre estudantes de diversos outros cursos da mesma universidade.

O uso excessivo de álcool é um dos fatores de risco para os altos índices de morbimortalidade e incapacidades no mundo. Estima-se que cerca de 3,3 milhões de pessoas morrem a cada ano em decorrência do consumo exacerbado do álcool, o que equivale a aproximadamente $6 \%$ de todas as mortes do planeta (WHO, 2014).

Levantamento realizado no Brasil sobre o consumo de álcool e outras drogas mostrou alguns efeitos prejudiciais desse hábito. Situações como problemas no trabalho, perda de emprego, prejuízos na família foram citadas por, respectivamente, $8 \%, 4,9 \%$ e $9 \%$ dos usuários de álcool entrevistados. Na mesma investigação, foi verificado que $32 \%$ dos adultos que bebiam não conseguiam parar depois de começar a beber (LARANJEIRA et al., 2014).

O estudo supracitado trouxe outros resultados em relação a comportamentos de risco vivenciados após o consumo do álcool, como dirigir embriagado e hábitos violentos. O hábito de andar armado foi verificado em $5 \%$ dos homens pesquisados, com uma proporção duplicada para os bebedores problemáticos (abusadores e/ou dependentes) menores de 30 anos de idade. $\mathrm{O}$ envolvimento em brigas com agressão física seguiu o mesmo padrão do hábito de andar armado, observando-se um aumento considerável na proporção do evento de 
$3 \%$ entre homens de maneira geral para $27 \%$ entre homens que bebiam de forma problemática na mesma faixa etária. Por outro lado, embora o hábito de conduzir veículos após beber ainda seja comum, esse comportamento apresentou declínio considerável no país, registrando uma redução de $21 \%$ em um período de seis anos nas ocorrências desse tipo. Tal queda atribui-se, primordialmente, às mudanças na legislação e na fiscalização de trânsito que buscam coibir o hábito de dirigir embriagado, por meio de penalizações mais rígidas para aqueles que são flagrados nessa situação. (LARANJEIRA et al., 2014).

Pesquisa norte americana informou que inúmeros acidentes automobilísticos com vítimas fatais e agressões ocorreram com jovens universitários de 18 a 24 anos de idade após uso excessivo do álcool entre os anos de 1993 e 2001 (WECHSLER et al., 2002). Outra pesquisa, realizada em São Paulo, verificou que 47,5\% dos universitários das áreas de humanas, exatas e biológicas costumavam beber e dirigir (PILLON; O’BRIEN; CHAVEZ, 2005). Não obstante, vários estudos mostraram que o uso do álcool aumentou, não somente o risco de violência, como também o comportamento sexual de risco, como multiplicidade de parceiros sexuais e exposição sexual desprotegida (TAPERT et al., 2001; SANTELLI et al., 2001; BASKIN-SOMMERS; SOMMERS, 2006).

Apesar de essas situações não serem verificadas diretamente quando se aborda o consumo de cigarro, um estudo realizado em Botucatu-SP e publicado em 2010 alertou para comportamentos de risco para doenças e agravos crônicos não transmissíveis em razão do tabagismo. Os resultados mostraram combinações do hábito tabágico com comportamentos como: sedentarismo, alimentação inadequada e consumo excessivo de álcool (BERTO; CARVALHAES; MOURA, 2010).

Ao tabagismo, são atribuídas cerca de seis milhões de mortes ao ano no mundo, incluídos os fumantes diretos e os passivos, ou seja, aqueles que inalam a fumaça sem propriamente fumar. Deste total de óbitos, cerca de $10 \%$ são atribuídos à exposição passiva do fumo em não fumantes (WHO, 2010).

O abuso e a dependência dessas drogas afetam diretamente os valores políticos, econômicos e sociais, pois, além de elevarem os índices de acidentes, violência e mortalidade, contribuem significativamente para o aumento dos gastos com tratamento médico e internações hospitalares, seja para o sistema de saúde particular, seja para o público (COTRIM; GAZAL-C; GOUVEIA, 2000).

Os custos sociais associados ao abuso de drogas podem ser divididos em três grupos: diretos, indiretos e intangíveis. Os diretos são aqueles que incidem diretamente sobre bens e 
serviços, como, por exemplo, despesas com pessoal, medicações e internações. Os indiretos são aqueles associados à perda de produção econômica, a exemplo das aposentadorias e licenças médicas. Já os intangíveis se referem aos custos do sofrimento físico e psíquico, que não são quantificáveis (LUCE et al., 1996; GALLASSI; ELIAS; ANDRADE, 2008; MORAES et al., 2006).

$\mathrm{O}$ alcoolismo também reflete negativamente sobre os sistemas produtivos, pois, em todo o mundo, nota-se que é nas faixas etárias mais jovens (de 20 a 49 anos) onde ocorre a maior perda de pessoas economicamente ativas em decorrência do álcool. Perda de produtividade, absenteísmo, desemprego e impacto previdenciário são exemplos de consequências diretas da interferência do alcoolismo na economia de um país (WHO, 2014).

Levantamento de orçamento domiciliar no Brasil, conduzido pelo Instituto Brasileiro de Geografia e Estatística (IBGE) entre 2008 e 2009, sinalizou que o consumo de bebida alcoólica na população brasileira aumentou, em média, 2,5\% ao ano durante os 40 anos anteriores à pesquisa. Dados do mesmo estudo ainda revelam que as despesas com bebidas alcoólicas têm uma maior participação nos gastos mensais conforme aumenta a renda familiar dos brasileiros (BRASIL, 2010).

Em pesquisa realizada em Brasília no período de 2000 a 2009, constatou-se que os gastos com as internações hospitalares por uso de substâncias psicoativas ficaram em torno de $\mathrm{R} \$ 1,2$ milhão. Desse total, notou-se que, em 8 dos 10 anos pesquisados, mais de 50\% representaram gastos com internações decorrentes do abuso de álcool e, na maioria das vezes, essas internações costumavam ser mais prolongadas, elevando assim os gastos com tratamento (PASSOS, 2011).

Os gastos públicos relacionados às doenças causadas pelo cigarro também foram quantificados. Estudo de 2013, baseado em dados colhidos no sistema Datasus do Ministério da Saúde, calculou que mais de $11 \%$ das internações hospitalares no Brasil de pessoas de 35 anos ou mais eram relacionadas a doenças causadas pelo tabagismo e, em $42 \%$ dessas internações, verificou-se a ocorrência de doenças cardiovasculares. Considerando a população de qualquer faixa etária, os gastos públicos com as internações relacionadas ao tabagismo responderam por $19 \%$ dos gastos hospitalares totais do país. Desses gastos, $54 \%$ eram relacionados às doenças do coração. Nesse mesmo ano, mais de 633.000 pessoas foram internadas por doenças provocadas pelo tabaco. Nessas pessoas registrou-se uma média de 7,2 dias de internação, o que gerou um custo de quase um bilhão e meio de reais com um valor médio de R\$2.356,17 por internação (SOUSA-CARMO; VILAR; MORAES, 2015). 
Complementando o estudo anterior, outra pesquisa, realizada no Rio de Janeiro, aferiu que a maior parcela de recursos públicos da saúde no Brasil foi direcionada para o tratamento de enfermidades do aparelho circulatório, seguidas pelas neoplasias e pelas doenças do aparelho respiratório (PINTO, 2007). Devido à relevância desse fato para o sistema de saúde nacional, entender a relação dessas doenças com o consumo de tabaco, conforme exposto no parágrafo anterior, é um ponto importante.

Nesse contexto, é adequado investigar como se dá o consumo de álcool e tabaco na população jovem, em especial no público universitário, que é considerado amplamente vulnerável a práticas de risco para a saúde, (ANDRADE; DUARTE; OLIVEIRA, 2010). Nesse período, ocorre com maior frequência o aparecimento e a consolidação de comportamentos de risco, especialmente aqueles relacionados ao uso de substâncias tóxicas, o que pode levar ao abuso e dependência de álcool e tabaco (ANDRADE; DUARTE; OLIVEIRA, 2010; GARCIA; MARTINI; GÁLVEZ, 2013).

Pesquisa feita com 1.264 graduandos da Universidade Federal de Santa Catarina revelou que a prevalência do tabagismo nesse público foi de 5,9\% e do consumo excessivo de álcool foi de $32,5 \%$. O consumo de álcool em excesso foi associado a uma maior classificação econômica do usuário, sendo mais prevalente nos homens do que nas mulheres (IMAI; COELHO; BASTOS, 2014). Tais achados se sustentaram em informações semelhantes geradas por pesquisas anteriores que apontaram a posição econômica mais alta associada ao abuso de álcool e prevalências maiores de uso excessivo de álcool na população universitária masculina entre acadêmicos brasileiros de cursos da área de saúde e ingleses de diversos cursos (SILVA et al., 2006; PEDROSA et al., 2011; HEATHER et al., 2011). Em relação ao tabagismo, observou-se uma menor prevalência em cursos da área de saúde (IMAI; COELHO; BASTOS, 2014), fato este também verificado na Jordânia, em 2002 (HADDAD; MALAK, 2002).

No contexto da rede particular de ensino brasileiro, um levantamento nacional mostrou que os estudantes de instituições privadas, quando comparados àqueles da rede pública, consumiam mais álcool, cigarro e outras drogas (CARLINI et al., 2007). Paralelamente, quando foram pesquisadas apenas instituições públicas, observou-se que a classe socioeconômica alta foi associada a um risco duas vezes maior para o uso de álcool quando comparada às classes mais baixas (BAUS; KUPEK; PIRES, 2002).

O consumo de álcool e tabaco foi novamente pesquisado no ambiente acadêmico, especificamente nos cursos de Ciências da Saúde no município de Quixadá, no Ceará, em 
2010. Na ocasião, observou-se que $39 \%$ dos participantes da pesquisa consumiam álcool e $6 \%$ tabaco. A curiosidade foi o gatilho mais prevalente para o consumo do álcool, enquanto a influência dos amigos foi o fator motivador de maior prevalência para o uso do tabaco (FREITAS et al., 2012).

Outro estudo, realizado com 926 universitários do curso de ciências biológicas, em São Paulo, revelou que as drogas mais consumidas pelos estudantes foram o álcool e o tabaco, com prevalências de $83,1 \%$ e $20,7 \%$, respectivamente. Foi visto, ainda, que aqueles que possuíam renda familiar alta e não declararam religião tiveram maior risco para o consumo de drogas (SILVA et al., 2006).

A prevalência de tabagismo entre estudantes da área de ciências da saúde foi quantificada em pesquisa no Rio Grande do Sul, onde viu-se que 16,5\% dos acadêmicos eram fumantes ativos no curso de medicina, por exemplo. Fatores como sexo masculino, pai fumante e uso regular de álcool foram significativamente associados ao tabagismo nessa população (STRAMARI; KURTZ; SILVA, 2009).

No Estado do Amazonas, 521 estudantes universitários de cursos da saúde também foram pesquisados quanto ao uso de álcool, tabaco e outras drogas. Mais uma vez, observouse altas prevalências de consumo dessas substâncias: dos 521 estudantes entrevistados, 87,7\% reportaram consumir álcool e 30,7\% consumiam tabaco. A pesquisa apontou, ainda, eventos consequentes ao uso do álcool, tais como acidentes, brigas e absenteísmo no trabalho e na sala de aula. Outro achado relevante foi que $47,3 \%$ dos estudantes dirigiram após beber (LUCAS et al., 2006).

Avaliando o consumo de álcool em graduandos do curso de enfermagem em um estudo feito no interior de Minas Gerais, observou-se que 61,4\% dos estudantes já se embriagaram pelo menos uma vez na vida, que $75 \%$ das mulheres faziam uso de bebida alcoólica e que 56,9\% delas usavam o álcool de forma problemática (PILLON et al., 2011). Outra investigação semelhante, porém só com estudantes do sexo feminino, realizada numa universidade estadual paulista em 2005, identificou alunas com consumo moderado e alto de álcool, principalmente nos primeiros dois semestres do curso de enfermagem. Do total de alunas pesquisadas, 94\% já usaram bebida alcoólica e grande parte delas já havia iniciado o consumo mesmo antes de entrar na faculdade. Para 47,6\% das respondentes, o consumo foi estimulado por amigos (BALAN, CAMPOS, 2006).

Diante do exposto, ações preventivas devem ser direcionadas de maneira especial para o público jovem. Sobre isso, pesquisa aponta que quando fatores de risco para o uso de 
drogas, incluídos álcool e tabaco, são identificados ainda durante a formação dos profissionais, maiores são as chances de que intervenções precoces de fato contribuam para a redução dos riscos de futuro comprometimento de habilidades que, por vezes, só se manifestarão no exercício da profissão (SPIER et al., 2000).

Ao se tentar inferir o porquê do uso problemático de álcool entre universitários, estudantes da área de saúde já mencionaram que um dos fatores motivadores é o excesso de cobrança exigida pelas universidades e a grande responsabilidade necessária para se trabalhar futuramente com a vida de outras pessoas (SANTOS et al., 2000).

Tendo em vista os fatos elencados, nota-se a importância mundial e nacional das discussões acerca do consumo de álcool e tabaco. Assim, argumenta-se que é relevante dimensionar essa problemática ainda durante a formação profissional de enfermeiros, especialmente no Distrito Federal, onde ainda são poucos os estudos da temática especificamente voltados para essa população. Com isso, a pesquisa desenvolvida neste trabalho pretende gerar informações que possam subsidiar as autoridades de saúde, bem como as instituições de ensino superior, com informações que favoreçam a adoção de medidas de prevenção e/ou eliminação desses hábitos entre aqueles que serão futuros profissionais promotores de saúde.

Assim, espera-se que a presente pesquisa possa contribuir efetivamente para ciência da enfermagem uma vez que será base para futuros estudos de intervenção a serem desenvolvidos junto à comunidade acadêmica e assim viabilizar a adoção de ações preventivas e reativas direcionadas às singularidades dos diferentes perfis de consumo do álcool e do tabaco. Sob essa perspectiva, este estudo tem por objetivo analisar a magnitude e o perfil de risco do consumo dessas drogas por alunos do curso de enfermagem em duas faculdades privadas do Distrito Federal. 


\section{ASPECTOS CONCEITUAIS DA TEMÁTICA INVESTIGADA}

\section{1 ÁLCOOL}

\subsubsection{Aspectos históricos}

Acredita-se que as bebidas alcoólicas tenham surgido na Pré-História, tendo acompanhado desde então a humanidade, sempre presentes nas culturas ao redor do mundo, seja como elemento indispensável em rituais religioso, seja como ingrediente de comemorações e confraternizações diversas (BACHELARD, 1994). O consumo dessa substância, por muito tempo, foi associado somente a ritos de alimentação e união entre as pessoas. No entanto, com as inúmeras transformações econômicas e sociais ocorridas nas populações, evidenciaram-se outras condições associadas ao uso do álcool, passando a ser condicionante de situações de agressividade, discórdia e dor entre as pessoas (GIGLIOTTI; BESSA, 2004).

Já na Idade Média, as bebidas destiladas, com maior concentração de álcool, passaram a ser produzidas em maior escala, tornando os problemas relacionados ao álcool relevantes no contexto social (BERRIDGE apud BAU, 2002).

Após a revolução industrial, o aumento na produção e na disponibilização do álcool fez cair significativamente seu preço, o que, consequentemente, contribuiu para o aumento do consumo. Nessa época, surgiram os primeiros conceitos de alcoolismo, com destaque para a definição do sueco Magnus Huss que em 1849 definiu "alcoolismo crônico" como um estado de intoxicação pelo álcool com sintomatologia física, psíquica ou mista (GIGLIOTTI; BESSA, 2004).

Mais tarde, no início da década de 80 do século XX, foi demonstrado que o alcoolismo é um hábito adquirido e que para compreendê-lo de maneira completa, seria também necessário compreender os fatores associados ao consumo do álcool (WAGNER apud ANDERSON; CASTRO FILHO, 2006).

Nos dias atuais, em meio à necessária compreensão desses fatores, vigora a formulação da OMS que define o alcoolista como um bebedor excessivo, cuja dependência alcoólica traz perturbações mentais, físicas, relacionais e de comportamento social e econômico (OMS, 2004). 


\subsubsection{Aspectos socioeconômicos e políticas públicas}

No intuito de frear o consumo desenfreado do álcool no mundo, a OMS estabeleceu princípios básicos para o desenvolvimento de políticas relacionadas ao álcool adotadas nos países. São exemplos desses princípios: a) as políticas e intervenções deverão ser orientadas e formuladas considerando os interesses da saúde pública; b) a proteção das populações de alto risco, que são expostas aos efeitos nocivos do alcoolismo deverá estar integrada nas políticas do álcool; c) indivíduos e famílias afetados pelo uso nocivo do álcool deverão ter acesso efetivo às estratégias preventivas e aos serviços de saúde; d) aqueles que optarem por não consumir álcool deverão ter sua decisão respeitada e ser protegidos das pressões para beber; e) as políticas e intervenções públicas para prevenir e reduzir os efeitos nocivos do álcool devem considerar todos os tipos de bebidas alcoólicas (WHO, 2014).

Assim, a partir dos referidos princípios, espera-se atingir a meta estipulada pela OMS, relativa à redução de pelo menos $10 \%$ no consumo nocivo mundial de álcool até o ano de 2025 (WHO, 2014).

No Brasil, o Ministério da Saúde é o órgão nacional responsável por elaborar a Política de Atenção Integral a Usuários de Álcool e outras Drogas, com o propósito explícito de prevenir, tratar e reabilitar os usuários dessas substâncias. As estratégias de ação determinadas pela política não enxergam a abstinência como o único objetivo a ser perseguido, uma vez que incorporam o conceito de "redução de danos". Reduzir danos significa, em linhas gerais, reconhecer cada usuário em suas peculiaridades e traçar com ele estratégias para a proteção de sua vida, que não necessariamente se resumem à abstinência. Com isso, busca-se aumentar o grau de liberdade e de coparticipação do usuário em seu tratamento (BRASIL, 2004a).

A política nacional antidrogas determina que ações preventivas ao uso indevido de drogas sejam implementadas na educação básica e na superior. Em suma, a política está focada no indivíduo e em seu contexto sociocultural, de maneira a desestimular a experimentação da droga e incentivar a redução do consumo, diminuindo os riscos e os danos do uso indevido. Para tanto, a política recomenda ações descentralizadas e capacitação contínua dos profissionais envolvidos no processo preventivo (ACSELRAD et al., 2012).

No Brasil, atualmente, a política nacional ora citada faz-se consolidada diante da organização dos serviços de atenção aos usuários de álcool na chamada Rede de Atenção Psicossocial (RAPS) para Pessoas com Transtornos Mentais e com Necessidades Decorrentes 
do Uso prejudicial de Crack, Álcool e outras Drogas, no âmbito do Sistema Único de Saúde (SUS). Dentre os diversos objetivos da Política, destacam-se: promover cuidados em saúde especialmente para grupos vulneráveis, dentre eles adolescentes e jovens; prevenir o consumo e a dependência do álcool e de outras drogas; reabilitar e inserir pessoas com necessidades decorrentes do uso do álcool e outras drogas por meio do acesso ao trabalho, renda e moradia solidária, entre outros (BRASIL, 2011).

A estratégia da Rede é recente e conta com a organização dos serviços a partir dos chamados "pontos de atenção à saúde". Na RAPS existem pontos de atenção na rede básica de saúde (Unidades Básicas de Saúde e Equipes de Atenção à Saúde), no âmbito hospitalar (Leitos de Saúde Mental em Hospital Geral e Referência) e na atenção domiciliar de caráter transitório (Unidades de Acolhimento e Serviços de Atenção em Regime Residencial, entre eles as Comunidades Terapêuticas). Ainda, a RAPS é composta por serviços de emergência e pelos Centros de Atenção Psicossocial (CAPS), abrangendo diversas modalidades, como os Centros de Atenção Psicossocial Álcool e Drogas (CAPS AD) nos municípios com mais de 70.000 habitantes (BRASIL, 2011).

As diretrizes apontadas pela Política incluem: utilização de recursos educacionais e de comunicação social para informar o cidadão sobre os efeitos nocivos do álcool; o controle da propaganda a fim de proteger segmentos vulneráveis de associações indevidas entre o consumo do álcool e estereótipos de sucesso e inclusão social; controle da venda, distribuição e locais de consumo com o intuito de dificultar o acesso ao álcool; discussão de uma política fiscal que desestimule o uso; ações de prevenção e tratamento nos ambientes de trabalho, dentre outras (BRASIL, 2004a).

Reformulações na legislação nacional também foram propostas no sentido de regulamentar a produção, o comércio e o consumo. A Constituição Federal em seu artigo 220 já prevê que compete à uma lei federal definir "os meios legais que garantam à pessoa e à família a possibilidade de se defenderem (...) da propaganda de produtos, práticas e serviços que possam ser nocivos à saúde e ao meio ambiente”. No parágrafo $4^{\circ}$ do mesmo artigo, a Constituição dispõe que "a propaganda comercial de tabaco, bebidas alcoólicas, agrotóxicos, medicamentos e terapias estará sujeita a restrições legais (...) e conterá, sempre que necessário, advertência sobre os malefícios decorrentes de seu uso." (ACSELRAD et al., 2012).

O desdobramento constitucional veio com a Lei 9294/96 que dispõe sobre as restrições ao uso e à propaganda de produtos derivados do tabaco (e outros produtos fumígenos), 
bebidas alcoólicas, medicamentos, terapias e defensivos agrícolas. No entanto, alguns dispositivos dessa Lei são criticados por não conferirem igual tratamento nas restrições impostas ao álcool e aos produtos fumígenos - por exemplo, o banimento de propagandas de cigarro, enquanto que não há impedimentos para as propagandas de bebidas alcoólicas (ACSELRAD et al., 2012).

Outro dispositivo legal - o artigo 63 da Lei de Contravenções Penais - proíbe o fornecimento de bebida alcoólica a menores de 18 anos, àqueles a quem se acham em estado de embriaguez e a pessoas que nitidamente sofrem de suas faculdades mentais (ACSELRAD et al., 2012).

Restrições administrativas também são impostas pela Lei 11705/2008 diante da venda ou do fornecimento impróprio de bebida alcoólica por varejista para consumo local em faixa de domínio de rodovias federais (ACSELRAD et al., 2012).

O consumo e o porte de bebida alcoólica em recintos esportivos foram proibidos pela Lei 10671/2003, intitulada Estatuto do Torcedor, de modo a preservar a integridade das pessoas e famílias ali presentes (ACSELRAD et al., 2012).

Aos motoristas, o Código de Trânsito Brasileiro, instituído pela Lei 9503/1997, veda a direção de veículos após o consumo de bebidas alcoólicas. A mesma lei prevê, ainda, que todo condutor envolvido em acidente de trânsito ou alvo de fiscalização, quando suspeito de dirigir sob efeito do álcool, seja submetido a teste de alcoolemia (ACSELRAD et al., 2012).

Paralelamente às estratégias preventivas, terapêuticas, fiscalizadoras e repressoras, persiste o grande desafio de se alcançar os resultados desejados com a aplicação dessas medidas. Isso se deve ao fato de que a principal dificuldade envolve o enfrentamento da força política e econômica das indústrias produtoras de álcool, que por vezes interferem na aprovação de ações redutoras de danos associadas às políticas de redução de consumo da substância (BRASIL, 2004b).

Pesquisadores colocam que, no Brasil, coexiste uma situação difícil: ao passo que existem poucos programas preventivos para o uso do álcool, há também poucas ações restritivas às propagandas de bebidas. Inclusive, menciona-se que, em meados de 2008, o país tentou restringir as propagandas televisas de bebidas alcoólicas por meio da Agência Nacional de Vigilância Sanitária (ANVISA), porém sem sucesso devido a repressão dessa proposta por movimentos liderados pelas indústrias cervejeiras e por associações representantes dos meios de comunicação (FARIA et al., 2011). 


\subsubsection{Efeitos prejudiciais do consumo}

O alcoolismo está associado a inúmeros riscos de doenças agudas e crônicas, principalmente quando o uso da substância é de forma nociva ou dependente. Para a OMS, o uso nocivo de álcool é um padrão de consumo que causa danos físicos ou mentais à saúde, enquanto que a dependência é o conjunto de fenômenos comportamentais, cognitivos e fisiológicos gerados a partir do uso repetido da substância e que, normalmente, enseja dificuldade no controle do uso e uma maior prioridade dada ao uso do álcool em detrimento de outras atividades e obrigações (WHO, 2014).

Doenças como depressão, ansiedade, hipertensão arterial, diabetes, isquemia miocárdica, fibrilação atrial, acidente vascular cerebral, cirrose hepática, pancreatite, cânceres diversos, entre outras, estão no rol dos agravos mais importantes que podem ser causados pelo consumo do álcool. Doenças infecciosas também podem entrar nessa lista, uma vez que o uso nocivo do álcool deprime o sistema imunológico (WHO, 2014).

Outro ponto negativo é o fato de que o álcool é a substância que tem maior relação com comportamentos de risco tais como problemas de relacionamento interpessoal no trabalho e na família, falta ao trabalho e escola, envolvimento em brigas com emprego de violência física, envolvimento em acidentes automobilísticos, prática de sexo desprotegido, dentre outros. Devido a ação da substância sobre as funções cognitivas, o consumo de álcool inibe o medo, a ansiedade e a capacidade do indivíduo de planejar ações em resposta a situações de ameaça (PILLON, O’BRIEN, CHAVEZ, 2005). Inúmeros estudos também apontam situações de risco, violência e/ou dano vivenciadas após ingestão de bebida alcoólica. Alguns deles indicam a existência de uma relação entre o uso de substâncias psicoativas e consequências como desintegração familiar, acidentes de trânsito, crimes e violência doméstica (ANDRADE, 2008; CHALUB, TELLES, 2006). 


\subsection{TABACO}

\subsubsection{Aspectos históricos}

O tabaco é uma planta nativa das Américas, cultivada e comercializada legalmente em todos os países há cerca de 8.000 anos, cujo consumo vem sendo combatido na sociedade moderna (OMS, 2002). Entretanto, contextos econômicos, sociais e sanitários entram em cena como obstáculos às tentativas de redução do consumo da substância. Sobre isso, exemplificase o caso do Brasil, que ocupa o lugar de segundo maior produtor de tabaco e líder em sua exportação ao mesmo tempo que o país tem papel significativo em relação às estratégias e políticas de combate ao consumo (BOEIRA; JOHNS, 2007).

A indústria do cigarro firmou-se no cenário mundial no final do século XIX, com a invenção da máquina de confecção de cigarros, em 1881, e domínio das multinacionais estadunidenses e britânicas. No Brasil, o sistema integrado de produção de fumo foi criado na região Sul do país em 1918 pela British American Tobacco (BAT), empresa que se tornou a maior fabricante de cigarros no mundo ao final da $2^{\text {a }}$ Guerra Mundial (ALMEIDA, 2005).

O tabagismo faz parte do grupo de transtornos mentais e comportamentais devidos ao uso de substância psicoativa na Classificação Estatística Internacional de Doenças e Problemas Relacionados à Saúde (CID-10), sendo considerada a maior causa isolada e evitável de adoecimento e morte precoce a nível mundial (BRASIL, 2008).

Além disso, o tabagismo é considerado uma doença epidêmica com alto poder de dependência, pois todos os produtos à base de tabaco também contêm a nicotina, substância responsável por esta consequência. Ademais, ao fumar, o indivíduo inala, em conjunto com a nicotina, mais de 4.700 substâncias tóxicas e cancerígenas como monóxido de carbono, amônia, arsênio, níquel dentre outras (ROSEMBERG, 2004).

\subsubsection{Aspectos socioeconômicos e políticas públicas}

O reconhecimento mundial de que a epidemia do tabagismo é um problema de saúde pública e que, para enfrentá-lo, são necessárias estratégias intersetoriais e de cooperação internacional levou a OMS, na 49ª Assembleia Mundial de Saúde (AMS), realizada em 1996, a decidir por elaborar o primeiro tratado internacional de saúde pública sobre o tema: a Convenção Quadro para Controle do Tabaco (CQCT), que propõe a adoção de medidas 
intersetoriais que detenham a expansão mundial do consumo do tabaco e seus efeitos nocivos. O texto final dessa Convenção foi aprovado em 2003, após 4 anos de discussões (CAVALCANTE, 2005).

As resoluções tomadas na AMS para o controle do tabagismo são estruturadas em 2 grandes blocos: medidas de redução da demanda por tabaco e medidas de redução da oferta de tabaco. No primeiro bloco foram definidas as seguintes estratégias: 1) Aumentar os impostos sobre os cigarros; 2) Publicar pesquisas sobre os efeitos do fumo sobre a saúde; 3) Informar os consumidores por meio de rótulos de advertência; 4) Gerar proibições em propagandas e promoções; 5) Formular programas de educação de controle do tabagismo nas escolas; 6) Restringir ao fumo em ambientes públicos e nos locais de trabalho e 7) Intervir terapeuticamente com a nicotina propiciando a cessão do hábito. No segundo bloco, preconizou-se: 1) Restringir o acesso dos jovens ao tabaco; 2) Substituir e diversificar a fumicultura; 3) Restringir o apoio e os subsídios relativos ao preço do tabaco e 4) Eliminar o contrabando (CAVALCANTE, 2005).

No Brasil, o Instituo Nacional do Câncer (INCA) é o órgão do Ministério da saúde responsável por conduzir as ações do Programa Nacional de Controle do Tabagismo (PNCT), que objetiva combater o início precoce do tabagismo, aumentar o percentual de ex-fumantes e proteger todos do tabagismo passivo (CAVALCANTE, 2005).

De antemão, destacam-se alguns marcos estratégicos de ações no país em prol do controle do tabagismo. Exemplos desses marcos de atuação foram a criação da Comissão Nacional para Implementação da CQCT, a incorporação de ações de prevenção e controle do tabagismo nos diferentes Programas do SUS, a regulação dos produtos do tabaco pela ANVISA, o fortalecimento da participação da sociedade civil por meio de organizações não governamentais - a exemplo da Aliança para Controle do Tabagismo no Brasil - e a inclusão da vigilância epidemiológica do tabagismo no sistema de vigilância de agravos não transmissíveis, coordenado pelo Ministério da Saúde (INCA, 2011).

O PNCT articula estratégias no campo da educação - com a realização de campanhas, ações escolares e em ambientes de trabalho - e, também, no contexto do tratamento da dependência do tabaco, onde são definidas as abordagens terapêuticas e disponibilizados os medicamentos necessários para tal. Outras estratégias são ligadas à mobilização social, ao monitoramento e avaliação das ações, à vigilância epidemiológica do tabagismo nas populações e à fiscalização do cumprimento das leis específicas sobre o tema (INCA, 2011). 
A legislação brasileira também contém dispositivos que regulam a venda, o consumo e a publicidade de produtos derivados do tabaco, os quais são listados a seguir:

- Lei 9.294/96, que proíbe que produtos fumígenos sejam vendidos para menores de 18 anos;

- Decreto 5.658/06, que promulga a CQCT, adotada pelos países membros da OMS, determinando a adoção de medidas intersetoriais para propagandas, patrocínio, advertências sanitárias, tabagismo passivo, tratamento de fumantes, comércio ilegal, preços e impostos;

- Lei 12.546/11, que alterou o sistema de tributação de cigarros e instituiu a política de preços mínimos;

- Lei 12.921/13, que veda a fabricação, a comercialização, a distribuição e a propaganda de produtos nacionais e importados, de qualquer natureza, bem como embalagens, destinadas ao público infanto-juvenil que reproduzam a forma de cigarros e similares; e

- Decreto 8.262/14 veda o consumo de derivados fumígenos do tabaco em locais coletivos e a exposição de produtos do tabaco nos pontos de venda.

No âmbito regulatório, resoluções da ANVISA determinam que as embalagens de cigarros contenham informações de alerta em relação às substâncias tóxicas neles contidas e às consequências negativas do consumo. Essas resoluções preveem, ainda, que a visualização dessas informações não poderá em qualquer hipótese ser dificultada ou impedida (ANVISA, 2015).

A epidemia do tabagismo pode ser associada ao comércio, que reúne algumas estratégias facilitadoras para o consumo. Elementos como o baixo preço dos produtos, a facilidade de acesso, o mercado ilegal gerando produtos ainda mais baratos, o lobby político e os incentivos fiscais conseguidos pelas multinacionais junto ao governo são estratégias do mercado do tabaco que facilitam a ampliação do consumo, sobretudo em países mais pobres (INCA, 2011).

Entretanto, embora o Brasil esteja em posição de destaque em relação aos outros países na redução da prevalência do tabagismo nos tempos atuais, ainda existem muitas dificuldades a serem enfrentadas, uma vez que o fácil acesso físico e o preço baixo dos cigarros, por exemplo, são entendidos como fatores facilitadores do consumo de cigarros no país (CAVALCANTE, 2005; GUINDON; TOBIN; YACH, 2002). Tal cenário é agravado 
quando se verifica que cerca de $35 \%$ do consumo nacional é proveniente de fontes ilegais, que barateiam ainda mais os cigarros no país (BRASIL, 2003).

No Brasil, as grandes multinacionais que dominam a comercialização de cigarros possuem mecanismos de inteligência que às mantêm atentas quanto às tendências do mercado e às políticas do governo para o controle do tabagismo. Dessa forma, conseguem reagir de maneira eficiente aos riscos que essas políticas podem impor aos seus negócios (PAHO, 2002; CAMPAIGN FOR TOBACCO FREE KIDS, 2001).

Outros artifícios aplicados por essas grandes empresas são os argumentos relacionados à oferta de emprego - propiciada pela fumicultura e pela manufatura dos cigarros - e o marketing social, por meio de doações para programas sociais (CAVALCANTE, 2005).

Diante desse cenário de desafios, comemoram-se resultados positivos no combate ao tabagismo no Brasil. De 1989 a 2005, por exemplo, o consumo per capita de cigarros caiu cerca de $32 \%$ (INCA, 2011).

Desse modo, apesar das dificuldades apontadas, os dados das pesquisas de prevalência do tabagismo somados ao grau elevado de consciência do brasileiro em relação aos malefícios causados pelo tabaco permitem inferir que a PNCT está alcançando os resultados almejados, indicando avanços na política de combate ao consumo de tabaco (BRASIL, 2003). Nesse contexto, o avanço das políticas brasileira na área dependem do entendimento de que o controle do tabagismo envolve o esforço conjunto de todos os setores da sociedade, das instituições governamentais e não governamentais, considerando não somente medidas preventivas e terapêuticas, mas principalmente a vontade de toda a sociedade (CAVALCANTE, 2005).

Ademais, integra o rol de desafios do PNCT a necessidade de ingresso sistemático da temática de controle do tabagismo nas grades curriculares da educação superior, inclusive buscando reduzir a prevalência do uso do tabaco na população feminina, na qual vem sendo registrado aumento expressivo no consumo da substância (INCA, 2011).

\subsubsection{Efeitos prejudiciais do consumo}

Estima-se que o total de óbitos no mundo decorrentes do tabagismo aumente para 7,5 milhões ao ano em 2020 (WHO, 2010). Tal afirmação sustenta-se em informações geradas por estudos anteriores que apontaram uma tendência de aumento na prevalência do tabagismo 
nos países em desenvolvimento e que cerca de metade dos fumantes morre devido à alguma condição associada ao tabagismo (OMS, 2004; HENNINGFIELD et al., 2005).

Para ilustrar o poder de adoecimento do tabaco, números da OMS mostram que cerca de $71 \%$ dos cânceres de pulmão, $42 \%$ das doenças respiratórias crônicas e quase $10 \%$ das doenças cardiovasculares são decorrentes do tabagismo (WHO, 2010). Outro estudo reitera que, dentre as doenças causadas pelo cigarro, as neoplasias diversas, as doenças ateroscleróticas e as doenças pulmonares estão entre as mais importantes (MAGLIARI et al., 2008). 


\section{OBJETIVOS}

\subsection{OBJETIVO GERAL}

Analisar a magnitude e o perfil de risco do consumo de álcool e de tabaco por alunos dos cursos de enfermagem de duas faculdades privadas no Distrito Federal.

\subsection{OBJETIVOS ESPECÍFICOS}

- Identificar o perfil sociodemográfico dos estudantes de enfermagem (idades, sexo, semestre em curso, estado civil, religião, fatores motivadores do uso, idade da primeira utilização);

- Caracterizar o consumo de álcool, tempo, tipo, frequência e quantidade;

- Verificar as situações de risco vivenciados após a ingestão do álcool;

- Caracterizar o uso do tabaco, tempo, formas e frequência do uso;

- Identificar as faixas de risco do consumo do álcool e do tabaco;

- Verificar a associação entre o uso do tabaco e o hábito de beber;

- Verificar a associação entre o perfil dos estudantes e as faixas de risco do consumo do álcool e do tabaco. 


\section{MATERIAIS E MÉTODOS}

\subsection{TIPO DE ESTUDO}

Trata-se de um estudo de base epidemiológica do tipo transversal descritivo e analítico envolvendo alunos dos cursos de enfermagem de duas faculdades privadas do Distrito Federal. Nesse tipo de estudo, causas e consequências são identificadas por ocasião da análise dos dados, com base na comparação de expostos e de não-expostos (PEREIRA, 2012).

\subsection{LOCAL DE REALIZAÇÃO DA PESQUISA E POPULAÇÃO ESTUDADA}

O estudo foi realizado em duas faculdades privadas e abrangeu alunos matriculados no curso de enfermagem. A escolha das faculdades justificou-se pelo fato de concentrarem os dois maiores volumes de matrículas no referido curso à época no Distrito Federal, favorecendo a representatividade da amostra. Compuseram então a população de referência para o estudo 2.760 alunos nas duas faculdades, sendo 1.160 alunos em uma e 1.600 na outra.

\subsection{TAMANHO DA AMOSTRA E SELEÇÃO DOS ESTUDANTES}

Considerou-se como base de referência para o cálculo da amostra a prevalência de 6,32\% de fumantes entre estudantes de enfermagem da Universidade de Brasília conforme apontado pelo estudo de Tauil, Coelho e Monteiro (2006). Para o cálculo amostral foi utilizado o software Epi-Info 3.0.3 e resultou na necessidade de se trabalhar com uma amostra de 122 estudantes, considerando um nível de confiança de $95 \%$ e margem de erro de $2 \%$. Diante da factibilidade de acesso para a coleta dos dados e da possibilidade de perdas, optouse por ampliar o número da amostra calculada para 200 alunos.

Para a seleção dos estudantes, todos os alunos constantes das listas de matrícula e que atendiam aos critérios de inclusão foram codificados em sequência numérica ordinal. Em seguida, foi realizada amostragem aleatória simples com o auxílio do software Excel® até que fossem selecionados todos os alunos da amostra. Segundo Barbetta (2004), neste tipo de amostragem probabilística, todos os elementos da população têm a mesma probabilidade de pertencer à amostra. 
Diante das 21 perdas registradas por não localização de alunos ou não concordância em participar, a amostra final resumiu-se a 179 alunos.

Dessa forma, mesmo com as perdas mencionadas, o número de 179 questionários preenchidos ainda superou em 57 alunos a amostra mínima calculada para o estudo.

\subsection{CRITÉRIOS DE INCLUSÃO E EXCLUSÃO}

O critério de inclusão dos estudantes no estudo foi estar regularmente matriculado no curso de enfermagem em ambas as faculdades.

Foram excluídos aqueles matriculados no primeiro semestre, por ainda estarem se adaptando ao universo acadêmico e os do último semestre que, devido à proximidade da apresentação de seus trabalhos de conclusão de curso, podiam apresentar diferentes níveis de ansiedade e, assim, possivelmente, ter seus hábitos de vida alterados durante o período da coleta de dados.

\subsection{INSTRUMENTO DE COLETA DE DADOS}

Utilizou-se um questionário constituído por 28 perguntas, autoaplicável e anônimo, adaptado ao estudo (Apêndice A). Segundo Gil (2008), o questionário é uma técnica de investigação composta por questões a serem aplicadas a pessoas a fim de se obter informações sobre seus comportamentos.

Além das perguntas elaboradas para construção do perfil epidemiológico, foram inseridas também no questionário as perguntas da ferramenta Alcool, Smoking and Substance Involvement Screening Test (ASSIST), elaborada sob a coordenação da OMS e com versão validada no Brasil, que objetiva triar o envolvimento de pessoas com o álcool, tabaco e outras drogas lícitas e ilícitas (WHO, 2015; HENRIQUE et al., 2004).

Originalmente, a ferramenta é composta por 8 perguntas com diferentes valores numéricos para cada resposta. A primeira questão é uma indagação sobre o uso ou não de álcool, tabaco e outras drogas na vida. A resposta negativa à primeira pergunta automaticamente encerra o preenchimento do questionário. A resposta positiva, no entanto, leva o respondente para as demais. Assim, dois escores diferentes poderão ser obtidos a partir do preenchimento da ferramenta: a) O Envolvimento Total para todas as classes de drogas, quando todas as questões devem ser respondidas e pontuadas e b) O Envolvimento com 
Substâncias Específicas, quando são excluídas as pontuações da primeira e a da última pergunta do questionário (FORMIGONI et al., 2014).

No presente estudo, a ferramenta ASSIST foi adaptada de modo a considerar apenas questões sobre o uso de álcool e tabaco. Desse modo, seguindo o critério para a triagem do envolvimento com substâncias específicas, definido na própria ferramenta, apenas 6 das 8 perguntas originais do ASSIST estão dentro do questionário da presente pesquisa, tendo sido excluídas a primeira e a última. A exclusão da última pergunta justifica-se pelo fato de ser uma indagação sobre uso de drogas injetáveis. Assim, foram então montados dois blocos específicos de perguntas: um para investigação do uso do álcool e outro para investigação do uso do tabaco.

O referido instrumento já foi traduzido para o português e também já testado quanto à confiabilidade e factibilidade de sua aplicação, com duas versões validadas no Brasil. A primeira, corresponde à versão original e foi concebida para ser aplicada mediante entrevista de pacientes por profissionais de saúde da atenção básica e com uma classificação final do entrevistado focada em níveis de necessidade de intervenção. A segunda versão, testada e validada no Brasil por Barreto (2012), foi adaptada da original para o autopreenchimento por estudantes universitários.

A confiabilidade da versão autoaplicável foi considerada boa a moderada com alfa de Cronbach de 0,90 para tabaco, e 0,71 para álcool (BARRETO, 2012). Christmann e Aelst (2006) apontam que este coeficiente avalia a confiabilidade de um instrumento por meio da consistência interna dos itens do questionário, ou seja, como os itens se relacionam entre si e contribuem para o resultado final. Seus valores variam entre 0 e 1 , havendo confiabilidade das medidas quando o coeficiente for maior que 0,7 .

Nesse sentido, por não haver entrevista, a versão de autopreenchimento traz como diferença essencial em relação à original uma explicação mais detalhada das perguntas e das opções de resposta, facilitando a compreensão de cada item pelos respondentes. A versão de autopreenchimento traz, ainda, uma classificação final focada na estratificação de risco do consumo das substâncias pesquisadas, conforme Anexo B, e não na necessidade de intervenção, como é apresentado na versão original. Porém, entende-se que qualquer uma das duas formas de classificação final é complementar à outra, pois o risco sugere intervenções que, por sua vez, são definidas de acordo com o risco (BARRETO, 2012).

Tendo em vista a descrição das pesquisas e considerando que a técnica de coleta de dados deste estudo foi o preenchimento do questionário pelos próprios estudantes, as 
perguntas e as opções de respostas foram extraídas a partir da versão do ASSIST de autopreenchimento.

Assim, com base nas respostas às questões do ASSIST no questionário, os participantes foram classificados de acordo com um escore numérico, em três diferentes perfis de risco do envolvimento com o álcool e com o tabaco. Esses perfis são: 1. Baixo Risco quando a soma dos valores de cada resposta atingiu uma pontuação de 0 a 10 para uso de álcool ou de 0 a 3 para o tabaco; 2. Risco Moderado - quando a soma dos valores de cada resposta atingiu uma pontuação de 11 a 26 para uso de álcool ou de 4 a 26 para o tabaco; e 3 . Alto Risco- quando a soma dos valores de cada resposta atingiu uma pontuação de 27 ou mais tanto para o uso de álcool quanto para o uso do tabaco (BARRETO, 2012).

Para a triagem do uso do álcool, as seis questões do ASSIST inseridas no questionário da pesquisa, perguntas 8 a 13, geraram dados sobre: frequência de uso da substância nos últimos três meses, problemas relacionados ao consumo, preocupação de pessoas próximas ao usuário em relação ao consumo, possíveis prejuízos em tarefas normalmente executadas pelo usuário, tentativas mal sucedidas de cessar ou reduzir o consumo e sentimento de compulsão para o consumo.

Já no bloco de perguntas para triagem do tabaco, a ferramenta ASSIST orienta a exclusão da questão que indaga possíveis prejuízos na execução de tarefas quando a substância pesquisada for o tabaco, inferindo que o consumo da substância não gera alteração no nível de consciência do indivíduo. Dessa forma, restaram apenas cinco perguntas, questões 21 a 25, para pontuação na triagem do uso de derivados do tabaco (HENRIQUE et al., 2004; FORMIGONI et al. 2014).

Por último, foram acrescidas outras perguntas formuladas pelo pesquisador, com o intuito de auxiliar nas respostas aos objetivos do estudo. Assim, essas perguntas visam a identificação das quantidades utilizadas de bebida alcoólica, dos riscos e conflitos vivenciados após o uso do álcool, dos fatores motivadores para o uso do álcool e do tabaco, dos tipos preferidos de bebidas alcoólicas e derivados do tabaco, da idade de experimentação das duas substâncias.

\subsection{OPERACIONALIZAÇÃO DO ESTUDO}

Após a liberação do Comitê de Ética em Pesquisa da Faculdade de Saúde da Universidade de Brasília, foi realizado um teste piloto do questionário, com população 
semelhante a que seria estudada. Nesse teste, 10 estudantes de enfermagem, de uma faculdade distinta das em estudo, responderam ao questionário e expuseram suas opiniões quanto à clareza das indagações e das opções de resposta. Com base nesse processo, foram feitos ajustes nas orientações escritas para o autopreenchimento, bem como nos enunciados das questões a fim de garantir a correta interpretação por parte dos respondentes.

Em seguida, foram enviados ofícios às coordenações dos cursos de ambas as faculdades solicitando autorização prévia para a execução da coleta de dados. Concedidas as autorizações e de posse das listas de matrícula, os alunos foram sorteados (conforme procedimento descrito na seção 4.3) e localizados em sala de aula para participarem da pesquisa entre os dias 21/03/2016 e 13/05/2016.

\subsection{PADRÕES DE REFERÊNCIA UTILIZADOS}

Foram caracterizados como expostos ao álcool e ao tabaco os respondentes que afirmaram respectivamente que usavam álcool e derivado do tabaco na ocasião do preenchimento do questionário, conforme as questões 7 e 20 do questionário. Em consequência, os não expostos ao álcool e ao tabaco foram aqueles que negaram o consumo das referidas substâncias ao responderem às mesmas questões.

Para investigar a quantidade do uso do álcool, foi usada a medida de dose como referência, padronizada da seguinte forma em inquérito brasileiro: em média, a dose-padrão refere-se a uma lata de cerveja ou chope de $350 \mathrm{ml}$, uma taça de vinho de $90 \mathrm{ml}$, uma dose de destilado de $30 \mathrm{ml}$, uma lata ou uma garrafa pequena de qualquer bebida ice. Cada dose contém cerca de $10 \mathrm{~g}$ a $12 \mathrm{~g}$ de álcool (LARANJEIRA et al., 2007).

$\mathrm{Na}$ investigação de uso do tabaco, optou-se por avaliar a frequência do uso de seus derivados, ao invés da quantidade ingerida da substância, por ser sabido que não existem níveis seguros de sua utilização - isto é, a ingestão de qualquer quantidade pode ser considerada um risco à saúde do usuário (ANVISA, 2015). Além disso, uma vez que a quantidade de tabaco varia significativamente de um produto para outro, inclusive em situações em que o indivíduo pode manipular a quantidade que deseja consumir por vez da substância, a estimação da quantidade ingerida do tabaco é menos precisa do que no caso do álcool, tornando a avaliação quantitativa pouco adequada nesse contexto. Exemplificando o argumento acima, cita-se o uso do narguilé, em que o usuário define quantas pedras do 
produto serão consumidas por vez, o que vai interferir diretamente na quantidade de tabaco consumida. Assim, na pergunta 21 do questionário, os respondentes que já utilizaram derivado do tabaco pelo menos uma única vez na vida são indagados se fazem uso diário, semanal, mensal, trimestral ou até se não fizeram uso nos 3 meses anteriores à pesquisa.

\subsection{ANÁLISE DOS DADOS}

Os dados foram armazenados inicialmente em planilha Excel® para posterior migração e análise utilizando a versão 21 do Software Statistical Package for the Social Sciences - SPSS. Para análise descritiva, optou-se por utilizar a frequência percentual das variáveis coletadas. Ademais, as prevalências para o consumo de álcool e de tabaco foram calculadas com Intervalo de Confiança (IC) de 95\% e Razão de Chances (RC). Por fim, para testar a significância das diferenças entre as proporções, foi utilizado o teste Qui- quadrado de Mantel-Haenszel com correção de Yates. As diferenças com valores $\mathrm{p}<0,05$ foram consideradas estatisticamente significantes. Os resultados da análise foram organizados em tabelas e figuras apresentadas na análise do Capítulo 5.

É relevante mencionar, ainda, que alguns estudantes não responderam a determinadas questões nos seus questionários, gerando perda de informação para a análise. Nos questionários em que alguma pergunta originária do ASSIST não foi respondida, o participante não teve calculada a pontuação para estabelecimento do grau de risco do consumo do álcool e/ou do tabaco. Apesar disso, ressalta-se que as demais questões preenchidas ainda foram utilizadas para a análise da amostra.

Registra-se que, para a construção das tabelas, não foram consideradas válidas questões não assinaladas ou aquelas em que foram marcadas mais de uma opção quando era solicitada apenas uma resposta.

\subsection{ASPECTOS ÉTICO-LEGAIS}

O projeto foi submetido e aprovado pelo Comitê de Ética em Pesquisa da Faculdade de Saúde da Universidade de Brasília, conforme Anexo D. A coleta de dados foi autorizada pelas duas faculdades mediante Termo de Concordância formalmente assinado. Após explicações quanto aos objetivos da pesquisa e sobre seu caráter sigiloso, os questionários 
foram aplicados àqueles alunos selecionados e que concordaram em participar, assinando previamente o Termo de Consentimento Livre e Esclarecido (TCLE), conforme anexo E. 


\section{RESULTADOS E DISCUSSÃO}

Os primeiros questionamentos buscaram informações sobre idade, sexo, estado civil, etnia e semestre em curso, que são sumarizadas nas Tabelas 1 e 2.

Na Tabela 1, tem-se a distribuição das variáveis de perfil epidemiológico da população estudada por sexo. Observa-se que a população estudada foi eminentemente feminina, com 89,4\% ( $\mathrm{n}=160)$ de mulheres e apenas 10,6\% $(\mathrm{n}=19)$ de homens. A faixa etária predominante foi de 22 anos ou mais, correspondendo a 63,7\% $(\mathrm{n}=114)$ dos participantes. Quanto ao estado civil, os solteiros representaram a maior proporção da amostra, 66,3\% (n = 118), seguidos por casados, $25,8 \%(\mathrm{n}=46)$. A etnia parda prevaleceu sobre as demais, representando pouco mais da metade dos estudantes, $51,4 \%(\mathrm{n}=90)$.

A predominância do sexo feminino corrobora com estudos semelhantes que evidenciam um maior número de mulheres no curso de enfermagem (PILLON et al., 2011; SILVA et al., 2012). Os solteiros em maior número e a predominância de pessoas na faixa etária de 22 anos ou mais também foram notados em estudos similares (LUCAS et al., 2006; PILLON et al., 2011). 
Tabela 1 - Perfil sociodemográfico dos estudantes por sexo - DF, 2016.

\begin{tabular}{|c|c|c|c|c|c|c|}
\hline \multirow{2}{*}{ Variáveis } & \multicolumn{2}{|c|}{ M } & \multicolumn{2}{|c|}{$\mathbf{F}$} & \multicolumn{2}{|c|}{ Total } \\
\hline & $\mathrm{n}$ & $\%$ & $\mathrm{~N}$ & $\%$ & $\mathrm{n}$ & $\%$ \\
\hline Idade & $n=19$ & 10,6 & $n=160$ & 89,4 & $n=179$ & $100 \%$ \\
\hline$<=18$ anos & 0 & 0,0 & 6 & 100,0 & 6 & 3,4 \\
\hline 19-21 anos & 7 & 11,9 & 52 & 88,1 & 59 & 33,0 \\
\hline 22 anos ou mais & 12 & 10,5 & 102 & 89,5 & 114 & 63,7 \\
\hline Estado Civil & $n=19$ & 10,7 & $n=159$ & 89,3 & $n=178$ & $100 \%$ \\
\hline Solteiro & 12 & 10,2 & 106 & 89,8 & 118 & 66,3 \\
\hline Casado & 4 & 8,7 & 42 & 91,3 & 46 & 25,8 \\
\hline Divorciado & 2 & 25,0 & 6 & 75,0 & 8 & 4,5 \\
\hline Outros & 1 & 16,7 & 5 & 83,3 & 6 & 3,4 \\
\hline Etnia & $n=18$ & 10,3 & $n=157$ & 89,7 & $n=175$ & $100 \%$ \\
\hline Branco & 6 & 11,8 & 45 & 88,2 & 51 & 29,1 \\
\hline Negro & 2 & 11,1 & 16 & 88,9 & 18 & 10,3 \\
\hline Pardo & 10 & 11,1 & 80 & 88,9 & 90 & 51,4 \\
\hline Amarelo & 0 & 0,0 & 12 & 100,0 & 12 & 6,9 \\
\hline Indígena & 0 & 0,0 & 4 & 100,0 & 4 & 2,3 \\
\hline Outros & 0 & 0,0 & 0 & 0,0 & 0 & 0,0 \\
\hline
\end{tabular}

Na Tabela 2, os estudantes foram distribuídos de acordo com o sexo e o semestre em curso, por faculdade estudada. Observa-se que quase metade dos respondentes eram alunos matriculados nos $3^{\circ}$ e $5^{\circ}$ semestres, representando $48,6 \%(n=87)$ dos estudantes. O semestre em que havia menos estudantes foi o $8^{\circ}$, com apenas $1,7 \%(\mathrm{n}=3)$ dos 179 alunos participantes. 
Tabela 2 - Distribuição dos estudantes conforme semestre e sexo, por faculdade- DF, 2016.

\begin{tabular}{|c|c|c|c|c|c|c|c|c|c|c|c|c|c|c|}
\hline \multirow[b]{3}{*}{ Semestre } & \multicolumn{4}{|c|}{ Faculdade 1} & \multicolumn{4}{|c|}{ Faculdade 2} & \multicolumn{4}{|c|}{ Total geral } & \multirow{2}{*}{\multicolumn{2}{|c|}{ Total }} \\
\hline & \multicolumn{2}{|c|}{$* \mathrm{M}$} & \multicolumn{2}{|c|}{$* * \mathrm{~F}$} & \multicolumn{2}{|c|}{$* \mathrm{M}$} & \multicolumn{2}{|c|}{$* * \mathrm{~F}$} & \multicolumn{2}{|c|}{$* \mathrm{M}$} & \multicolumn{2}{|c|}{$* * \mathrm{~F}$} & & \\
\hline & $\mathrm{N}$ & $\%$ & $\mathrm{~N}$ & $\%$ & $\mathrm{n}$ & $\%$ & $\mathrm{~N}$ & $\%$ & $\mathrm{n}$ & $\%$ & $\mathrm{n}$ & $\%$ & $\mathrm{n}$ & $\%$ \\
\hline 2 & 0 & 0,0 & 10 & 100,0 & 1 & 20,0 & 4 & 80,0 & 1 & 6,7 & 14 & 93,3 & 15 & 8,4 \\
\hline 3 & 3 & 15,8 & 16 & 84,2 & 3 & 10,7 & 25 & 89,3 & 6 & 12,8 & 41 & 87,2 & 47 & 26,3 \\
\hline 4 & 1 & 8,3 & 11 & 91,7 & 4 & 21,1 & 15 & 78,9 & 5 & 16,1 & 26 & 83,9 & 31 & 17,3 \\
\hline 5 & 1 & 5,3 & 18 & 94,7 & 1 & 4,8 & 20 & 95,2 & 2 & 5,0 & 38 & 95,0 & 40 & 22,3 \\
\hline 6 & 0 & 0,0 & 15 & 100,0 & 2 & 28,6 & 5 & 71,4 & 2 & 9,1 & 20 & 90,9 & 22 & 12,3 \\
\hline 7 & 0 & 0,0 & 13 & 100,0 & 2 & 25,0 & 6 & 75,0 & 2 & 9,5 & 19 & 90,5 & 21 & 11,7 \\
\hline 8 & 1 & 33,3 & 2 & 66,7 & 0 & 0,0 & 0 & 0,0 & 1 & 33,3 & 2 & 66,7 & 3 & 1,7 \\
\hline Total & 6 & 6,6 & 85 & 93,4 & 13 & 14,8 & 75 & 85,2 & 19 & 11,2 & 160 & 94,7 & 179 & 100,0 \\
\hline
\end{tabular}

*M - masculino; **F - feminino 
Na Tabela 3, são apresentadas as prevalências de consumo na vida e consumo atual de álcool e tabaco na população estudada. Ressalta-se que apenas os participantes que já experimentaram cada uma das drogas foram considerados para o cálculo da prevalência do uso atual dessas substâncias.

A partir dos dados, observa-se um comportamento dicotômico no consumo das duas substâncias: enquanto a maioria da amostra já experimentou e faz uso de álcool, apenas uma minoria faz (ou já fez) uso de tabaco.

Em relação ao álcool, a maioria $(n=156)$ já experimentou a substância, gerando uma prevalência de uso na vida de $87,2 \%$, resultado ligeiramente menor que os $90,4 \%$ registrados por Pedrosa et al. (2011). Os usuários atuais $(n=90)$ representam uma prevalência de consumo de álcool de 50,2\% na amostra estudada, resultado este maior que os 39\% encontrados no estudo de Freitas et al. (2012)

Em relação ao tabaco, a maioria dos respondentes afirmou nunca ter experimentado a substância, 59,2\% $(\mathrm{n}=106)$. Por conseguinte, a prevalência de uso na vida desta droga foi de 40,8\% ( $\mathrm{n}=73$ ), superando o percentual de 27,8\% verificado por Pedrosa et al. (2011) e também os 33\% encontrados por Santos, Pereira e Siqueira (2013). Avaliando os consumidores atuais $(n=13)$, obteve-se uma prevalência de consumo de tabaco de 7,3\%, em relação ao total de 179 estudantes da amostra, resultado que supera os 6\% verificados na pesquisa de Freitas et al. (2012).

Tabela 3 - Distribuição do comportamento de consumo de álcool e de tabaco na população estudada - DF, 2016.

\begin{tabular}{lccc}
\hline & Frequência & Percentual & IC 95\% \\
\hline & $\mathrm{N}$ & $\%$ & $\mathrm{IC}$ \\
\hline Q.6 Usou álcool na vida & & & \\
Não & $23 / 179$ & 12,8 & $7,94-17,74$ \\
Sim & $156 / 179$ & 87,2 & $82,26-92,06$ \\
Q.7 Atualmente usa álcool & & & \\
Não & $66 / 156$ & 42,3 & $34,55-50,05$ \\
Sim & $90 / 156$ & 57,7 & $49,95-65,45$ \\
Q.19 Usou tabaco na vida & & & \\
Não & $106 / 179$ & 59,2 & $52-66,4$ \\
Sim & $73 / 179$ & 40,8 & $33,6-48$ \\
Q.20 Atualmente usa tabaco & & & \\
Não & $59 / 72$ & 81,9 & $73,01-90,79$ \\
Sim & $13 / 72$ & 18,1 & $9,21-26,99$ \\
\hline
\end{tabular}


Entre aqueles que já utilizaram álcool na vida $(\mathrm{n}=156)$, a maioria, 57,7\% ( $\mathrm{n}=90)$, atualmente consome a droga. Pedrosa et al. (2011) registraram um percentual de $81,6 \%$ de estudantes que afirmaram ainda consumir álcool entre os que já experimentaram a droga.

Entre os que já utilizaram tabaco na vida $(\mathrm{n}=73)$, a minoria, 18,1\% $(\mathrm{n}=13)$, segue consumindo a substância, o que corrobora o estudo de Silva et al. (2012), que encontraram um percentual de14,7\% para essa mesma análise. Registra-se que uma pessoa não respondeu sobre o uso atual do tabaco, gerando diferença no universo populacional considerado para o cálculo desta prevalência.

Claramente, nota-se com esses achados que o percentual de abandono do tabaco é bem superior ao do álcool, talvez pelo reflexo das ações de combate ao consumo do tabaco que favoreceram uma tendência de diminuição gradativa desse hábito no país desde o ano de 1989 em pessoas com idade igual ou superior a 18 anos (INCA, 2011).

$\mathrm{Na}$ Tabela 4, é apresentada a presença de algum tipo de associação entre o consumo de álcool e o consumo de tabaco na população estudada. Constatou-se que o uso do álcool está significativamente $(\mathrm{p}<0,01)$ associado ao uso do tabaco. Além disso, observa-se que uma pessoa que já usou álcool na vida tem 18,86 vezes mais chance de também ter usado algum derivado do tabaco do que uma pessoa que nunca usou álcool. Apenas um estudante já utilizou o tabaco e não utilizou álcool.

Corroborando com este achado, ao pesquisarem as relações entre o consumo de drogas lícitas e ilícitas entre universitários, Santos, Pereira e Siqueira (2013) evidenciaram que 100\% das pessoas que já usaram tabaco na vida, também já usaram álcool. De forma similar, Andrade, Duarte e Oliveira (2010) e Cunha (2010) analisaram que o consumo de álcool e de tabaco muitas vezes ocorre de forma simultânea, classificando o tabaco como a droga mais associada ao consumo do álcool.

Tabela 4 - Teste de independência de Qui-Quadrado e razão de chances para o uso de álcool e tabaco - DF, 2016.

\begin{tabular}{lcccccc}
\hline \multirow{2}{*}{$\begin{array}{l}\text { Uso de álcool } \\
\text { na vida }\end{array}$} & \multicolumn{2}{c}{ Uso de tabaco na vida } & Total & $\begin{array}{c}\text { Razão de } \\
\text { Chances } \\
\text { RC - Odds Ratio }\end{array}$ & $\begin{array}{c}\text { Teste } \\
\text { Qui-quadrado* }\end{array}$ & $P$ \\
\cline { 2 - 4 } & $\operatorname{Sim}$ & Não & & 18,86 & 12,83 & 0,00034 \\
Sim & $72(46,2 \%)$ & $84(53,8 \%)$ & 156 & & & \\
Não & $1(4,3 \%)$ & $22(95,7 \%)$ & 23 & & & \\
\hline *Qui-Quadrado com correção de Yates por conter células menores que 5. & &
\end{tabular}

A faixa etária de experimentação das duas drogas pela população estudada é representada na Figura 1, evidenciando que o primeiro consumo tanto de álcool como de 
tabaco foi mais prevalente na faixa etária de 16 a 18 anos com percentuais de 38,7\% ( $\mathrm{n}=60)$ e $44,8 \%(n=30)$, respectivamente. Complementarmente, registra-se que $74,2 \%$ das pessoas experimentaram o álcool com idade igual ou menor que 18 anos e, de forma similar, 71,7\% experimentaram o tabaco também nesta faixa de idade, período relativamente anterior ao ingresso na universidade, que geralmente ocorre a partir dos 18 anos.

Ressalta-se que para o cálculo destas prevalências, a população considerada como universo para o álcool foi de 155 pessoas e, para o tabaco, 67 pessoas. Esta diferença para os 156 que já usaram álcool e para os 73 que já usaram tabaco na vida se explica pelo fato de que alguns participantes não responderam a questão que conduz a essa análise.

Estudo de 2013 realizado no Rio de Janeiro com 161 estudantes de enfermagem de uma universidade privada apontou que a experimentação do álcool foi mais prevalente em faixa etária menor (de 14 a 15 anos de idade) do que a encontrada na presente pesquisa. No mesmo estudo, foi evidenciado que $83,5 \%$ das pessoas utilizaram a droga pela primeira vez antes dos 18 anos, superando o percentual de 74,2\% verificado no presente estudo (JOMAR; SILVA, 2013).

Outra pesquisa que buscou pesquisar o uso de tabaco entre 68 estudantes de enfermagem do Espírito Santo, evidenciou que a experimentação da droga foi mais frequente em pessoas com idade entre 16 e 20 anos. Esse estudo mostrou, ainda, que $90 \%$ das pessoas fizeram uso de tabaco pela primeira vez antes dos 21 anos de idade (SILVA et al., 2012) No presente estudo esse percentual ficou em pelo menos $86,6 \%$.

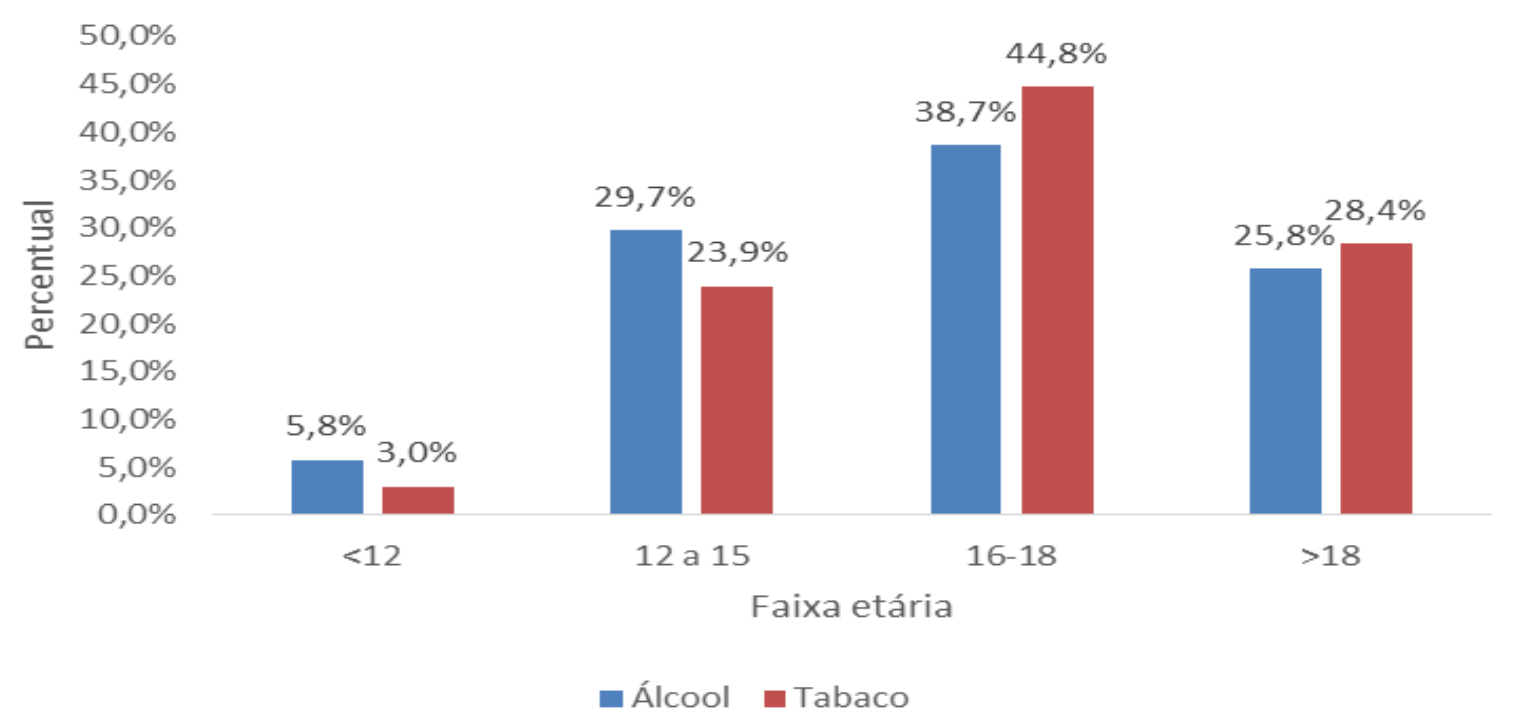

Figura 1 - Distribuição das faixas etárias de experimentação de álcool e de tabaco pela população estudada - DF, 2016. 
O comportamento de uso na vida e uso atual de álcool e de tabaco é apresentado na Tabela 5, agrupando os dados por sexo dos estudantes. Pode-se notar que não foram encontradas diferenças significativas entre o sexo e o consumo de álcool e tabaco, ou seja, na população estudada, não há evidências de que o uso das substâncias esteja associado ao gênero. Entretanto, observa-se que entre os 179 estudantes que participaram da pesquisa, todos os homens $(n=19)$ já utilizaram álcool na vida. Entre as mulheres, a maioria $(n=137)$ também já experimentou a substância. Quanto aos derivados do tabaco, 65 mulheres e 8 homens já fizeram uso de tabaco na vida.

Entre aqueles que já utilizaram álcool na vida, buscou-se saber quantos atualmente ainda consomem a substância. Em ambos os sexos, a maioria afirmou ainda consumir álcool, sendo 13 dos 19 homens e 77 das 137 mulheres. Isso significa que 6 homens e 60 mulheres deixaram de beber. Ademais, observa-se que a descontinuação do uso foi maior entre as mulheres, pois aquelas que deixaram de beber representaram $43,8 \%$ do total de mulheres que já utilizaram álcool enquanto que, entre os homens, apenas 31,6\% deixaram de beber. Este achado, quando em comparação com as estatísticas nacionais, contrapõe estudo recente que mostrou um aumento considerável no consumo de álcool pela população feminina no Brasil (LARANJEIRA et al., 2014).

De forma similar, também buscou-se saber quantos dentre os que já utilizaram derivados de tabaco na vida ainda fazem uso da substância atualmente. Desta vez, o resultado mostrou trajetória inversa aos resultados verificados para o consumo de álcool, pois a maioria de ambos os sexos afirmou não mais fazer uso da substância atualmente, sendo 7 dos 8 homens e 52 das 64 mulheres. Portanto, constata-se que 87,5\% dos homens e $81,2 \%$ das mulheres descontinuaram o uso de derivados do tabaco. 
Tabela 5 - Distribuição do comportamento de consumo na vida e consumo atual de álcool e de tabaco por sexo na população estudada - DF 2016.

\begin{tabular}{lcccc}
\hline & Feminino & Masculino & Qui-quadrado* & $P$ \\
\hline Uso de álcool na vida & & & & \\
Sim & $137 / 156(87,8 \%)$ & $19 / 156(12,2 \%)$ & 1,98 & 0,1592 \\
Não & $23 / 23(100,0 \%)$ & $0 / 23(0,0 \%)$ & & \\
Atualmente usa álcool & & & & 0,4459 \\
$\quad$ Sim & $77 / 90(85,6 \%)$ & $13 / 90(14,4 \%)$ & 0,58 & \\
Não & $60 / 66(90,9 \%)$ & $6 / 66(9,1 \%)$ & & \\
Usou Tabaco na vida & & & \\
$\quad$ Sim & $65 / 73(89,0 \%)$ & $8 / 73(11,0 \%)$ & 0,00 & \\
Não & $95 / 106(89,6 \%)$ & $11 / 106(10,4 \%)$ & & \\
Atualmente usa tabaco & & & & \\
Sim & $12 / 13(92,3 \%)$ & $1 / 13(7,7 \%)$ & 0,00 & \\
Não & $52 / 59(88,1 \%)$ & $7 / 59(11,9 \%)$ & & \\
\hline
\end{tabular}

*Qui-Quadrado com correção de Yates por conter células menores que 5

A Tabela 6 mostra a distribuição das prevalências de relato e fatores associados ao uso entre aqueles que já experimentaram álcool na população estudada. Todas as variáveis foram indagadas a todos os respondentes que já utilizaram álcool na vida, com exceção do número de doses consumidas, que foi a única variável respondida somente por aqueles que fazem uso atual da substância. 
Tabela 6 - Distribuição das prevalências de relato e fatores associados ao uso de álcool na população estudada - DF, 2016.

\begin{tabular}{|c|c|c|}
\hline & Frequência & IC $95 \%$ \\
\hline \multicolumn{3}{|l|}{ Sexo } \\
\hline Feminino & $137 / 156(87,8 \%)$ & $82,7-93,0$ \\
\hline Masculino & $19 / 156(12,2 \%)$ & $7,0-17,3$ \\
\hline \multicolumn{3}{|l|}{ Idade } \\
\hline Até 18 anos & $6 / 156(3,8 \%)$ & $0,8-6,9$ \\
\hline $19-21$ anos & $50 / 156(32,1 \%)$ & $24,7-39,4$ \\
\hline 22 anos ou mais & $100 / 156(64,1 \%)$ & $56,6-71,6$ \\
\hline \multicolumn{3}{|l|}{ Estado Civil } \\
\hline Solteiro & $104 / 155(67,1 \%)$ & $59,7-74,5$ \\
\hline Casado & $39 / 155(25,2 \%)$ & $18,3-32,0$ \\
\hline Divorciado & $7 / 155(4,5 \%)$ & $1,2-7,8$ \\
\hline Outros & $5 / 155(3,2 \%)$ & $0,4-6,0$ \\
\hline \multicolumn{3}{|l|}{ Etnia } \\
\hline Amarelo & $12 / 152(7,9 \%)$ & $3,6-12,2$ \\
\hline Branco & $47 / 152(30,9 \%)$ & $23,6-38,3$ \\
\hline Indígena & $2 / 152(1,3 \%)$ & $0,0-3,1$ \\
\hline Negro & $16 / 152(10,5 \%)$ & $5,6-15,4$ \\
\hline Pardo & $75 / 152(49,3 \%)$ & $41,4-57,3$ \\
\hline \multicolumn{3}{|l|}{ Idade $1^{\circ}$ uso } \\
\hline$<12$ anos & $9 / 155(5,8 \%)$ & $2,1-9,5$ \\
\hline $12-15$ anos & $46 / 155(29,7 \%)$ & $22,5-36,9$ \\
\hline $16-18$ anos & $60 / 155(38,7 \%)$ & $31,0-46,4$ \\
\hline$>18$ anos & $40 / 155(25,8 \%)$ & $18,9-32,7$ \\
\hline \multicolumn{3}{|l|}{ Motivação para $1^{\circ}$ uso } \\
\hline Influência amigos & $44 / 145(30,3 \%)$ & $22,9-37,8$ \\
\hline Curiosidade & $95 / 145(65,5 \%)$ & $57,8-73,3$ \\
\hline Problemas pessoais & $3 / 145(2,1 \%)$ & $0,0-4,4$ \\
\hline Propaganda na mídia & $0 / 145(0,0 \%)$ & $0,0-0,0$ \\
\hline Outros & $3 / 145(2,1 \%)$ & $0,0-4,4$ \\
\hline \multicolumn{3}{|l|}{ Bebida predileta } \\
\hline Destilados & $28 / 129(21,7 \%)$ & $14,6-28,8$ \\
\hline Vinho & $23 / 129(17,8 \%)$ & $11,2-24,4$ \\
\hline Cerveja & $46 / 129(35,7 \%)$ & $27,4-43,9$ \\
\hline Ice & $32 / 129(24,8 \%)$ & $17,4-32,3$ \\
\hline \multicolumn{3}{|c|}{$\mathbf{N}^{0}$ médio de doses consumidas } \\
\hline Até 4 doses & $42 / 87(48,3 \%)$ & $36,4-57,0$ \\
\hline 5 a 9 doses & $29 / 87(33,3 \%)$ & $22,6-41,9$ \\
\hline 10 a 15 doses & $10 / 87(11,5 \%)$ & $4,6-17,6$ \\
\hline Mais de 15 doses & $6 / 87(6,9 \%)$ & $1,5-11,8$ \\
\hline
\end{tabular}

Nota: nem todos os estudantes responderam a todas as perguntas, gerando universos diferentes para os cálculos das proporções em cada variável. Dessa forma, salienta-se que um participante não respondeu seu estado civil, quatro não responderam suas etnias, um não respondeu com que idade fez o primeiro uso, 11 não responderam o que os motivaram a experimentar o álcool, 27 não responderam suas bebidas preferidas e três não responderam o número de doses que consomem. 
Na tabela acima, portanto, verifica-se que as mulheres representaram $87,8 \%(\mathrm{n}=137)$ do total de estudantes que já experimentaram álcool. Sobre isso, cabe destacar que essa diferença se deve, em grande medida, ao fato de a população estudada ser predominantemente feminina. A faixa etária de 22 anos ou mais, o estado civil solteiro e a etnia parda compuseram a maioria dos relatos dentro dessas variáveis correspondendo, respectivamente, a 64,1\% ( $\mathrm{n}=100), 67,1 \%(\mathrm{n}=100)$ e 49,3\% $(\mathrm{n}=75)$ do total de estudantes que já experimentaram álcool e responderam a essas questões.

Nesta mesma tabela foram distribuídas também as frequências de relato sobre faixa etária de experimentação do álcool, motivação para o primeiro uso, bebida predileta e número de doses consumidas. Observa-se que a faixa de idade predominante para o primeiro uso do álcool foi entre 16 e 18 anos, 38,7\% ( $\mathrm{n}=60)$. Dado adicional revela que nove estudantes relataram experimentação de álcool com idade inferior a 12 anos.

A curiosidade foi o motivo mais relatado para motivar a experimentação da substância, 65,5\% ( $\mathrm{n}=95)$, seguido da influência de amigos, 30,3\% ( $\mathrm{n}=44)$. Freitas et al. (2012) registraram também que esse motivo foi o mais prevalente para experimentação de álcool entre universitários de cursos da saúde no Ceará.

A bebida preferida pelos respondentes foi a cerveja, representando $35,7 \%(n=46)$ dos que opinaram neste questionamento. Jomar e Silva (2013), de forma similar, verificaram a predileção pela cerveja por $33,1 \%$ dos universitários de sua pesquisa. Levantamento da OMS também mostrou a cerveja como o tipo de bebida alcoólica mais consumida no continente americano (WHO, 2014).

Registrou-se que o número de doses consumidas é inversamente proporcional às frequências de relato, ou seja, quanto maior o número de doses, menor o percentual de relato de consumo. Ademais, $51,7 \%$ dos estudantes afirmaram fazer uso de 5 ou mais doses em média por vez, superando os $32,1 \%$ e os $32,5 \%$ verificados em outros estudos (JOMAR; SILVA, 2013; IMAI; COELHO; BASTOS, 2014).

A OMS orienta que para evitar problemas com o consumo do álcool, homens saudáveis podem consumir no máximo três doses-padrão/dia e mulheres saudáveis não mais que duas doses-padrão/dia, o que gera preocupação em relação ao achado da presente pesquisa (WHO, 2011).

A Tabela 7 traz a distribuição das prevalências de relato e fatores associados ao uso de derivados de tabaco entre aqueles que já experimentaram a substância na população estudada. Todas as variáveis foram indagadas à totalidade dos respondentes que já utilizaram tabaco na vida. 
Tabela 7 - Distribuição das prevalências de relato e fatores associados ao uso de tabaco na população estudada - DF, 2016.

\begin{tabular}{|c|c|c|}
\hline & Frequência & IC $95 \%$ \\
\hline \multicolumn{3}{|l|}{ Sexo } \\
\hline Feminino & $65 / 73(89,0 \%)$ & $81,9-96,2$ \\
\hline Masculino & $8 / 73(11,0 \%)$ & $3,8-18,1$ \\
\hline \multicolumn{3}{|l|}{ Idade } \\
\hline Até 18 anos & $5 / 73(6,8 \%)$ & $1,1-12,6$ \\
\hline $19-21$ anos & $32 / 73(43,8 \%)$ & $32,5-55,2$ \\
\hline 22 anos ou mais & $36 / 73(49,3 \%)$ & $37,8-60,8$ \\
\hline \multicolumn{3}{|l|}{ Estado Civil } \\
\hline Solteiro & $51 / 73(69,9 \%)$ & $59,3-80,4$ \\
\hline Casado & $16 / 73(21,9 \%)$ & $12,4-31,4$ \\
\hline Divorciado & $4 / 73(5,5 \%)$ & $0,3-10,7$ \\
\hline Outros & $2 / 73(2,7 \%)$ & $0,0-6,5$ \\
\hline \multicolumn{3}{|l|}{ Etnia } \\
\hline Amarelo & $8 / 71(11,3 \%)$ & $3,9-18,6$ \\
\hline Branco & $27 / 71(38,0 \%)$ & $26,7-49,3$ \\
\hline Indígena & $0 / 71(0,0 \%)$ & $0,0-0,0$ \\
\hline Negro & $3 / 71(4,2 \%)$ & $0,0-8,9$ \\
\hline Pardo & $33 / 71(46,5 \%)$ & $34,9-58,1$ \\
\hline \multicolumn{3}{|l|}{ Idade $1^{\circ}$ uso } \\
\hline$<12$ anos & $2 / 67(3,0 \%)$ & $0,0-7,1$ \\
\hline $12-15$ anos & $16 / 67(23,9 \%)$ & $13,7-34,1$ \\
\hline $16-18$ anos & $30 / 67(44,8 \%)$ & $32,9-56,7$ \\
\hline$>18$ anos & $19 / 67(28,4 \%)$ & $17,6-39,2$ \\
\hline \multicolumn{3}{|l|}{ Motivação para $1^{\circ}$ uso } \\
\hline Influência amigos & $18 / 65(27,7 \%)$ & $16,8-38,6$ \\
\hline Curiosidade & $45 / 65(69,2 \%)$ & $58,0-80,5$ \\
\hline Problemas pessoais & $1 / 65(1,5 \%)$ & $0,0-4,5$ \\
\hline Propaganda na mídia & $0 / 65(0,0 \%)$ & $0,0-0,0$ \\
\hline Outros & $1 / 65(1,5 \%)$ & $0,0-4,5$ \\
\hline \multicolumn{3}{|l|}{ Derivado predileto } \\
\hline Cigarretes & $3 / 59(5,1 \%)$ & $0,0-10,7$ \\
\hline Cigarro comum & $20 / 59(33,9 \%)$ & $21,8-46,0$ \\
\hline Narguillé & $36 / 59(61,0 \%)$ & $48,6-73,5$ \\
\hline
\end{tabular}

Nota: nem todos os estudantes responderam a todas as perguntas, gerando universos diferentes para os cálculos das proporções em cada variável. Dessa forma, salienta-se que 2 participantes não responderam suas etnias, 6 não responderam com que idade fizeram o primeiro uso, 8 não responderam o que os motivaram a experimentar o tabaco e 14 não responderam suas predileções entre os derivados do tabaco.

De forma semelhante aos estudantes que já utilizaram álcool, o perfil daqueles que já consumiram tabaco também revelou as mesmas predominâncias de relato dentro das variáveis investigadas em comum. A maioria desses estudantes também foi de mulheres, $89 \%(\mathrm{n}=65)$. A faixa etária de 22 anos ou mais registrou 49,3\% $(n=36)$ dos estudantes e o estado civil 
solteiro e a etnia parda igualmente prevaleceram com seus percentuais, nesta ordem, em $69,9 \%(n=51)$ e 46,5\% ( $n=33)$ dos estudantes que já experimentaram derivados do tabaco.

$\mathrm{Na}$ Tabela 7, também foram distribuídas as frequências de relato sobre faixa etária de experimentação do tabaco, motivação para a experimentação e predileção entre os derivados do tabaco.

De forma semelhante ao álcool, a faixa etária que prevaleceu para a primeira utilização do tabaco foi de 16 a 18 anos, 44,8\% ( $\mathrm{n}=30)$ e a motivação predominante foi a curiosidade, $69,2 \%(\mathrm{n}=45)$. A curiosidade também foi verificada como o principal motivo para a primeira utilização do tabaco por $75 \%$ dos estudantes de enfermagem pesquisados por Bourguignon et al. (2011) no Espírito Santo.

Dentre os derivados do tabaco, o narguilé foi o mais citado como preferido, com $61 \%$ $(n=36)$ entre os estudantes que opinaram nesta questão, contrapondo a preferência nacional pelo cigarro comum (BRASIL, 2003). Estudo feito com universitários do curso de odontologia da cidade de Curitiba em 2016 revelou percentual muito semelhante de 66,23\% de predileção pelo narguilé. O crescimento desta modalidade de consumo do tabaco é preocupante, uma vez que neste mesmo estudo foi verificado também que a prevalência de uso do narguilé superou em mais de $15,2 \%$ a média nacional de 0,8\% (BECKERT et al., 2016). Adicionalmente, preocupa o fato de que um único sopro de narguilé apresenta quase a mesma quantidade de fumaça inalada em um único cigarro comum. Assim, uma sessão de uso do narguilé de mais ou menos 30 minutos pode ser equivalente a fumar de 20 a 30 cigarros (ERIKSEN et al., 2015).

Registra-se que o charuto, bem como outras variações de derivados do tabaco, que não as apresentadas na tabela, não foram citadas por nenhum dos participantes.

A Tabela 8 reúne a distribuição das frequências de relato do consumo de álcool e de tabaco entre aqueles que já experimentaram cada uma das drogas na população estudada, com base nas seis questões da ferramenta ASSIST que foram incluídas no questionário da pesquisa. Os dados estão apresentados de acordo com as frequências de consumo nos últimos 3 meses, forte desejo ou urgência em consumir, problemas associados ao consumo de ambas as drogas e negligência de atividades associada ao uso do álcool. A ferramenta orienta que, em se tratando de derivados do tabaco, a negligência de atividades relacionada ao uso da substância não seja questionada, o que explica a ausência de informação de frequência de relato nesta variável para o tabaco.

Para essas variáveis, as opções de resposta são padronizadas na ferramenta de acordo com a seguinte escala: nunca nos últimos 3 meses, uma ou duas vezes nos últimos 3 meses, 
mensalmente (de uma a três vezes em 1 mês), semanalmente (de uma a quatro vezes na semana) e diariamente (de 5 a 7 dias na semana).

$\mathrm{Na}$ mesma tabela, também são apresentadas as frequências com que os respondentes citaram a preocupação de outros com o consumo do álcool e do tabaco, bem como as tentativas mal sucedidas de controlar, reduzir ou cessar o consumo de ambas as drogas considerando não só os últimos 3 meses mas durante toda a vida. Para estas variáveis, as opções de resposta são padronizadas na ferramenta de acordo com a seguinte escala: nunca; sim, mas não nos últimos 3 meses e sim, nos últimos 3 meses.

Observa-se na tabela que a maioria dos respondentes afirmou ter consumido álcool nos últimos 3 meses, equivalendo a 65,4\% $(\mathrm{n}=102)$ dos estudantes que já o experimentaram. Já para o tabaco, $75 \%(\mathrm{n}=54)$ afirmaram não ter feito uso da droga nos últimos 3 meses. Estudo semelhante de aplicação do ASSIST com universitários do curso de enfermagem em Rondônia encontrou uma maior prevalência de consumo de álcool nos últimos 3 meses, $75,2 \%$. Coincidentemente, para o tabaco, foi encontrada a mesma prevalência de $25 \%$ de uso da substância no mesmo período (VALE; UESUGUI; PEREIRA, 2014). Além disso, Destacase que nenhum respondente informou fazer uso diário do álcool e que 5,6\% consomem diariamente o tabaco. Na mesma pesquisa citada acima foi verificado o consumo diário de álcool em 5\% e de tabaco em 35\% dos indivíduos da amostra (VALE; UESUGUI; PEREIRA, 2014). Em outro estudo, foi constatado que entre os estudantes que consumiam álcool mensalmente, apenas 0,9\% o faziam diariamente (JUNIOR; GAYA, 2015). Na variável forte desejo ou urgência em consumir, conforme orientação da ferramenta ASSIST, excluem-se dentre os que já experimentaram o álcool $(n=156)$ aqueles que nunca o utilizaram nos últimos 3 meses $(n=54)$, resultando em 102 participantes. Destes, a maioria, 54\% $(n=55)$, afirmou ter sentido desejo ou urgência para consumir o álcool, com predominância para aqueles que tiveram esta sensação uma ou duas vezes. O mesmo percentual, 54\%, foi encontrado por Vale, Uesugui e Pereira (2014) em pesquisa com acadêmicos de enfermagem. Outro estudo, com acadêmicos de medicina em uma universidade privada de Curitiba, evidenciou um percentual mais baixo, 23,9\% (TOCKUS; GONÇALVES, 2008). Nenhuma pessoa informou ter sentido forte desejo ou urgência para consumir o álcool diariamente.

Para o tabaco, um dos respondentes entre os que informaram já ter utilizado tabaco na vida $(n=73)$ não respondeu se fez uso nos últimos 3 meses, motivo pelo qual, o número utilizado para o cálculo da subtração passou a ser 72 e não 73 pessoas. Assim, com a exclusão dos 54 que não utilizaram tabaco nos últimos 3 meses, restaram 18 pessoas como universo para o cálculo da prevalência. Destes, a maioria, representada por $83,3 \%(\mathrm{n}=15)$, afirmou ter 
sentido forte desejo ou urgência em consumir derivado do tabaco nos últimos 3 meses, predominando aqueles que relataram esta sensação uma ou duas vezes. Assim, somente quatro pessoas $(22,2 \%)$ relataram ter sentido diariamente forte desejo ou urgência para consumir o tabaco, o que pode sugerir risco de dependência. Pesquisa semelhante apontou que $65 \%$ das pessoas que utilizaram tabaco nos últimos 3 meses também experimentaram o mesmo sentimento, sendo $26 \%$ delas numa frequência diária (VALE; UESUGUI; PEREIRA, 2014). Na pesquisa de Tockus e Gonçalves (2008) este percentual foi de 12,5\%.

Sobre a variável que indaga a ocorrência de problema (de saúde, social, legal ou financeiro), nota-se que a maioria dos respondentes informou não ter tido nenhum dos problemas citados em razão do uso do álcool, 70,6\% $(n=72)$, e do tabaco, 77,8\% ( $n=14)$, nos últimos 3 meses. No entanto, o percentual de 29,4\% de relato de problemas após o uso do álcool supera bastante os 19,3\% verificados por Jomar e Silva (2013). Estudo semelhante registrou uma maioria que relatou não ter tido problema com o álcool, 88\%, nem com o tabaco, 85\% (VALE; UESUGUI; PEREIRA, 2014). Mais enfaticamente, Tockus e Gonçalves (2008) apontaram que 94,3\% não tiveram problemas com o uso do álcool.

Em relação à negligência de atividades em razão do uso da droga observa-se que a maioria das pessoas que utilizaram álcool nos últimos 3 meses, 81,2\% $(\mathrm{n}=82)$, relatou nunca ter deixado de fazer nenhuma atividade em razão do uso da substância. Apenas $4 \%(\mathrm{n}=4)$ dos respondentes nesta questão informaram a negligência de atividades numa periodicidade mensal e somente uma pessoa informou que semanalmente deixou de fazer alguma atividade esperada por ela nos últimos 3 meses em razão do uso do álcool. Vale, Uesugui e Pereira (2014) registraram um percentual menor para esta negligência: 16\% relataram ter deixado de fazer alguma atividade por eles esperadas após o consumo do álcool, contra os 18,8\% verificados na presente pesquisa.

Para as duas últimas variáveis da tabela novamente se considerou o universo de todos aqueles que já utilizaram álcool e tabaco na vida, não somente nos últimos 3 meses.

Em relação ao relato dos participantes sobre preocupação de outras pessoas com a sua utilização das duas drogas, 11 pessoas não responderam para o álcool e 5 também não o fizeram para o tabaco. A maioria dos respondentes, 79,3\% $(\mathrm{n}=115)$, relatou que nunca houve preocupação de outras pessoas com seu consumo de álcool, percentual maior que o encontrado por Vale, Uesugui e Pereira (2014). Para o tabaco, também a maioria, 80,9\% (n = 55), informou nunca ter havido preocupação de outras pessoas com seu uso, corroborando com o achado de Tockus e Gonçalves (2008). Vale mencionar que o percentual de pessoas 
que relataram preocupação recente de outros com seu uso de substâncias nos últimos 3 meses, foi de $8,3 \%$ para o consumo de álcool e 11,8\% para tabaco.

Quanto ao relato dos participantes sobre tentativas frustradas de controle, redução ou abandono do uso das duas substâncias, 22 pessoas deixaram de responder a questão para o álcool e 3 pessoas para o tabaco. Novamente, uma maioria expressiva, 70,1\% $(n=94)$, relatou não ter tido nenhuma tentativa frustrada de controlar, reduzir ou cessar o consumo do álcool. A pesquisa de Tockus e Gonçalves (2008) também encontrou que a maioria dos consumidores de álcool não teve problemas nesse sentido, porém o percentual foi ainda maior, chegando a $92 \%$.

Para o tabaco, a maioria, 71,4\% $(\mathrm{n}=50)$, relatou também não ter vivenciado nenhuma tentativa mal sucedida de controlar, reduzir ou cessar o consumo da substância, corroborando com os resultados encontrados por Vale, Uesugui e Pereira (2014).

É importante frisar que que nestes números podem estar incluídas tanto pessoas que tentaram controlar, reduzir ou cessar o consumo e efetivamente conseguiram, quanto aqueles que nunca sequer tentaram. Por conseguinte, este fato não permite inferir que a totalidade destas pessoas efetivamente conseguiu controlar, reduzir ou cessar o consumo dessas drogas, uma vez que não é possível averiguar se houve, de fato, uma tentativa nesse sentido.

Outro aspecto relevante observado na Tabela 8 é que 29,9\% $(\mathrm{n}=40)$ dos respondentes já vivenciaram uma tentativa sem sucesso de controlar, reduzir ou cessar o uso do álcool. Para o tabaco, este percentual foi de 28,5\% ( $\mathrm{n}=20)$. Silva et al. (2012) identificaram um percentual próximo de pessoas que já tentaram para de fumar e não conseguiram (30\%).

Porém, salienta-se que não significa dizer que todas essas pessoas atualmente consomem as drogas, uma vez que é possível que esses números incluam aqueles que já vivenciaram uma tentativa frustrada de controle, redução ou abandono, mas que atualmente não mais consomem as substâncias. Fato que embasa esse argumento é que o número de respondentes que vivenciaram uma tentativa frustrada em relação ao tabaco $(n=20)$ é maior que o número de pessoas que atualmente consomem a substância $(n=13)$, conforme disposto na Tabela 3. 
Tabela 8 - Distribuição dos estudantes de acordo com as opções de resposta às questões do ASSIST na população estudada para ambas as drogas - DF, 2016.

\begin{tabular}{|c|c|c|c|c|}
\hline & Álcool & IC $95 \%$ & Tabaco & IC $95 \%$ \\
\hline \multicolumn{5}{|l|}{ Consumo nos últimos 3 meses } \\
\hline Nunca & $54 / 156(34,6 \%)$ & $27,1-42,1$ & $54 / 72(75,0 \%)$ & $65,0-85,0$ \\
\hline 1 ou 2 vezes & $48 / 156(30,8 \%)$ & $23,5-38,0$ & $7 / 72(9,7 \%)$ & $2,9-16,6$ \\
\hline Mensalmente & $32 / 156(20,5 \%)$ & $14,2-26,8$ & $5 / 72(6,9 \%)$ & $1,1-12,8$ \\
\hline Semanalmente & $22 / 156(14,1 \%)$ & $8,6-19,6$ & $2 / 72(2,8 \%)$ & $0,0-6,6$ \\
\hline Diariamente & $0 / 156(0,0 \%)$ & $0,0-0,0$ & $4 / 72(5,6 \%)$ & $0,3-10,8$ \\
\hline \multicolumn{5}{|l|}{$\begin{array}{l}\text { Forte desejo ou urgência em consumir } \\
\text { nos últimos } 3 \text { meses }\end{array}$} \\
\hline Nunca & $47 / 102(46,1 \%)$ & $36,4-55,8$ & $3 / 18(16,7 \%)$ & $0,0-33,9$ \\
\hline 1 ou 2 vezes & $27 / 102(26,5 \%)$ & $17,9-35,0$ & $8 / 18(44,4 \%)$ & $21,5-67,4$ \\
\hline Mensalmente & $17 / 102(16,7 \%)$ & $9,4-23,9$ & $1 / 18(5,6 \%)$ & $0,0-16,1$ \\
\hline Semanalmente & $11 / 102(10,8 \%)$ & $4,8-16,8$ & $2 / 18(11,1 \%)$ & $0,0-25,6$ \\
\hline Diariamente & $0 / 102(0,0 \%)$ & $0,0-0,0$ & $4 / 18(22,2 \%)$ & $3,0-41,4$ \\
\hline \multicolumn{5}{|c|}{ Problemas associados ao uso nos últimos 3 meses } \\
\hline Nunca & $72 / 102(70,6 \%)$ & $61,7-79,4$ & $14 / 18(77,8 \%)$ & $58,6-97,0$ \\
\hline 1 ou 2 vezes & $20 / 102(19,6 \%)$ & $11,9-27,3$ & $1 / 18(5,6 \%)$ & $0,0-16,1$ \\
\hline Mensalmente & $7 / 102(6,9 \%)$ & $2,0-11,8$ & $2 / 18(11,1 \%)$ & $0,0-25,6$ \\
\hline Semanalmente & $3 / 102(2,9 \%)$ & $0,0-6,2$ & $0 / 18(0,0 \%)$ & $0,0-0,0$ \\
\hline Diariamente & $0 / 102(0,0 \%)$ & $0,0-0,0$ & $1 / 18(5,6 \%)$ & $0,0-16,1$ \\
\hline \multicolumn{5}{|c|}{$\begin{array}{l}\text { Negligência de atividades associada ao uso } \\
\text { nos últimos } 3 \text { meses }\end{array}$} \\
\hline Nunca & $82 / 101(81,2 \%)$ & $73,6-88,8$ & - & - \\
\hline 1 ou 2 vezes & $14 / 101(13,9 \%)$ & $7,1-20,6$ & - & - \\
\hline Mensalmente & $4 / 101(4,0 \%)$ & $0,2-7,8$ & - & - \\
\hline Semanalmente & $1 / 101(1,0 \%)$ & $0,0-2,9$ & - & - \\
\hline Diariamente & $0 / 101(0,0 \%)$ & $0,0-0,0$ & - & - \\
\hline \multicolumn{5}{|l|}{ Preocupação de outros } \\
\hline Nunca & $115 / 145(79,3 \%)$ & $72,7-85,9$ & $55 / 68(80,9 \%)$ & $71,5-90,2$ \\
\hline Sim, mas não nos últimos 3 meses & $18 / 145(12,4 \%)$ & $7,0-17,8$ & $5 / 68(7,4 \%)$ & $1,1-13,6$ \\
\hline Sim, nos últimos 3 meses & $12 / 145(8,3 \%)$ & $3,8-12,8$ & $8 / 68(11,8 \%)$ & $4,1-19,4$ \\
\hline \multicolumn{5}{|c|}{$\begin{array}{l}\text { Tentativa sem sucesso de controlar, reduzir } \\
\text { ou cessar o consumo }\end{array}$} \\
\hline Nunca & $94 / 134(70,1 \%)$ & $62,4-77,9$ & $50 / 70(71,4 \%)$ & $60,8-82,0$ \\
\hline Sim, mas não nos últimos 3 meses & $28 / 134(20,9 \%)$ & $14,0-27,8$ & $15 / 70(21,4 \%)$ & $11,8-31,0$ \\
\hline Sim, nos últimos 3 meses & $12 / 134(9,0 \%)$ & $4,1-13,8$ & $5 / 70(7,1 \%)$ & $1,1-13,2$ \\
\hline
\end{tabular}

Todas essas variáveis da tabela anterior são questões extraídas da ferramenta ASSIST e, portanto, as opções de resposta têm diferentes pesos que lhes são atribuídos, conforme apresentado no Anexo B. Dessa forma, os participantes que afirmaram já ter consumido álcool e/ou tabaco na vida e que responderam a todas essas questões tiveram ao final uma pontuação calculada para cada droga. Assim, verifica-se na Tabela 9 a distribuição da quantidade de pessoas que pontuaram em cada questão, ou seja, que assinalaram suas 
respostas diferentes da opção "nunca", pois esta é a única das opções de resposta que tem peso 0 (zero).

Tabela 9 - Porcentagem de participantes que pontuaram em cada questão do ASSIST segundo a droga na população estudada - DF, 2016.

\begin{tabular}{cccccccc}
\hline & \multicolumn{7}{c}{ Percentual de Respostas Positivas } \\
\cline { 2 - 8 } Drogas & $\mathrm{A}$ & $\mathrm{B}$ & $\mathrm{C} *$ & $\mathrm{D}^{*}$ & $\mathrm{E}$ & $\mathrm{F}$ & $\mathrm{G}$ \\
\cline { 2 - 8 } Álcool & 156 & 102 & 55 & 30 & $19 / 101$ & $30 / 145$ & $40 / 134$ \\
& $(87,2 \%)$ & $(65,4 \%)$ & $(53,9 \%)$ & $(29,4 \%)$ & $(18,8 \%)$ & $(20,7 \%)$ & $(29,9 \%)$ \\
Tabaco & 73 & $18 / 72$ & 15 & 4 & - & $13 / 68$ & $20 / 70$ \\
& $(40,8 \%)$ & $(25,0 \%)$ & $(83,3 \%)$ & $(22,2 \%)$ & - & $(19,1 \%)$ & $(28,6 \%)$ \\
\hline
\end{tabular}

A - Uso na vida; B - Uso nos últimos 3 meses; C - Forte desejo ou urgência em consumir; D - Problemas associados; E - Negligência de atividades; F - Preocupação de outros; G - Tentativa de controle sem sucesso;

* Nos últimos 3 meses.

Registra-se preliminarmente que os percentuais da primeira coluna representam a proporção de pessoas que já usaram álcool e tabaco na vida em relação ao total de participantes da pesquisa, 179 estudantes. Os percentuais da segunda coluna representam a proporção de pessoas que utilizaram álcool e tabaco nos últimos 3 meses dentre aqueles que afirmaram já ter utilizado as drogas na vida e responderam à questão. Os percentuais das colunas assinaladas com asterisco representam a proporção de suas frequências em relação aqueles que afirmaram ter utilizado as drogas nos últimos 3 meses e responderam a essas questões. Os percentuais das duas últimas colunas da direita representam a proporção de suas frequências absolutas entre aqueles que já usaram álcool e tabaco na vida e responderam a essas questões.

Observa-se na Tabela 9 que o álcool foi a droga mais consumida tanto na vida, 87,2\% $(\mathrm{n}=156)$, quanto nos últimos 3 meses, 65,4\% $(\mathrm{n}=102)$, corroborando com o achado de Santos, Pereira e Siqueira (2013) que demonstraram uma prevalência de uso de álcool na vida de $85 \%$, superando todas as demais drogas. O tabaco foi a droga que gerou maior desejo ou urgência de consumo (na comparação com o álcool), pois 83,3\% $(\mathrm{n}=15)$ dos respondentes que utilizaram a substância nos últimos 3 meses afirmaram ter experimentado esta sensação. Esse resultado também foi encontrado por Vale, Uesugui e Pereira (2014).

A ocorrência de problemas relacionados ao uso do álcool foi sensivelmente mais frequente, $29,4 \%(\mathrm{n}=30)$, que a ocorrência de problemas relacionados ao uso do tabaco, $22,2 \%(n=4)$. Essa diferença contrasta com a evidência encontrada em outro estudo que apontou a maior ocorrência de problemas relacionados ao uso do tabaco, 17\%, do que em relação ao consumo de álcool, 11\% (VALE; UESUGUI; PEREIRA, 2014). 
Negligência de atividades em razão do consumo de álcool foi citada por 18,8\% (n = 19) daqueles que fizeram uso da droga nos últimos 3 meses. No contexto universitário, podese citar a presença assídua nas aulas, a realização de trabalhos acadêmicos e provas, estágios e tempo de estudo como atividades esperadas pelo público estudantil (TOCKUS; GOLÇALVES, 2008). Na mesma pesquisa citada no parágrafo anterior, 16\% dos estudantes afirmaram negligência de atividades como as citadas após o consumo do álcool (VALE; UESUGUI; PEREIRA, 2014). Conforme já dito anteriormente, essa variável não foi avaliada em relação ao tabaco.

A pontuação nas questões da pesquisa pode ser então classificada em faixas que determinam tanto a necessidade de intervenção terapêutica, como prevê a tabela de pontuação da versão original de entrevista do ASSIST constante no Anexo C, como o grau de risco do consumo previsto na versão autoaplicável da ferramenta constante no Anexo B. Neste estudo, em razão da autoaplicação dos questionários, optou-se por utilizar a estratificação de risco proposta na versão autoaplicável da ferramenta, enquadrando, portanto, cada pontuação nas faixas de Baixo Risco, Risco Moderado e Alto Risco. Naturalmente, o enquadramento nestas faixas apontará necessidades de intervenção para cada caso.

Salienta-se que aqueles que deixaram de responder pelo menos uma das questões do ASSIST não tiveram pontuação final calculada ou para o álcool ou para o tabaco ou para ambas as drogas e, portanto, não foram enquadrados em nenhuma das faixas supracitadas.

Barreto (2012) apresenta as faixas de risco de consumo explicitadas no Anexo C com a seguinte organização: Baixo Risco (quando a soma dos valores de cada resposta atingir uma pontuação de 0 a 10 para uso de álcool e de 0 a 3 para o tabaco), Risco Moderado (quando a soma dos valores de cada resposta atingir uma pontuação de 11 a 26 para uso de álcool e de 4 a 26 para o tabaco), Alto Risco (quando a soma dos valores de cada resposta atingir uma pontuação de 27 ou mais tanto para o uso de álcool quanto para o uso do tabaco).

Cada faixa de risco, por sua vez, traz explicações sobre o que quer dizer estar classificado como risco baixo, moderado ou alto igualmente para qualquer das drogas. A classificação Baixo Risco significa que o respondente apresenta baixo risco de estar atualmente experimentando problemas de saúde, sociais, financeiros ou legais relacionados ao uso da substância e, ao mesmo tempo, um baixo risco de desenvolver problemas futuros, caso o padrão de consumo seja mantido. A classificação Risco Moderado significa que o indivíduo já pode estar apresentando alguns problemas relacionados ao consumo da droga, inclusive de saúde. Essa classificação indica ainda que, caso não esteja apresentando, poderá ter problemas futuros e até desenvolvimento de dependência da droga se o padrão de uso for mantido. Nesta 
faixa recomenda-se que o consumo seja reduzido ou até cessado para se evitar ou amenizar problemas futuros. Por fim, a classificação Alto Risco significa que o indivíduo já apresenta problemas relacionados ao consumo da droga e que a dependência já deve ser considerada. Nessa última categoria, recomenda-se a procura por atendimento especializado, inclusive de um médico de confiança ou na Unidade Básica de Saúde para que sejam feitos uma avaliação clínica e os devidos encaminhamentos necessários (BARRETO, 2012).

Importante ressaltar que uma revisão integrativa da literatura realizada no Brasil sobre a aplicação do instrumento ASSIST identificou poucos estudos. Ademais, as pesquisas que efetivamente utilizaram todo o potencial da ferramenta ao calcular os escores de respostas dos participantes e distribuí-los nas faixas de risco de consumo das drogas, explorando assim a indicação de intervenções direcionadas foram ainda menos frequentes. A revisão evidenciou, pois, que na maioria das pesquisas, a utilização da ferramenta teve como objetivo apenas identificar o envolvimento com as drogas e testar variáveis e hipóteses (SILVA et al., 2016).

Posto isto, o presente trabalho avança em relação aos estudos citados ao utilizar a ferramenta para identificar os grupos de risco associados ao consumo de álcool. Assim, a Tabela 10 traz a associação entre as variáveis de perfil dos estudantes que tiveram pontuação calculada no ASSIST para o uso do álcool e as faixas de risco de consumo em que foram classificados. De forma complementar, a Tabela 11 traz o teste do Qui-Quadrado para essa associação. 
Tabela 10 - Perfil dos estudantes por faixa de risco do ASSIST para o álcool na população estudada - DF, 2016.

\begin{tabular}{|c|c|c|c|c|c|c|}
\hline & Baixo Risco & IC $95 \%$ & Risco Moderado & IC 95\% & Alto Risco & IC $95 \%$ \\
\hline \multicolumn{7}{|l|}{ Sexo } \\
\hline Feminino & $85 / 113(75,2 \%)$ & $67,3-83,2$ & $25 / 113(22,1 \%)$ & $14,5-29,8$ & $3 / 113(2,7 \%)$ & $0,0-5,6$ \\
\hline Masculino & $11 / 15(73,3 \%)$ & $51,0-95,7$ & $4 / 15(26,7 \%)$ & $4,3-49,0$ & $0 / 15(0,0 \%)$ & $0,0-0,0$ \\
\hline \multicolumn{7}{|l|}{ Idade } \\
\hline$<18$ & $5 / 6(83,3 \%)$ & $53,5-100,0$ & $1 / 6(16,7 \%)$ & $0,0-46,5$ & $0 / 6(0,0 \%)$ & $0,0-0,0$ \\
\hline $19-21$ & $32 / 45(71,1 \%)$ & $57,9-84,4$ & $11 / 45(24,4 \%)$ & $11,9-37,0$ & $2 / 45(4,4 \%)$ & $0,010,5$ \\
\hline$>22$ & $59 / 77(76,6 \%)$ & $67,2-86,1$ & $17 / 77(22,1 \%)$ & $12,8-31,3$ & $1 / 77(1,3 \%)$ & $0,0-3,8$ \\
\hline \multicolumn{7}{|l|}{ Estado Civil } \\
\hline Solteiro & 70/93 (75,3\%) & $66,5-84,0$ & $20 / 93(21,5 \%)$ & $13,2-29,9$ & $3 / 93(3,2 \%)$ & $0,0-6,8$ \\
\hline Casado & $20 / 26(76,9 \%)$ & $60,7-93,1$ & $6 / 26(23,1 \%)$ & $6,9-39,3$ & $0 / 26(0,0 \%)$ & $0,0-0,0$ \\
\hline Divorciado & $3 / 5(60,0 \%)$ & $17,1-100,0$ & $2 / 5(40,0 \%)$ & $0,0-82,9$ & $0 / 5(0,0 \%)$ & $0,0-0,0$ \\
\hline Outros & $3 / 4(75,0 \%)$ & $32,6-100,0$ & $1 / 4(25,0 \%)$ & $0,0-67,4$ & $0 / 4(0,0 \%)$ & $0,0-0,0$ \\
\hline \multicolumn{7}{|l|}{ Etnia } \\
\hline Amarelo & $5 / 9(55,6 \%)$ & $23,1-88,0$ & $3 / 9(33,3 \%)$ & $2,5-64,1$ & $1 / 9(11,1 \%)$ & $0,031,6$ \\
\hline Branco & $28 / 40(70,0 \%)$ & $55,8-84,2$ & $12 / 40(30,0 \%)$ & $15,8-44,2$ & $0 / 40(0,0 \%)$ & $0,0-0,0$ \\
\hline Indígena & $2 / 2(100,0 \%)$ & $100,0-100,0$ & $0 / 2(0,0 \%)$ & $0,0-0,0$ & $0 / 2(0,0 \%)$ & $0,0-0,0$ \\
\hline Negro & $11 / 11(100,0 \%)$ & $100,0-100,0$ & $0 / 11(0,0 \%)$ & $0,0-0,0$ & $0 / 11(0,0 \%)$ & $0,0-0,0$ \\
\hline Pardo & $48 / 64(75,0 \%)$ & $64,4-85,6$ & $14 / 64(21,9 \%)$ & $11,7-32,0$ & $2 / 64(3,1 \%)$ & $0,0-7,4$ \\
\hline \multicolumn{7}{|l|}{ Idade $1^{\circ}$ uso } \\
\hline$<12$ & $5 / 5(100,0 \%)$ & $100,0-100,0$ & $0 / 5(0,0 \%)$ & $0,0-0,0$ & $0 / 5(0,0 \%)$ & $0,0-0,0$ \\
\hline $12-15$ & $25 / 41(61,0 \%)$ & $46,0-75,9$ & $16 / 41(39,0 \%)$ & $24,1-54,0$ & $0 / 41(0,0 \%)$ & $0,0-0,0$ \\
\hline $16-18$ & $43 / 53(81,1 \%)$ & $70,6-91,7$ & $7 / 53(13,2 \%)$ & $4,1-22,3$ & $3 / 53(5,7 \%)$ & $0,011,9$ \\
\hline$>18$ & $22 / 28(78,6 \%)$ & $63,4-93,8$ & $6 / 28(21,4 \%)$ & $6,2-36,6$ & $0 / 28(0,0 \%)$ & $0,0-0,0$ \\
\hline \multicolumn{2}{|c|}{$\begin{array}{l}\text { Motivação para } 1^{\circ} \text { uso } \\
\text { Influência de }\end{array}$} & $58,7-87,3$ & $9 / 37(24,3 \%)$ & $10,5-38,1$ & $1 / 37(2,7 \%)$ & $0,0-7,9$ \\
\hline $\begin{array}{l}\text { Curiosidade } \\
\text { Problemas }\end{array}$ & $65 / 80(81,3 \%)$ & $72,7-89,8$ & $14 / 80(17,5 \%)$ & $9,2-25,8$ & $1 / 80(1,3 \%)$ & $0,0-3,7$ \\
\hline pessoais & $1 / 3(33,3 \%)$ & $0,0-86,7$ & $2 / 3(66,7 \%)$ & $13,3-100,0$ & $0 / 3(0,0 \%)$ & $0,0-0,0$ \\
\hline Outros & $0 / 3(0,0 \%)$ & $0,0-0,0$ & $3 / 3(100,0 \%)$ & $100,0-100,0$ & $0 / 3(0,0 \%)$ & $0,0-0,0$ \\
\hline \multicolumn{7}{|l|}{ Bebida predileta } \\
\hline Destilados & $14 / 22(63,6 \%)$ & $43,5-83,7$ & $8 / 22(36,4 \%)$ & $16,3-56,5$ & $0 / 22(0,0 \%)$ & $0,0-0,0$ \\
\hline Vinho & $17 / 18(94,4 \%)$ & $83,9-100,0$ & $1 / 18(5,6 \%)$ & $0,0-16,1$ & $0 / 18(0,0 \%)$ & $0,0-0,0$ \\
\hline Cerveja & $28 / 41(68,3 \%)$ & $54,0-82,5$ & $12 / 41(29,3 \%)$ & $15,3-43,2$ & $1 / 41(2,4 \%)$ & $0,0-7,2$ \\
\hline Ice & $22 / 29(75,9 \%)$ & $60,3-91,4$ & $6 / 29(20,7 \%)$ & $5,9-35,4$ & $1 / 29(3,4 \%)$ & $0,010,1$ \\
\hline \multicolumn{7}{|c|}{$\mathbf{N}^{\circ}$ médio de doses consumidas } \\
\hline Até 4 & $35 / 43(81,4 \%)$ & $69,8-93,0$ & $8 / 43(18,6 \%)$ & $7,0-30,2$ & $0 / 43(0,0 \%)$ & $0,0-0,0$ \\
\hline 5 a 9 & $18 / 29(62,1 \%)$ & $44,4-79,7$ & $10 / 29(34,5 \%)$ & $17,2-51,8$ & $1 / 29(3,4 \%)$ & $0,0-10,1$ \\
\hline 10 a 15 & $3 / 9(33,3 \%)$ & $2,5-64,1$ & $5 / 9(55,6 \%)$ & $23,1-88,0$ & $1 / 9(11,1 \%)$ & $0,0-31,6$ \\
\hline Mais de 15 & $1 / 6(16,7 \%)$ & $0,0-46,5$ & $5 / 6(83,3 \%)$ & $53,5-100,0$ & $0 / 6(0,0 \%)$ & $0,0-0,0$ \\
\hline
\end{tabular}


Tabela 11 - Teste Qui-Quadrado entre o perfil dos estudantes e as faixas de risco do ASSIST para o uso de álcool - DF, 2016.

\begin{tabular}{lcc}
\hline Variáveis & Teste Qui-Quadrado & $P$ \\
\hline Sexo & 0,53 & 0,7691 \\
Idade & 1,69 & 0,7925 \\
Estado Civil & 1,89 & 0,7567 \\
Etnia & 10,26 & 0,2472 \\
Idade $1^{\circ}$ uso & 10,13 & 0,1194 \\
Motivação para $1^{\circ}$ uso & 16,88 & 0,0097 \\
Bebida predileta & 7,22 & 0,3011 \\
$\mathrm{~N}^{\circ}$ de doses & 11,93 & 0,0636 \\
\hline
\end{tabular}

Os resultados mostram que das 156 pessoas que já utilizaram álcool na vida e que, portanto, poderiam submeter-se à pontuação da ferramenta, apenas 128 pessoas, sendo 113 mulheres e 15 homens, efetivamente responderam a todas as questões possibilitando assim o cálculo do escore numérico para definição da faixa de risco de consumo da droga.

$\mathrm{Na}$ faixa de baixo risco foram classificadas 96 pessoas e nas faixas de risco moderado e alto, juntas, 32 pessoas. Esses números representaram percentuais respectivos de $75 \%$ e $25 \%$ em relação a todos os classificados no ASSIST para o álcool. Estudo semelhante com acadêmicos de enfermagem registrou percentuais de $84 \%$ dos indivíduos em padrão de baixo risco e 16\% em médio e alto risco (SANTOS; PEREIRA; SIQUEIRA, 2013). Os 2,3\% de estudantes classificados em alto risco encontrados no presente trabalho foram compatíveis com o percentual de 2,6\% encontrado por Andrade et al. (2012) em pesquisa com mais de 12.000 universitários brasileiros diferentes cursos. Entretanto, estudo recente mostrou percentuais bastante distintos nas faixas de baixo e alto risco, em que foi constatado que apenas $42,7 \%$ dos universitários foram classificados na primeira, enquanto $6,4 \%$ foram enquadrados na segunda (JUNIOR; GAYA, 2015). Essa diferença nos resultados pode ser explicada pela maior presença de homens no grupo estudado por Junior e Gaya, (2015) em relação ao grupo eminentemente feminino desta pesquisa, já que outros estudos apontam que o consumo do álcool é significativamente mais prevalente na população masculina (PEDROSA et al., 2011; HEATHER et al., 2011; IMAI; COELHO; BASTOS, 2014).

Verifica-se que quanto ao sexo, embora não tenha havido diferença significativa, a maioria dos homens, 73,3\% $(\mathrm{n}=11)$, e das mulheres, 75,2\% $(\mathrm{n}=85)$, foi classificada na faixa de baixo risco. O percentual maior de mulheres em consumo de baixo risco contrapõem o resultado da pesquisa de Pillon et al. (2011) em que a maioria das estudantes de enfermagem de uma faculdade do interior de Minas Gerais utilizava álcool de forma problemática. 
Nenhum homem foi classificado na faixa de alto risco, porém três mulheres o foram. Nesse caso, entretanto, não cabe inferir que o fato de ser mulher gera maior probabilidade de ser classificado em alto risco, pois, além de ter sido demonstrado não ser estatisticamente significante, a população do estudo é predominantemente feminina.

Quanto à idade, observa-se que em todas as faixas etárias o maior percentual foi de pessoas classificadas na faixa de baixo risco. Constata-se entre os estudantes de 19 a 21 anos um maior percentual em relação aos demais nas faixas de risco moderado e alto. Esse resultado é coerente com o de Santos, Pereira e Siqueira (2013), que identificaram que 97,2\% das pessoas classificadas em risco moderado e alto tinham entre 18 e 24 anos de idade. Também nota-se que nenhuma pessoa com idade até 18 anos foi classificada na faixa de alto risco.

Embora essas diferenças não tenham sido significativas, a faixa etária de pessoas entre 19 e 21 anos compõe a maioria do público universitário, o que nos indica que é preciso atenção para esse fato. Conforme já citado por Garcia, Martini e Gálvez (2013) é no período universitário onde mais frequentemente aparecem e se consolidam comportamentos de risco, principalmente relacionados ao consumo de substâncias tóxicas.

O estado civil dos estudantes, quando associado às faixas de risco do ASSIST, também não revelou diferenças significativas. Em todos os estados civis, a maioria das pessoas foi classificada na faixa de baixo risco com percentuais de 75,3\%,76,9\%, 60\% e $75 \%$ entre casados, solteiros, divorciados e outros, respectivamente. Igualmente, em todas as etnias o maior percentual de pessoas esteve na faixa de baixo risco, salientando que $100 \%$ dos indígenas e dos negros foram classificados nesta faixa, sem diferenças significativas. Cabe observar que não foram encontradas referências na literatura para comparar os resultados nessas comparações.

Em relação à idade de experimentação do álcool, novamente os maiores percentuais foram encontrados na faixa de baixo risco de consumo em todas as faixas etárias. Ainda sobre esse tópico, nota-se que $100 \%$ das pessoas que experimentaram o álcool com menos de 12 anos foram classificados em baixo risco. Além disso, apenas 3 pessoas na faixa de alto risco fizeram uso de álcool com idades entre 16 e 18 anos, porém, também sem diferenças significativas. Estudos brasileiros sobre alcoolismo na adolescência mostraram que indivíduos mais jovens tendem a desenvolver rapidamente mecanismos adaptativos de tolerância ao álcool favorecendo o uso da droga. Logo, quanto mais cedo a experimentação e continuação do uso da droga, mais provável que ocorra dependência (SBP, 2007; PECHANSKY; SZOBOT; SCIVOLETTO, 2004). 
Quanto à motivação para o primeiro uso do álcool, pode-se notar que alunos que começaram a beber por influência de amigos ou por curiosidade tiveram mais chances de serem classificados em consumo de alto risco, visto que, nesta faixa, apenas foram classificados alunos que iniciaram o consumo do álcool por esses motivos. Ademais, ressaltase que a associação da motivação para experimentação com as faixas de risco do ASSIST revelou um valor de $\mathrm{p}$ significativo $(\mathrm{p}=0,0097)$. Alunos que iniciaram o consumo do álcool por problemas pessoais ou outros motivos foram classificados, geralmente, na faixa de risco moderado. Rozin e Zagonel (2012) identificaram que a curiosidade e a pressão dos amigos estiveram relacionadas a um maior risco de desenvolvimento de dependência, corroborando com o achado desta pesquisa.

Tal achado nos remete a considerar que o ambiente acadêmico proporciona ao jovem que ingressa na universidade a ampliação dos seus contatos sociais e a natural inserção em grupos formados por seus pares. Dessa forma, os hábitos e costumes acabam sendo compartilhados e por vezes incorporados aos comportamentos de cada um. Nesse contexto, o uso de substâncias tóxicas, em especial do álcool, costumeiramente passa a ser compartilhado dentro do grupo, favorecendo ainda mais a permanência no hábito e um consequente aumento na frequência e na quantidade consumidas. Balan e Campos (2006) já consideravam o ambiente universitário como sendo um espaço de certa permissividade para a continuidade do comportamento de beber. A incitação ao uso do álcool é ainda fomentada nos convites de festas universitárias em que se busca além do incentivo, facilitar e baratear o consumo da droga, como por exemplo em convites que dizem: Noite da Cerva - concorra a seis cervas pela melhor fantasia (PILLON; WEBSTER, 2006).

É fato, pois, que, sendo a constituição de grupos entre os estudantes algo natural e necessário dentro do processo de formação profissional, o consumo excessivo do álcool é algo que deve ser desencorajado, principalmente em razão das implicações negativas que esse hábito trará para a vida pessoal e profissional desses estudantes. Um exemplo disso foi o que pesquisadores verificaram a respeito de uma maior tendência de problemas profissionais em decorrência do uso abusivo do álcool entre enfermeiras que iniciaram o consumo da droga durante a formação acadêmica (SISNEY, 1995). Não se afastam ainda problemas relacionados ao aprendizado dentro da academia, uma vez que são comuns situações de atrasos frequentes e alunos que dormem durante as aulas pelo fato de terem bebido em excesso em festas ou comemorações na noite anterior (BALAN; CAMPOS, 2006).

Acrescenta-se ainda que, embora a maioria dos alunos desta pesquisa que iniciaram o consumo do álcool por curiosidade e/ou influência de amigos tenha sido classificada em 
consumo de baixo risco, são grandes as chances que o ambiente acadêmico proporciona à continuidade do consumo, o que pode levar a um padrão de uso mais problemático ao longo do tempo e a consequente instalação de problemas de saúde, sociais e profissionais (PILLON et al., 2011).

Para os tipos de bebidas apontadas como prediletas pelos respondentes, ao serem associadas com as faixas de risco do ASSIST, também não foram encontradas diferenças significativas. Cabe salientar que o maior percentual de pessoas classificadas na faixa de baixo risco tem o vinho como bebida predileta. Já os destilados e a cerveja são as bebidas preferidas da maioria das pessoas classificadas em risco moderado. Apenas a cerveja e a ice foram os únicos tipos de bebida alcoólica citados por pessoas classificadas em todas as faixas de risco. Coincidentemente, estas também foram as bebidas preferidas pela maioria.

Em relação ao número médio de doses consumidas e sua associação com as faixas de risco, embora diferenças significativas não tenham sido verificadas, observa-se na tabela que, quanto maior o número de doses consumidas, maior o percentual de pessoas em risco moderado e menor o percentual de pessoas classificadas em baixo risco. Na faixa de alto risco somente foram classificadas pessoas que informaram beber 5 ou mais doses por vez, o chamado binge drink. Pesquisa recente com universitários dos cursos de educação física, farmácia e enfermagem apontou que a maioria dos estudantes faz uso problemático do álcool, consumindo altas doses de bebidas por ocasião (WERNER; SIQUEIRA; LEMES, 2015).

A fim de verificar a influência do semestre em curso nas classificações de risco do ASSIST para o uso do álcool, apresenta-se a distribuição dos estudantes para essa associação na Tabela 12. 
Tabela 12 - Distribuição dos estudantes que já utilizaram álcool na vida por semestre e faixa de risco do ASSIST para a droga na população estudada- DF, 2016.

\begin{tabular}{cccccccc}
\hline & Baixo Risco & IC 95\% & $\begin{array}{c}\text { Risco } \\
\text { Moderado }\end{array}$ & IC 95\% & Alto Risco & IC 95\% & $p$ \\
\hline $\begin{array}{c}\text { Semestre } \\
2\end{array}$ & $10 / 13(76,9 \%)$ & $54,0-99,8$ & $3 / 13(23,1 \%)$ & $0,2-46,0$ & $0 / 13(0,0 \%)$ & $0,0-0,0$ & 0,39 \\
3 & $22 / 39(56,4 \%)$ & $40,8-72,0$ & $8 / 39(20,5 \%)$ & $7,8-33,2$ & $0 / 39(0,0 \%)$ & $0,0-0,0$ & \\
4 & $13 / 27(48,1 \%)$ & $29,3-67,0$ & $8 / 27(29,6 \%)$ & $12,4-46,9$ & $1 / 27(3,7 \%)$ & $0,0-10,8$ & \\
5 & $27 / 37(73,0 \%)$ & $58,7-87,3$ & $5 / 37(13,5 \%)$ & $2,5-24,5$ & $2 / 37(5,4 \%)$ & $0,0-12,7$ & \\
6 & $14 / 21(66,7 \%)$ & $46,5-86,8$ & $3 / 21(14,3 \%)$ & $0,0-29,3$ & $0 / 21(0,0 \%)$ & $0,0-0,0$ & \\
7 & $10 / 18(55,6 \%)$ & $32,6-78,5$ & $1 / 18(5,6 \%)$ & $0,0-16,1$ & $0 / 18(0,0 \%)$ & $0,0-0,0$ & \\
8 & $0 / 1(0,0 \%)$ & $0,0-0,0$ & $1 / 1(100,0 \%)$ & $100,0-100,0$ & $0 / 1(0,0 \%)$ & $0,0-0,0$ & \\
\hline
\end{tabular}

A tabela mostra que entre os alunos do $2^{\circ}$ ao $7^{\circ}$ semestres, que já consumiram álcool na vida, a maioria entre aqueles que responderam a todas as questões do ASSIST foi classificada dentro da faixa de baixo risco no consumo do álcool. $\mathrm{O} 4^{\circ}$ e o $5^{\circ}$ semestres foram os únicos que tiveram alunos classificados na faixa de alto risco, com um e dois alunos, respectivamente. No $8^{\circ}$ semestre, o único aluno que já experimentou álcool na vida foi classificado na faixa de risco moderado. Constata-se, ainda, que não existiu associação significativa entre as duas variáveis ( $\mathrm{p}=0,39)$, ou seja, não há evidências conclusivas de que a faixa de classificação do risco do consumo de álcool está relacionada ao semestre que o estudante está cursando.

Na Tabela 13 é mostrada a associação entre as variáveis de perfil dos estudantes que tiveram pontuação calculada no ASSIST para o uso do tabaco e as faixas de risco de consumo em que foram classificados. De forma complementar, a Tabela 14 traz o teste do QuiQuadrado para esta associação. 
Tabela 13 - Perfil dos estudantes por faixa de risco do ASSIST para o tabaco na população estudada - DF, 2016.

\begin{tabular}{|c|c|c|c|c|c|c|}
\hline & Baixo Risco & IC $95 \%$ & Risco Moderado & IC $95 \%$ & Alto Risco & IC $95 \%$ \\
\hline \multicolumn{7}{|l|}{ Sexo } \\
\hline Feminino & $48 / 63(76,2 \%)$ & $65,7-86,7$ & $13 / 63(20,6 \%)$ & $10,6-30,6$ & $2 / 63(3,2 \%)$ & $0,0-7,5$ \\
\hline Masculino & $4 / 7(57,1 \%)$ & $20,5-93,8$ & $3 / 7(42,9 \%)$ & $6,2-79,5$ & $0 / 7(0,0 \%)$ & $0,0-0,0$ \\
\hline \multicolumn{7}{|l|}{ Idade } \\
\hline$<18$ & $20 / 32(62,5 \%)$ & $45,7-79,3$ & $11 / 32(34,4 \%)$ & $17,9-50,8$ & $1 / 32(3,1 \%)$ & $0,0-9,2$ \\
\hline $19-21$ & $5 / 5(100,0 \%)$ & $100,0-100,0$ & $0 / 5(0,0 \%)$ & $0,0-0,0$ & $0 / 5(0,0 \%)$ & $0,0-0,0$ \\
\hline$>22$ & $27 / 33(81,8 \%)$ & $68,7-95,0$ & $5 / 33(15,2 \%)$ & $2,9-27,4$ & $1 / 33(3,0 \%)$ & $0,0-8,9$ \\
\hline \multicolumn{7}{|l|}{ Estado Civil } \\
\hline Solteiro & $35 / 50(70,0 \%)$ & $57,3-82,7$ & $13 / 50(26,0 \%)$ & $13,8-38,2$ & $2 / 50(4,0 \%)$ & $0,0-9,4$ \\
\hline Casado & $12 / 14(85,7 \%)$ & $67,4-100,0$ & $2 / 14(14,3 \%)$ & $0,0-32,6$ & $0 / 14(0,0 \%)$ & $0,0-0,0$ \\
\hline Divorciado & $3 / 4(75,0 \%)$ & $32,6-100,0$ & $1 / 4(25,0 \%)$ & $0,0-67,4$ & $0 / 4(0,0 \%)$ & $0,0-0,0$ \\
\hline Outros & $2 / 2(100,0 \%)$ & $100,0-100,0$ & $0 / 2(0,0 \%)$ & $0,0-0,0$ & $0 / 2(0,0 \%)$ & $0,0-0,0$ \\
\hline \multicolumn{7}{|l|}{ Etnia } \\
\hline Amarelo & $8 / 8(100,0 \%)$ & $100,0-100,0$ & $0 / 8(0,0 \%)$ & $0,0-0,0$ & $0 / 8(0,0 \%)$ & $0,0-0,0$ \\
\hline Branco & $17 / 25(68,0 \%)$ & $49,7-86,3$ & $7 / 25(28,0 \%)$ & $10,4-45,6$ & $1 / 25(4,0 \%)$ & $0,0-11,7$ \\
\hline Negro & $2 / 3(66,7 \%)$ & $13,3-100,0$ & $1 / 3(33,3 \%)$ & $0,0-86,7$ & $0 / 3(0,0 \%)$ & $0,0-0,0$ \\
\hline Pardo & $23 / 32(71,9 \%)$ & $56,3-87,5$ & $8 / 32(25,0 \%)$ & $10,0-40,0$ & $1 / 32(3,1 \%)$ & $0,0-9,2$ \\
\hline \multicolumn{7}{|l|}{ Idade $1^{\circ}$ uso } \\
\hline$<12$ & $0 / 1(0,0 \%)$ & $0,0-0,0$ & $1 / 1(100,0 \%)$ & $100,0-100,0$ & $0 / 1(0,0 \%)$ & $0,0-0,0$ \\
\hline $12-15$ & $9 / 16(56,3 \%)$ & $31,9-80,6$ & $5 / 16(31,3 \%)$ & $8,5-54,0$ & $2 / 16(12,5 \%)$ & $0,0-28,7$ \\
\hline $16-18$ & $28 / 30(93,3 \%)$ & $84,4-100,0$ & $2 / 30(6,7 \%)$ & $0,0-15,6$ & $0 / 30(0,0 \%)$ & $0,0-0,0$ \\
\hline$>18$ & $12 / 19(63,2 \%)$ & $41,5-84,8$ & $7 / 19(36,8 \%)$ & $15,2-58,5$ & $0 / 19(0,0 \%)$ & $0,0-0,0$ \\
\hline \multicolumn{7}{|c|}{$\begin{array}{l}\text { Motivação para } 1^{\circ} \text { uso } \\
\text { Influência }\end{array}$} \\
\hline amigos & $17 / 18(94,4 \%)$ & $83,9-100,0$ & $1 / 18(5,6 \%)$ & $0,0-16,1$ & $0 / 18(0,0 \%)$ & $0,0-0,0$ \\
\hline $\begin{array}{l}\text { Curiosidade } \\
\text { Problemas }\end{array}$ & $29 / 44(65,9 \%)$ & $51,9-79,9$ & $13 / 44(29,5 \%)$ & $16,1-43,0$ & $2 / 44(4,5 \%)$ & $0,0-10,7$ \\
\hline pessoais & $1 / 1(100,0 \%)$ & $100,0-100,0$ & $0 / 1(0,0 \%)$ & $0,0-0,0$ & $0 / 1(0,0 \%)$ & $0,0-0,0$ \\
\hline \begin{tabular}{l}
\multicolumn{1}{c}{ Outros } \\
Derivado \\
predileto
\end{tabular} & $0 / 1(0,0 \%)$ & $0,0-0,0$ & $1 / 1(100,0 \%)$ & $100,0-100,0$ & $0 / 1(0,0 \%)$ & $0,0-0,0$ \\
\hline Cigarretes & $2 / 3(66,7 \%)$ & $13,3-100,0$ & $1 / 3(33,3 \%)$ & $0,0-86,7$ & $0 / 3(0,0 \%)$ & $0,0-0,0$ \\
\hline Cigarro & $15 / 20(75,0 \%)$ & $56,0-94,0$ & $3 / 20(15,0 \%)$ & $0,0-30,6$ & $2 / 20(10,0 \%)$ & $0,0-23,1$ \\
\hline Narguillé & $27 / 36(75,0 \%)$ & $60,9-89,1$ & $9 / 36(25,0 \%)$ & $10,9-39,1$ & $0 / 36(0,0 \%)$ & $0,0-0,0$ \\
\hline
\end{tabular}


Tabela 14 - Teste Qui-Quadrado entre as variáveis do perfil dos estudantes e as faixas de risco do ASSIST para o uso de derivados do tabaco - DF, 2016.

\begin{tabular}{lcc}
\hline Variáveis & Teste Qui-Quadrado & $p$ \\
\hline Sexo & 1,89 & 0,3885 \\
Idade & 5,31 & 0,2572 \\
Estado Civil & 2,48 & 0,8708 \\
Etnia & 3,57 & 0,7351 \\
Idade $1^{\circ}$ uso & 15,93 & 0,0141 \\
Motivação para o $1^{\circ}$ uso & 9,05 & 0,1707 \\
Derivado predileto & 4,69 & 0,3203 \\
\hline
\end{tabular}

Os dados mostram que, das 73 pessoas que já utilizaram tabaco na vida e que, portanto, poderiam submeter-se à pontuação da ferramenta, 70 pessoas, sendo 63 mulheres e 7 homens, efetivamente responderam a todas as questões possibilitando assim o cálculo do escore numérico para definição da faixa de risco de consumo da droga.

$\mathrm{Na}$ faixa de baixo risco foram classificadas 52 pessoas e em risco moderado, 16 pessoas. Já na faixa de alto risco, registraram-se apenas duas pessoas. Esses números representaram percentuais respectivos de 74,3\%, 22,8\% e 2,9\% em relação a todos os classificados no ASSIST para o tabaco.

Pesquisa recente com a mesma ferramenta evidenciou situação mais preocupante sobre os percentuais encontrados para as faixas de classificação de risco para uso do tabaco. Os dados do estudo mostraram um menor percentual de universitários na faixa de baixo risco, $48,1 \%$, e maiores percentuais nas faixas de risco moderado e alto, 46,2\% e 5,8\%, respectivamente (JUNIOR; GAYA, 2015). Os resultados mais preocupantes encontrados no estudo citado talvez possam ser explicados pela maior presença de homens no grupo estudado em relação ao grupo desta pesquisa, já que outros estudos com universitários apontam que o consumo de derivados do tabaco é mais prevalente na população masculina (ANDRADE; DUARTE; OLIVEIRA, 2010; FREITAS et al., 2012; IMAI; COELHO; BASTOS, 2014; LARANJEIRA et al., 2014).

Outra possível explicação para a constatação de menores percentuais no consumo de médio e alto risco neste estudo em relação à pesquisa de Junior e Gaya (2015) corresponde à diminuição progressiva do hábito tabágico no Brasil, verificado desde o início da década de 90 (INCA, 2011). 
Verifica-se que quanto ao sexo, embora não tenha havido diferença significativa, a maioria dos homens, $57,1 \%(\mathrm{n}=4)$, e das mulheres, $76,2 \%(\mathrm{n}=48)$, foi classificada na faixa de baixo risco. Nenhum homem foi classificado na faixa de alto risco, porém duas mulheres o foram, o que pode sugerir tanto a maior prevalência do sexo feminino nesta faixa quanto refletir simplesmente a predominância do sexo na amostra. Bittencourt, Paula e Araújo (2015) verificaram em seu estudo com pessoas que buscavam atendimento para tratamento de dependência nicotínica que, embora mais mulheres tenham procurado o serviço, inclusive por se preocuparam mais com a saúde em relação aos homens, não houveram diferenças significativas na associação do sexo com o risco de dependência para uso do tabaco.

Quanto à idade, observa-se que embora em todas as faixas etárias o maior percentual tenha sido de pessoas em baixo risco, constata-se o maior percentual de estudantes com idade até 18 anos em relação às demais faixas etárias no grupo de risco moderado. Observa-se, ainda, que todos os estudantes de 19 a 21 anos de idade foram classificados na faixa de baixo risco. Mesmo que essas diferenças não tenham sido significativas, vale salientar o fato de que as pessoas mais jovens estão consumindo derivados do tabaco de forma mais preocupante. A necessidade de intervenções em fases mais vulneráveis, a exemplo da vida acadêmica, foi apontada como necessária em estudo semelhante com população tabagista (BITTENCOURT; PAULA; ARAUJO, 2015).

O estado civil dos estudantes, quando associado às faixas de risco do ASSIST, também não revelou diferenças significativas, ainda que em todas as suas variações a maioria das pessoas tenha sido classificada na faixa de baixo risco com percentuais de 70\%, 85,7\%, 75\% e $100 \%$ entre casados, solteiros, divorciados e outros, respectivamente. Salienta-se que os solteiros apresentaram o perfil de consumo mais preocupante, uma vez que tiveram o menor percentual de pessoas classificadas na faixa de baixo risco e maior nas faixas de risco moderado e alto. Entretanto, contrapondo este achado, o estudo feito por Bittencourt, Paula e Araújo (2015) revelou predominância de casados entre os indivíduos que buscaram atendimento para dependência nicotínica.

De forma similar, em todas as etnias o maior percentual de pessoas esteve na faixa de baixo risco, salientando que $100 \%$ dos amarelos $(n=8)$ foram classificados nesta faixa, sem diferenças significativas. Cabe notar que não foram encontradas referências na literatura para a comparação desses resultados.

Em relação à idade do primeiro uso do tabaco, entre todas as pessoas que experimentaram a droga com 12 anos ou mais, os maiores percentuais foram registrados na faixa de baixo risco e o único participante que fez uso pela primeira vez com menos de 12 
anos foi classificado na faixa de risco moderado. Registra-se que estudantes que experimentaram o tabaco com idade entre 12 e 15 anos foram os únicos a serem classificados dentro da faixa de alto risco. Esta associação entre a idade de experimentação do tabaco e as faixas de risco do ASSIST mostrou-se como a única significativa ( $\mathrm{p}=0,0141)$, conforme apresentado na Tabela 14. Estudo feito por Bittencourt, Paula e Araújo (2015) também evidenciou relação estatisticamente significante entre essas variáveis $(p=0,047)$, verificando um maior grau de dependência nos indivíduos que tiveram início precoce do uso do tabaco. A idade do primeiro uso também foi semelhante à encontrada nesta pesquisa, com média de início de consumo de $15 \pm 3$ anos.

O achado descrito acima é motivo de preocupação, uma vez que quanto mais cedo se inicia o consumo do tabaco, mais aumenta o tempo de exposição do indivíduo aos malefícios por ele causados. Ainda que inúmeros artifícios legais tenham sido editados pelo poder público no sentido de restringir ao máximo o acesso de jovens menores de idade ao tabaco, observa-se o fácil acesso à droga pelo público adolescente.

Considerando que a idade universitária inicia-se geralmente com 18 anos, fica evidente que grande parte das pessoas que experimentaram o tabaco ainda mais jovens é composta por adolescentes em idade escolar. Nesse sentido, pesquisadores alertam sobre a necessidade de intervenções preventivas o mais cedo possível, citando que o ambiente escolar deve ser também contemplado com estratégias de promoção da saúde que levem informações sobre as consequências negativas do uso do tabaco para que sua experimentação seja desencorajada e que cada vez mais a prevalência do consumo da droga seja reduzida entre escolares (IMAI; COELHO; BASTOS, 2014). Complementando esse raciocínio, se autores apontam os estudantes universitários como um público vulnerável para o uso de drogas em razão de sua imaturidade, jovens escolares tornam-se ainda mais vulneráveis.

Não se pode negligenciar também o impacto causado pelo consumo do tabaco no universo familiar desses jovens. Na maioria das vezes, o usuário tenta manter seu uso sob sigilo, principalmente por esperar reações de reprovação principalmente por parte dos pais e até pelo estigma negativo que se criou na sociedade perante o consumo da droga. Interessante é notar ainda que a percepção dos malefícios causados pelo tabaco e a intenção de cessar o consumo também já coexistem na maioria dessas pessoas, conforme aponta estudo nacional feito com fumantes (MACNALLY et al., 2013). Entretanto, fatores como as altas concentrações de nicotina nos derivados do tabaco, que elevam o risco de instauração da dependência da droga, e o consumo iniciado precocemente e mantido de maneira frequente dificultam o processo de interrupção do consumo do tabaco. Dessa forma, instala-se uma 
situação desfavorável que aponta para maiores chances desses jovens que precocemente experimentaram o tabaco desenvolverem um perfil de uso de alto risco para a dependência química.

Quanto à motivação para o primeiro uso do tabaco, novamente não foram encontradas diferenças significativas. Na tabela, pode-se notar que alunos que iniciaram o consumo por influência de amigos ou por problemas pessoais se concentram na faixa de baixo risco. Os que o fizeram por curiosidade foram os únicos classificados na faixa de alto risco e a única pessoa que experimentou por outros motivos foi classificada em risco moderado.

Para os derivados do tabaco apontados como prediletos, ao serem associados com as faixas de risco do ASSIST, também não foram contabilizadas diferenças significativas. Verifica-se que o maior percentual de pessoas classificadas na faixa de baixo risco tem como derivados prediletos o cigarro comum e o narguillé. Já os cigarretes são os derivados do tabaco preferidos da maioria das pessoas classificadas em risco moderado. Apenas o cigarro comum foi citado por pessoas classificadas na faixa de alto risco.

A fim de verificar também a influência do semestre em curso nas classificações de risco do ASSIST para o uso do tabaco, a distribuição dos estudantes nesta associação é apresentada na Tabela 15, a seguir.

Tabela 15 - Distribuição dos estudantes que já utilizaram tabaco na vida por semestre e faixa de risco do ASSIST para a droga na população estudada- DF, 2016.

\begin{tabular}{cccccccc}
\hline & Baixo Risco & IC 95\% & $\begin{array}{c}\text { Risco } \\
\text { Moderado }\end{array}$ & IC 95\% & Alto Risco & IC 95\% & $p$ \\
\hline Semestre & & & & & & & 0,16 \\
2 & $3 / 4(75,0 \%)$ & $32,6-100,0$ & $0 / 4(0,0 \%)$ & $0,0-0,0$ & $1 / 4(25,0 \%)$ & $0,0-67,4$ & \\
3 & $14 / 18(77,8 \%)$ & $58,6-97,0$ & $4 / 18(22,2 \%)$ & $3,0-41,4$ & $0 / 18(0,0 \%)$ & $0,0-0,0$ & \\
4 & $11 / 15(73,3 \%)$ & $51,0-95,7$ & $4 / 15(26,7 \%)$ & $4,3-49,0$ & $0 / 15(0,0 \%)$ & $0,0-0,0$ & \\
5 & $10 / 15(66,7 \%)$ & $42,8-90,5$ & $5 / 15(33,3 \%)$ & $9,5-57,2$ & $0 / 15(0,0 \%)$ & $0,0-0,0$ & \\
6 & $7 / 13(53,8 \%)$ & $26,7-80,9$ & $3 / 13(23,1 \%)$ & $0,2-46,0$ & $1 / 13(7,7 \%)$ & $0,0-22,2$ & \\
7 & $7 / 8(87,5 \%)$ & $64,6-100,0$ & $0 / 8(0,0 \%)$ & $0,0-0,0$ & $0 / 8(0,0 \%)$ & $0,0-0,0$ & \\
\hline
\end{tabular}

Os dados demonstram que em todos os semestres, entre os alunos que já consumiram tabaco na vida, a maioria entre aqueles que responderam a todas as questões do ASSIST foi classificada dentro da faixa de baixo risco no consumo do tabaco. $\mathrm{O} 2^{\circ}$ e o $6^{\circ}$ semestres foram os únicos que tiveram alunos (um entrevistado em cada) classificados na faixa de alto risco. $\mathrm{Na}$ faixa de baixo risco, identificou-se uma redução progressiva do percentual de estudantes do $3^{\circ}$ ao $6^{\circ}$ semestre, com o maior percentual sendo registrado no $7^{\circ}$ semestre. Não foi 
registrado, entre os três alunos do $8^{\circ}$ semestre que participaram da pesquisa, nenhum que já tenha consumido tabaco na vida. Ao todo, 16 pessoas foram classificadas na faixa de risco moderado para o consumo de tabaco. Além disso, constata-se que não há associação significativa entre as duas variáveis $(\mathrm{p}=0,16)$, ou seja, a faixa de classificação do risco do consumo de tabaco independe do semestre que o estudante está cursando.

Outra situação investigada na pesquisa foi a vivência de situações de risco após o consumo do álcool tais como brigas, acidentes de trânsito, absenteísmo na escola ou trabalho, hábito de dirigir, entre outras. Sobre isso, Marin e Queiroz (2000) e Minayo e Deslandes (1998) apud Galassi (2008) já apontavam que em diversos países o álcool era responsável por $30 \%$ a 50\% dos acidentes de trânsito graves e fatais e que 50\% de todos os homicídios, mais de $30 \%$ dos suicídios e uma ampla gama de comportamentos violentos eram associados ao consumo do álcool. Savater (2000) apud Acselrad (2012) cita que é recorrente afirmar que o uso do álcool prejudica a produtividade, provoca o absenteísmo e traz perturbações à disciplina no trabalho. Não obstante, é preciso levar em consideração a relação entre o consumo de álcool e outros fatores ao avaliar essa questão. Nesse sentido, Melo (2005) apud Acselrad et al. (2012) salienta que não é possível estabelecer nexo causal isolado entre o álcool e comportamentos violentos, uma vez que fatores como pressões socioeconômicas, ambiente sociocultural complexo e exigente e estilo educacional rígido, por exemplo, quando somados ao uso do álcool, potencializam a possibilidade de atos de violência após o consumo da substância.

Dessa forma, entendendo que as frequências de relato dessas situações vivenciadas após o uso do álcool podem se comportar de maneira diferente nos indivíduos conforme a faixa de risco do seu consumo, procurou-se fazer a associação entre as variáveis: situação vivenciada após uso do álcool e classificação de risco na ferramenta ASSIST (ver Tabela 16). Os percentuais apresentados foram gerados a partir da frequência absoluta do relato da situação em relação ao número total de pessoas classificadas em cada faixa de risco, de 96, 29 e 3 pessoas para as faixas de baixo, moderado e alto risco, respectivamente.

Tabela 16 - Distribuição das situações vivenciadas após consumo do álcool por faixa de risco do ASSIST - DF, 2016.

\begin{tabular}{lcccc}
\hline Situação Vivenciada & Baixo Risco & Risco Moderado & Alto Risco & $p$ \\
\hline & & & & 0,32 \\
Briga & $11 / 96(11,5 \%)$ & $4 / 29(13,8 \%)$ & $1 / 3(33,3 \%)$ & \\
Acidente de trânsito & $4 / 96(4,2 \%)$ & $0 / 29(0,0 \%)$ & $0 / 3(0,0 \%)$ & \\
Faltou à escola ou trabalho & $18 / 96(18,8 \%)$ & $11 / 29(37,9 \%)$ & $2 / 3(66,7 \%)$ & \\
Dirigiu veículo & $23 / 96(24,0 \%)$ & $8 / 29(27,6 \%)$ & $0 / 3(0,0 \%)$ & \\
\hline
\end{tabular}


A partir da tabela, verifica-se que, embora não tenha sido verificada significância estatística entre as situações vivenciadas e a faixa de risco do consumo, excetuando-se os acidentes de trânsito, todas as outras situações vivenciadas revelaram percentuais de ocorrência maiores entre as pessoas com consumo classificado em médio ou alto risco em comparação com aquelas de consumo de baixo risco.

Nota-se que entre as pessoas com consumo classificado como de baixo risco, a situação vivenciada mais relatada foi o ato de dirigir veículo após o consumo do álcool, 24\% ( $\mathrm{n}=23)$. Quando comparado à população total do estudo esse número, acrescido dos 8 estudantes em consumo de risco moderado, representou $17,3 \%$ dos estudantes que responderam ao questionário. Esse percentual é ligeiramente menor que os $18 \%$ encontrados por Andrade, Duarte e Oliveira (2010) em pesquisa nacional com cerca de 12.000 universitários de diversos cursos e maior que os 16,5\% verificados por Picolotto et al., (2010) em pesquisa com acadêmicos de enfermagem. Tal fato não deixa de ser preocupante, pois sugere que muitos estudantes ainda não deixam de dirigir após consumir álcool, mesmo com todos os esforços preventivos, repressivos e punitivos imprimidos pelo poder público em relação a essa prática.

A situação mais relatada entre as pessoas com consumo classificado em médio e alto risco foi a abstinência na escola ou no trabalho, superando os percentuais de relato das outras situações nessas duas faixas. Considerando-se por sua vez todo o público pesquisado, esse absenteísmo foi citado por 17,3\% $(\mathrm{n}=31)$ dos estudantes. Pesquisa semelhante feita com acadêmicos de enfermagem em Passo Fundo revelou que $21 \%$ dos alunos afirmaram ter faltado à escola após ingerirem bebida alcoólica (PICOLOTTO et al., 2010).

Ademais, foram relatadas em campo aberto no questionário outras situações vivenciadas pelos participantes que não aquelas listadas nas opções de resposta. Uma pessoa relatou ida ao hospital com mal estar provocado pela ingestão do álcool, outra relatou surto psicótico e tentativa de suicídio e uma terceira pessoa relatou hipoglicemia.

Por fim, no intuito de reforçar o caráter de ligação comumente estabelecido e evidenciado na Tabela 4 entre o consumo do álcool e do tabaco, é apresentada a seguir a associação entre indivíduos que foram classificados com base na ferramenta ASSIST para ambas as drogas nos 9 cruzamentos possíveis entre as 3 faixas de risco de uso do álcool e do tabaco. 
Tabela 17 - Teste de independência de Qui-Quadrado entre as classificações de risco do ASSIST para o álcool e para o tabaco - DF, 2016.

\begin{tabular}{|c|c|c|c|c|c|c|c|}
\hline \multirow{2}{*}{$\begin{array}{l}\text { Classificação de } \\
\text { Risco Álcool }\end{array}$} & \multicolumn{3}{|c|}{ Classificação de Risco Tabaco } & \multirow{2}{*}{ Total } & \multirow{2}{*}{$\begin{array}{l}\text { Razão de } \\
\text { Chances }\end{array}$} & \multirow{2}{*}{$\begin{array}{c}\text { Teste } \\
\text { Qui- } \\
\text { quadrado }\end{array}$} & \multirow{2}{*}{$p$} \\
\hline & Baixo Risco & Risco Moderado & Alto Risco & & & & \\
\hline Baixo Risco & $37(90,2 \%)$ & $4(9,8 \%)$ & $0(0,0 \%)$ & 41 & 9,25 & 13,83 & 0,00787 \\
\hline Risco Moderado & $9(45,0 \%)$ & $9(45,0 \%)$ & $2(10,0 \%)$ & 20 & 1 & & \\
\hline Alto Risco & $1(50,0 \%)$ & $1(50,0 \%)$ & $0(0,0 \%)$ & 2 & 1 & & \\
\hline
\end{tabular}

*Qui-Quadrado com correção de Yates por conter células menores que 5

A tabela 17 permite concluir que 63 pessoas tiveram classificação de risco de consumo para ambas as drogas. Destas, 37 foram classificadas simultaneamente em baixo risco para o álcool e para o tabaco, nove pessoas em risco moderado para ambas as substâncias e nenhuma pessoa foi classificada na faixa de alto risco de consumo para as duas drogas.

Pode-se notar, ainda, que a associação entre as classificações de risco de consumo do álcool e do tabaco foi estatisticamente significante $(\mathrm{p}=0,00787)$. Além disso, constata-se por meio da razão de chances que os alunos classificados em baixo risco para o álcool tiveram 9,25 vezes mais chance de serem também classificados em baixo risco no tabaco do que os alunos de risco moderado e alto. Já os alunos enquadrados em consumo de risco moderado e alto para o álcool têm a mesma chance de serem também alocados na faixa de baixo risco para o tabaco.

Este achado reforça o caráter de ligação entre o consumo de ambas as drogas sugerindo, portanto, que as pessoas com consumo de álcool de médio e alto riscos têm maiores chances de também serem consumidoras de tabaco em riscos semelhantes. 


\section{CONCLUSÃO}

Sobre o perfil sociodemográfico, nota-se que a população estudada foi predominantemente feminina, representando $89,4 \%(\mathrm{n}=160)$ da amostra total. Além disso, a maioria dos respondentes, $63,7 \%(\mathrm{n}=114)$, tinha idade igual ou superior a 22 anos, 66,3\% $(\mathrm{n}=118)$ eram solteiros e 51,4\% $(\mathrm{n}=90)$ de etnia parda. Mais da metade dos alunos, $52 \%(\mathrm{n}$ =93), estava cursando até o $4^{\circ}$ semestre.

Em relação ao consumo de álcool, contabilizou-se que que 87,2\% (n=156) dos respondentes já haviam consumido a substância pelo menos uma vez na vida e 73,2\% o experimentaram com idade igual ou menor que 18 anos. A prevalência de uso atual do álcool na população estudada foi de $50,2 \%(\mathrm{n}=90)$.

Todos os homens que participaram da pesquisa já fizeram uso de álcool pelo menos uma vez na vida e a descontinuação do uso foi maior entre as mulheres. Entretanto, não foram encontradas diferenças significativas para o uso na vida e o uso atual da droga entre o sexo dos respondentes.

A curiosidade foi o motivo mais relatado para motivar a experimentação da substância e a bebida preferida pelos respondentes foi a cerveja.

A maioria dos estudantes afirmou ter utilizado álcool nos últimos 3 meses em quantidade maior que 5 doses por ocasião. Essa maioria declarou, também, que não teve problemas de qualquer ordem, que não foram negligentes com suas atividades em razão do consumo e que não experimentaram tentativas frustradas de controle, redução ou cessação do hábito.

Dos 128 acadêmicos que responderam a todas as questões do ASSIST para o álcool, $75 \%$ tiveram consumo classificado como de baixo risco. Dentre as variáveis "sexo", "idade", "semestre em curso", “estado civil”, “etnia", "idade de experimentação", "bebida predileta", "número de doses consumidas por vez" e "motivação para o primeiro uso", apenas esta última mostrou significância estatística quando da associação com as faixas de risco do ASSIST, com valor de $\mathrm{p}=0,0097$. Assim, observou-se que os alunos que começaram a consumir álcool por influência de amigos ou por curiosidade foram mais classificados na faixa de baixo risco, enquanto que aqueles que iniciaram o consumo por problemas pessoais ou outros motivos foram mais classificados na faixa de risco moderado.

Embora sem diferenças significativas, estudantes entre 19 e 21 anos, faixa etária que compõe grande parte do público universitário, tiveram consumo do álcool mais frequentemente classificado como de médio e alto risco, o que sugere necessidade de atenção 
para o fato. Merece alerta, ainda, o fato de três mulheres terem tido consumo classificado como de alto risco, sugerindo quadro de dependência alcoólica e necessidade de intervenção terapêutica com profissional especializado.

Quanto às situações de risco e/ou indesejadas vivenciadas após o uso do álcool, embora não tenha havido significância estatística na comparação dessa variável com o consumo da substância, excetuando-se os acidentes de trânsito, todas as outras situações relatadas (brigas, falta à escola ou trabalho e dirigir veículo) revelaram percentuais de ocorrência maiores entre as pessoas com consumo classificado em médio ou alto risco do que entre aqueles enquadrados como de baixo risco. Entre as pessoas com consumo considerado de baixo risco, a situação vivenciada mais relatada foi o ato de dirigir veículo após o consumo do álcool. Entre aquelas com consumo de risco moderado e alto, a situação mais citada foi a abstinência à escola ou ao trabalho.

Em relação ao consumo de tabaco, 40,8\% (n=106) dos respondentes já haviam consumido pelo menos uma vez na vida a droga. Desses, 71,7\% das pessoas experimentaram a substância com idade igual ou menor que 18 anos. A prevalência de uso atual do tabaco na população estudada foi de $7,6 \%(n=13)$.

Também não foram encontradas diferenças significativas entre o gênero dos respondentes para as variáveis de uso na vida e uso atual do tabaco. Apesar disso, observou-se que a maioria dos homens, $87,5 \%$, e das mulheres, $81,2 \%$, descontinuou o consumo da substância.

O principal fator motivador para o primeiro uso do tabaco também foi a curiosidade e o derivado da substância preferido pelos respondentes foi o narguilé. A prevalência de consumo deste derivado nesta pesquisa superou em mais de $15 \%$ a média nacional, gerando alerta importante devido ao teor expressivamente maior de substâncias tóxicas inaladas por meio do narguilé quando comparado aos outros derivados.

A maioria dos estudantes afirmou não ter utilizado tabaco nos últimos 3 meses. Entre os que consumiram, 83,3\% afirmaram que experimentaram nesse período a sensação de forte desejo ou urgência em consumir o tabaco. A maioria dos estudantes que consumiram tabaco nos últimos 3 meses informou não ter tido problemas de saúde, social, legal ou financeiro em razão do uso da substância.

A maioria dos respondentes ainda informou que outras pessoas não manifestaram preocupação quanto ao uso do tabaco pelos próprios estudantes e que não vivenciaram tentativas frustradas de controle, redução ou cessação do hábito tabágico. 
Dos 70 estudantes que responderam a todas as questões do ASSIST para o tabaco, $74,3 \%$ tiveram consumo classificado como de baixo risco. Dentre as variáveis "sexo", "idade", "semestre em curso", "estado civil", "etnia", "derivado predileto", "motivação para o primeiro uso" e "idade de experimentação", esta última foi a única que mostrou significância estatística quando da associação com as faixas de risco do ASSIST, com valor de $p=0,0141$. Assim, observou-se que o primeiro uso da substância entre os estudantes com consumo classificado em baixo risco ocorreu mais frequentemente na faixa etária entre 16 e 18 anos. Entre os classificados em consumo de risco moderado, a experimentação foi mais frequente entre os maiores de 18 anos e os únicos dois estudantes com consumo de tabaco classificado como de alto risco informaram ter experimentado a substância com idade igual ou inferior a 15 anos, tornando-se, assim, candidatos potenciais de intervenção terapêutica.

Cruzando as classificações de risco de consumo de ambas as drogas, observou-se, que os alunos alocados em consumo de baixo risco para o álcool tiveram 9,25 vezes mais chance de serem também classificados em baixo risco no tabaco do que os alunos de consumo de risco moderado e alto. Já os alunos enquadrados em consumos moderado e alto para o álcool têm a mesma chance de serem igualmente alocados na faixa de baixo risco para o tabaco, o que reforça o caráter de ligação entre o consumo das duas substâncias.

Os resultados desse estudo apontam para a necessidade de orientação ao público participante, extensivamente a toda a comunidade acadêmica, sobre as condutas a serem tomadas diante das possíveis classificações de risco para o consumo de álcool e de tabaco.

Cabe notar que ainda são necessários novos estudos que aprofundem outros fatores associados aos hábitos etílico e tabágico entre acadêmicos de enfermagem e que utilizem plenamente a capacidade de aplicação da ferramenta ASSIST em sua modalidade de autopreenchimento a fim de que se obtenham outros resultados para comparação com os desta pesquisa.

Os resultados sobre a temática exposta nesse trabalho podem auxiliar na condução de novas discussões no meio acadêmico acerca do consumo dessas drogas entre estudantes de enfermagem, contribuindo na adoção de estratégias promotoras de saúde dirigidas a esta população. Estratégias estas que podem surgir principalmente de estudos de intervenção que seguramente poderão ser conduzidos a partir dos resultados desta pesquisa no intuito de que sejam fomentadas ações preventivas e reativas frente às singularidades dos diferentes perfis de consumo do álcool e do tabaco e com foco na orientação para adoção de hábitos de vida saudáveis. 
Merece destaque ainda o fato de que os estudantes de enfermagem, futuros profissionais da área da saúde, por vezes são tidos como modelo de comportamento social perante o consumo de drogas. Assim sendo, a credibilidade do profissional enfermeiro, que tem sua prática inteiramente voltada à promoção da saúde, fica suscetível de ser abalada aos olhos da sociedade quando este tem entre seus hábitos de vida o consumo de drogas como o álcool e o tabaco. Nesse sentido, o presente trabalho também vem instigar a comunidade acadêmica de enfermagem para que sejam desde já agentes de mudança e inspiração de um estilo de vida saudável e livre de vícios, contribuindo positivamente para o marketing da profissão.

Paralelamente, as informações geradas pelos dados da pesquisa subsidiarão também os gestores públicos em prol do desenvolvimento ou fortalecimento de políticas públicas direcionadas ao público universitário.

Como limitações do estudo, cita-se que o perfil sociodemográfico dos participantes poderia ter sido mais amplo, com a inserção de outras variáveis como religião, moradia, consumo das substâncias por familiares, locais onde as substâncias são usadas, entre outras. Entretanto, ressalta-se que o enfoque maior foi dado à identificação do perfil do consumo de acordo com as variáveis obtidas na ferramenta ASSIST.

Outros fatores limitantes da análise foram a perda de dados pelo não preenchimento de determinadas questões pelos respondentes e o caráter temporal do estudo transversal, que restringe as inferências de causa e efeito no tocante a possíveis associações entre as faixas de risco de consumo em que os participantes foram classificados e as variáveis que qualificaram esse consumo ao longo do tempo. 


\section{REFERÊNCIAS}

ACSELRAD, G. et al. Consumo de bebidas alcoólicas no Brasil: estudo com base em fontes secundárias. Rio de Janeiro: Faculdade Latinoamericana de Ciências Sociais FLACSO, 2012. 162p.

AGÊNCIA NACIONAL DE VIGILÂNCIA SANITÁRIA. Derivados do tabaco. Assuntos de interesse. Legislação. Disponível em <http://s.anvisa.gov.br/wps/s/r/bTok>. Acesso em: 06/09/2015.

ALMEIDA, G. E. G. de. Fumo: servidão moderna e violação de direitos humanos. Curitiba: Ed. Terra de Direitos, 2005.

ANDERSON, M. I. P.; CASTRO FILHO, E. D. de. Sistema de Educação médica continuada à distância: programa de atualização em medicina de saúde e comunidade. Porto Alegre: Artmed/Panamericana, 2006.

ANDRADE, A. G. A importância do conhecimento científico no combate ao uso nocivo de tabaco, álcool e drogas ilícitas. Revista de psiquiatria Clínica, São Paulo, v. 35, supl. 1, 2008 .

ANDRADE, A. G.; DUARTE, P. C. A. V. de; OLIVEIRA L.G. de. I Levantamento Nacional sobre o Uso de Álcool, Tabaco, e outras Drogas entre Universitários das 27 Capitais Brasileiras. Brasília, SENAD: 2010, 279p.

ANDRADE, A.G. et al. Use of alcohol and other drugs among Brazilian college students: effects of gender and age. Rev Bras Psiquiatr, v. 34, n. 3, p. 294-305, 2012. Disponível em: <http://www.scielo.br/pdf/rbp/v34n3/v34n3a09.pdf>. Acesso em: 23/09/2016.

ANDRADE, A. P. A. de. et al. Prevalência e características do tabagismo em jovens da Universidade de Brasília. J Bras Pneumol, v. 1, n. 32, p. 23-28, 2006.

ASMA, S. et al. The GATS Atlas. Atlanta, CDC Foundation: 2015, 128p.

BACHELARD, G. A psicanálise do fogo. São Paulo: Martins Fontes, 1999.

BALAN, T. G.; CAMPOS, C. J. G. Padrão de consumo de bebidas alcoólicas entre graduandas de enfermagem de uma universidade estadual paulista. Rev SMAD, Rev. Eletrônica Saúde Mental Álcool Drog., v. 2, n. 2, 2006. Disponívelem: <http://www2.eerp.usp.br/resmad/artigos/2006v2n2a02.pdf>. Acesso em: 11/09/2015.

BARBETTA, P. A. Estatística Aplicada às Ciências Sociais. 5. ed. Florianópolis: Editora da UFSC, 2004.

BARRETO, H. A. G. Confiabilidade teste-reteste do ASSIST na forma de autopreenchimento em estudantes universitários. 2012. 115p. Dissertação (Mestrado em Farmacologia) - Setor de Ciências Biológicas, Universidade Federal do Paraná, Curitiba, 2012. 
BASKIN-SOMMERS, A.; SOMMERS, I. The co-occurrence of substance use and high-risk behaviors. J Adolescent Health, v. 38, n. 5, p. 609-611, 2006.

BAU, C. H. D. Estado atual e perspectiva da genética e epidemiologia do alcoolismo. Ciênc Saúde Coletiva, v. 7, n. 1, p. 183-190, 2002.

BAUS, J.; KUPEK, E.; PIRES, M. Prevalência e fatores de risco relacionados ao uso de drogas entre escolares. Rev Saúde Pública, São Paulo, v. 36, n. 1, p. 40-46, 2002.

BERTO, S. J. P.; CARVALHAES, M. A. B. L; MOURA, E. C. de. Tabagismo associado a outros fatores comportamentais de risco de doenças e agravos crônicos não transmissíveis. Caderno de Saúde Pública, Rio de Janeiro, v. 26, n. 8, p. 1573-1582, Agosto, 2010. Disponível em: $<$ http://www.scielo.br/scielo.php?script=sci_arttext\&pid=S0102-311X2010000800011\&lng=en\&nrm=iso>.

Acesso em09/09/2015.

BITTENCOURT, L. F. V.; PAULA, D. J. da C.; ARAÚJO, N. L. de. Associação do grau de dependência do tabaco com as características sociodemográficas de fumantes. Rev.EnfUFJF, Juiz de Fora, v. 1, n. 1, p. 105-111, 2015.

BOEIRA, S. L.; JOHNS, P. Indústria de Tabaco vs. Organização Mundial de Saúde: um confronto histórico entre redes sociais de stakeholders. Revista Internacional Interdisciplinar Interthesis, Florianópolis, v. 4, n. 1, p. 1-25, 2007. ISSN 1807-1384. Disponível em: <https://periodicos.ufsc.br/index.php/interthesis/article/view/895/10851>. Acesso em: 28/09/2015.

BOURGUIGNON, L. N. et al. O uso do Tabaco entre estudantes de enfermagem do Centro Universitário do Espírito Santo (Ceunes). Revista Brasileira de Pesquisa em Saúde, v. 13, n. 4, p. 35-40, 2011.

BRASIL. Ministério da Saúde. Departamento de Informática do Sus (DATASUS). Décima Revisão da Classificação Estatística Intemacional de Doenças e Problemas Relacionados à Saúde. Versão 2008. v. 1. Disponívelem: <http://www.datasus.gov.br/cid10/V2008/cid10.htm>. Acesso em: 13/09/2015.

BRASIL. Ministério da Saúde. Instituto Nacional do Câncer. Programa Nacional de Controle do Tabagismo e Outros Fatores de Risco de Câncer - Modelo Lógico e Avaliação, 2003.

BRASIL. Ministério da Saúde. Secretaria de Atenção à Saúde. A Política do Ministério da Saúde para Atenção Integral a Usuários de Álcool e outras Drogas/Ministério da Saúde. 2.ed. rev. ampl. Brasília: Ministério da Saúde, 2004a.

BRASIL. Ministério da Saúde. Secretaria de Atenção à Saúde. Departamento de Ações Programáticas Estratégicas. Álcool e redução de danos: uma abordagem inovadora para países em transição. Ministério da Saúde, Secretaria de Atenção à Saúde, Departamento de Ações Programáticas Estratégicas. 1. ed. em português, ampl. Brasília: Ministério da Saúde, 2004b.

BRASIL. Ministério do Planejamento Orçamento e Gestão. Instituto Brasileiro de Geografia e Estatística (IBGE). Pesquisa de Orçamentos Familiares 2008-2009: Despesas, Rendimentos e Condições de Vida. Rio de Janeiro, 2010. 222 p. 
BRASIL. Portaria n. 3.088, de 23 de dezembro de 2011. Institui a Rede de Atenção Psicossocial para pessoas com sofrimento ou transtorno mental, incluindo aquelas com necessidades decorrentes do uso de crack, álcool e outras drogas, no âmbito do Sistema Único de Saúde (SUS). Disponível em: http://bvsms.saude.gov.br/bvs/saudelegis/gm/2011/prt3088_23_12_2011_rep.html>. Acesso em: 05/09/2015.

CAMPAIGN FOR TOBACCO FREE KIDS. Golden Leaf Barren Harvest: The Costs of Tobacco Farming. Center for Tobacco Control Research and Education. San Francisco: University of California, 2001.

CARLINI, E. A. et al. II Levantamento Domiciliar sobre o uso de Drogas Psicotrópicas no Brasil: estudo envolvendo as 108 maiores cidades do país - 2005. São Paulo: CEBRID - Centro Brasileiro de Informações sobre Drogas Psicotrópicas, Departamento de Psicobiologia. UNIFESP. 2007, 468 p.

CAVAlCANTE, T. M. O controle do tabagismo no Brasil: avanços e desafios. Rev. Psiq. Clín., São Paulo, v. 32, n. 5, p. 283-300, 2005.

CHALUB, M.; TELlES, L. E. de B. Álcool, drogas e crime. Revista brasileira de psiquiatria, São Paulo, v. 28, supl. 2, p. S69-73, out. 2006.

CHRISTMANN, A., AELST, V. S. Robust estimation of Cronbach's alpha. Journal of Multivariate Analysis, 2006, v. 97, 7. ed. 1660-1674. Disponível em: < http://dx.doi.org/10.1016/j.jmva.2005.05.012>. Acesso em: 23/10/2015.

COTRIM, B. C.; Gazal-C. C.; Gouveia N. Comportamento de saúde entre jovens estudantes das redes pública e privada da área metropolitana do estado de São Paulo. Rev Saúde Pública, São Paulo, v. 34, n. 6, p. 636-645, 2000.

CUFFA, Marina de. Percepção e comportamento de risco de beber e dirigir: um perfil do universitário de Curitiba. 2012. 133 f. Dissertação (Mestrado em Psicologia) - Setor de Ciências Humanas, Letras e Artes, Universidade Federal do Paraná, Curitiba, 2012.

CUNHA, S. Efeito da exposição a imagens relacionadas ao álcool nos vieses de atenção e de avaliação para o cigarro. 2010. 83 f. Dissertação (Mestrado em Psicologia) - Programa de Pós Graduação em Psicologia, Universidade Federal do Rio Grande do Sul, Porto Alegre, 2010.

DONATI, F. A. et al. Condutas de risco em jovens mulheres: álcool e sexo não seguro, temas necessários na formação de professores. Rev. Plures Humanidades, Ribeirão Preto, v. 13, n. 2, p. 257-274, jul./dez. 2012.

ERIKSEN, M. et al. The tobacco atlas. 5. ed. Atlanta: American Cancer Society, 2015.

FARIA, R. et al. Propaganda de álcool e associação ao consumo de cerveja por adolescentes. Rev. Saúde Pública, São Paulo, v. 45, n. 3, p. 441-447, 2011.

FOLHA DE SÃO PAULO. - GP Brasil de F-1 já trabalha contra Lei do cigarro. Jornal Folha de São Paulo, 01/12/2002. 
FORMIGONI, M. L. O. S. et al. SUPERA - Sistema para Detecção do uso abusivo e dependência de substâncias psicoativas: encaminhamento, intervenção breve, reinserção social e acompanhamento. Módulo 3 - Detecção do uso e diagnóstico da dependência de substâncias psicoativas. Brasília: Secretaria Nacional de Políticas Sobre Drogas, 2014.

FREITAS, R. L . M. de. et al. Perfil da utilização de drogas lícitas e ilícitas por universitários de uma instituição privada. SMAD, Rev. Eletrônica Saúde Mental Álcool Drog., v. 8, n. 3, p. 118-126, 2012.

GALDURÓZ, J. C. F. et al. V Levantamento nacional sobre o consumo de drogas psicotrópicas entre estudantes do ensino fundamental e médio da rede pública de ensino nas 27 capitais brasileiras. São Paulo: CEBRID, 2004.

GALLASSI, A. D.; ELIAS, P. E. M.; ANDRADE, A. G. de. Caracterização do gasto SUS com internações de dependentes de substâncias psicoativas no período de 2000 a 2002 no município de Campinas - SP. Rev. Psiq. Clím, São Paulo, v. 35, n. 1, p. 2-7, 2008. Disponível em: < http://repositorio.unb.br/handle/10482/11313 >. Acesso em: $15 / 09 / 15$.

GARCIA, E. G; MARTINI, J. G; GÁLVEZ, A. M. P. Consumo de álcool e práticas sexuais de risco: o padrão dos estudantes de enfermagem de uma universidade espanhola. Rev. Latino-Am. Enfermagem, Ribeirão Preto, v. 21, n. 4, [07 telas], jul./ago. 2013.

GIL, A. C. Como elaborar projetos de pesquisa. São Paulo: Atlas, 2008.

GILIOTTI, A.; BESSA, M. A. Síndrome de Dependência do Álcool: critérios diagnósticos. Rev Bras Psiquiatr, v. 26, n. 1, p. 11-13, 2004.

GUIDON, G.; BOISCLAIR D. P. Current and future trends in tobacco use. Health Nutrition and Population Discussion Paper. World Bank Human Development Network, 2003.

GUINDON, E., TOBIN, D., YACH, D. - Trends and affordability if cigarettes prices: ample room for tax increases and related health gains. Tob Control 2002, 11: 35-43.

HADDAD, L. G., MALAK, M. Z. Smoking habits and attitudes towards smoking among university students in Jordan. Int J Nurs Stud, v. 39, n. 8, p. 793-802, 2002.

HEATHER N. et al. Alcohol use disorders and hazardous drinking among undergraduates at English universities. Alcohol Alcohol, v. 46, n. 3, p. 270-277, 2011. Disponível em: < http://alcalc.oxfordjournals.org/content/46/3/270>. Acesso em: 12/02/16.

HENNINGFIELD, J.E. et al. Pharmacotherapy for nicotine dependence. CA: A Cancer Journal for Clinicians, [S.1.], v. 55, n. 5, p. 281-289, 2005.

HENRIQUE, I.F.S. et al. Validação da versão brasileira do teste de triagem do envolvimento com álcool, cigarro e outras substâncias. Rev Assoc Med Bras, v. 50, n. 2, p. 199-206, 2004.

IMAI, F. I.; COELHO, I. Z.; BASTOS, J. L. Consumo excessivo de álcool, tabagismo e fatores associados em amostra representativa de graduandos da Universidade Federal 
de Santa Catarina, 2012: estudo transversal. Epidemiol. Serv. Saúde, v. 23, n. 3, p. 435446. 2014.

INSTITUTO NACIONAL DO CÂNCER. Ministério da Saúde. Pesquisa especial de tabagismo - PETab: relatório Brasil. Rio de Janeiro: INCA, 2011. 199 p.

JOMAR, R. T.; SILVA, E. dos S. Consumo de bebidas alcoólicas entre estudantes de Enfermagem. Aquichan, v.13, n. 2, p. 226-233, 2013.

JUNIOR, G. A.; GAYA, C. de M. Implicações do uso de álcool, tabaco e outras drogas na vida do universitário. Rev Bras Promoç Saúde, v. 28, n. 1, p. 67-74, 2015. Disponível em: <http://dx.doi.org/10.5020/18061230.2015.p67>. Acesso em: 20/07/2016.

LARANJEIRA, R. et al. I Levantamento Nacional sobre os Padrões de Consumo de Álcool na População Brasileira. Brasília: SENAD - Secretaria Nacional de Políticas sobre Drogas, 76 p., 2007.

LARANJEIRA, R. et al. II Levantamento Nacional de Álcool e Drogas. São Paulo: Instituto Nacional de Ciência e Tecnologia para Políticas Públicas de Álcool e Outras Drogas (INPAD). UNIFESP, 2014.

LUCAS, A. C. dos S. et al. Uso de psicotrópicos entre universitários da área da saúde da Universidade Federal do Amazonas, Brasil. Cad. Saúde Pública, Rio de Janeiro, v. 22, n. 3, p. 663-671, 2006.

LUCE B. R. et al. Estimating Costs in Cost-Effectiveness Analysis. In: CostEffectiveness in Health and Medicine. New York: Oxford University Press, 1996.

MAGLIARI, R. T. et al. Prevalência de tabagismo em estudantes de faculdade de medicina. Rev. Med., São Paulo, v. 84, n. 4, p. 264-271, 2008.

MANDIL, A. et al. Smoking among university students: a gender analysis. Journal of Infection and Public Health, Saudi Arabian, v. 3, n. 4, p. 179-87, 2010.

MCNAlly, M. et al. Relatório da Pesquisa ITC Brasil sobre Publicidade, promoção e patrocínio do tabaco. [S. 1.]: Sentrik Graphic Solutions Inc., 2013. 33 p.

MORAES, E. et al. Conceitos introdutórios de economia da saúde e o impacto social do abuso de álcool. Revista brasileira de psiquiatria, v. 28, n. 4, p. 321-325, 2006. Disponívelem: <http://www.scielo.br/scielo.php?pid=S151644462006000400014\&script=sci_abstract\&tlng=pt $>$. Acesso em: 20/09/15.

ORGANIZAÇÃO MUNDIAL DE SAÚDE - OMS. Neurociências: Consumo de substâncias psicoativas. Genebra: OMS, 2004.

ORGANIZACIÓN MUNDIAL DE LA SALUD - OMS. Informe sobre la Salud en el mundo 2002: Reducir los riesgos y promover uma vida sana. Ginebra: OMS, 2002. 182p.

ORGANIZACIÓN PANAMERICANA DE LA SALUD - OPAS. Neurociencia del consumo y dependencia de sustancias psicoactivas. Whashington, D.C: OPAS, 2005. 263p. 
PADUANI, G. F. et al. Consumo de álcool e fumo entre os estudantes da Faculdade de Medicina da Universidade Federal de Uberlândia. Rev Bras Educ Med, v. 1, n. 32, p. 66-75. 2008.

PAN AMERICAN HEALTH ORGANIZATION - PAHO. Profits Over People - Tobacco Industry Activities to Market Cigarettes and Undermine Public Health in Latin America and Caribbean. Whashington, D.C: OPAS, 2002. Disponívelem: < http://iris.paho.org/xmlui/handle/123456789/2807>. Acesso em 29/08/2015.

PASSOS, C.B.C. Internações Decorrentes do Uso de Substâncias Psicoativas no Distrito Federal entre os Anos de 2000 a 2009. 2011. 86 f. Dissertação (Mestrado Profissional em Saúde Pública) - Centro de Pesquisas Aggeu Magalhães, Fundação Oswaldo Cruz, Recife, 2011.

PECHANSKY, F; SZOBOT, C. M; SCIVOLETTO, S. Uso de álcool em entre adolescentes: conceitos, características epidemiológicas e fatores etiopatogênicos. Rev Bras Psiquiatr, v. 26, supl. 1, p. 14-17, 2004.

PEDROSA, A. A. et al. Consumo de álcool entre estudantes universitários. Cad Saude Publica, Rio de Janeiro, v. 27, n. 8, p. 1611-1621, 2011.

PEREIRA, M. G. Métodos empregados em epidemiologia. In: prática. Rio de Janeiro: Guanabara Koogan, 2012. p. 269-288.

Epidemiologia: teoria e

PICOLOTTO, E. et al. Prevalência e fatores associados com o consumo de substâncias psicoativas por acadêmicos de enfermagem da Universidade de Passo Fundo. Cien Saúde Colet, v. 15, n. 3, p. 645-654, 2010.

PILLON, S. C. et al. Uso de álcool e espiritualidade entre estudantes de enfermagem. Rev Esc Enferm USP, v. 45, n. 1, p. 100-107, 2011.

PILLON, S. C; O'BRIEN, B; CHAVEZ, K. A. P. A relação entre o uso de drogas e comportamentos de risco entre universitários brasileiros. Rev. Latino-Am. Enfermagem, Ribeirão Preto, v. 13, n. spe2, p. 1169-1176, dez. 2005. Disponível em: < http://dx.doi.org/10.1590/S0104-11692005000800011>. Acesso em: 10/12/15.

PILLON, S. C; WEBSTER, C. M. C. Teste de identificação de problemas relacionados ao uso de álcool entre estudantes universitários. Rev Enferm UERJ, v. 14, n. 3, p. 325-332, 2006.

PINTO, M. F. T. Custos de Doenças Tabaco - Relacionadas: uma análise sob a perspectiva da economia e da epidemiologia. 2007. 223p. Tese (Doutorado em Ciências na Área de Saúde Pública) - Fundação Oswaldo Cruz, Escola Nacional de Saúde Pública, Rio de Janeiro, 2007.

ROSEMBERG, J. Nicotina: droga universal. São Paulo: SES/CVE, 2004.

ROZIN, L.; ZAGONEL, I. P. S. Fatores de risco para dependência de álcool em adolescentes. Acta Paul Enferm, v. 25, n. 2, p. 314-318, 2012.

RUBIO, C. R. Estudo sobre o uso de tabaco e de álcool por estudantes da área de saúde da Universidade de Brasília, Distrito Federal, Brasil, 2007. 2008. 84f. Dissertação 
(Mestrado em Ciências da Saúde) - Programa de Pós-graduação em Ciências da Saúde, Universidade de Brasília, 2008.

SANTELLI, J. et al. Timing of alcohol and other drug use and sexual risk behaviors among unmarried adolescents and young adults. Family Planning Perspectives, v. 33, n. 5, p 200205, 2001.

SANTOS, L.V. et al. Percepção de estudantes da área da saúde sobre abuso de álcool no meio acadêmico. In: VI Encontro de Pesquisadores em Saúde Mental e V Encontro de Especialistas em Enfermagem Psiquiátrica. Ribeirão Preto: FIERP/EERP- USP/FAPESP, 2000.

SANTOS, M. V. F.; PEREIRA, D. S.; SIQUEIRA, M. M. Uso de álcool e tabaco entre estudantes de Psicologia da Universidade Federal do Espírito Santo. J. bras. psiquiatr., v. 62, n. 1, p. 22-30, 2013. Disponível em: 〈http://dx.doi.org/10.1590/S0047-20852013000100004〉. Acesso em: 20/04/2016.

SHAFEY, O. et al. The tobacco atlas. 3. ed. Atlanta, GA. American Cancer Society, 2009.

SILVA, A. C. et al. Aplicação do instrumento Alcohol, Smoking and Substance Involvement Screening Test (ASSIST): uma revisão integrativa. Rev Gaúcha Enferm, v. 37, n. 1, 2016. Disponível em: < http://seer.ufrgs.br/index.php/RevistaGauchadeEnfermagem/article/view/52918 > . Acesso em: 23/09/2016.

SILVA, B. P. et al. Uso do tabaco entre estudantes de uma faculdade privada. SMAD, Rev. Eletrônica Saúde Mental Álcool Drog., v. 8, n. 2, p. 64-70, 2012.

SILVA, L. V.; et al. Fatores associados ao consumo de álcool e drogas entre estudantes universitários. Rev Saude Publica, São Paulo, v. 40, n. 2, p. 280-288, 2006.

SISNEY, K. F. The relationship between social support and depression in recovering chemically dependent nurses. J Addict Nurs., v. 7, n. 1, p. 19-25, 1995.

SOCIEDADE BRASILEIRA DE PEDIATRIA - SBP. Uso e abuso de álcool na adolescência. Adolescência \& Saúde, v. 4, n. 3, 2007.

SOUSA-CARMO, Sílvia von Tiesenhausen de; VILAR, Maria Cristina Horta; MORAES, Marco Antonio de. Gastos hospitalares de doenças tabaco-relacionadas no Sistema Único de Saúde - SUS: um estudo comparativo entre o Brasil, Região Sudeste e estado de São Paulo no ano de 2013. Bepa, São Paulo, v. 12, n. 140, p.3-14, 2015.

SPIER, E. et al. Impaired student performance in the clinical setting: a constructive approach. Nurse Educ, v. 25, n. 1, p. 38-42, 2000.

STRAMARI, L. M.; KURTZ, M.; SILVA, L. C. C. da. Prevalência e fatores associados ao tabagismo em estudantes de medicina de uma universidade em Passo Fundo (RS). J Bras Pneumol, v. 35, n. 5, p. 442-448, 2009.

TAPERT, S. et al. Adolescent substance use and sexual risk-taking behavior. J Adolescent Health, v. 28, n. 3, p. 181-189, 2001. 
TAUIL, M. de C.; COELHO, R. A. C.; MONTEIRO, P. S. Prevalência do uso de fumo entre alunos do curso de graduação em enfermagem da Universidade de Brasília. Comum Ciênc Saúde, v. 17, n. 2, p. 121-127, 2006.

TOCKUS, D.; GONÇALVES, P. S. Detecção do uso de drogas de abuso por estudantes de medicina de uma universidade privada. J. bras. psiquiatr., v. 57, n. 3, p. 184-187, 2008. Disponível em: <http://dx.doi.org/10.1590/S0047-20852008000300005>. Acesso em 20/07/16.

VALE, J. de S., UESUGUI, H. M., PEREIRA, R. A. Perfil do consumo de álcool, tabaco e maconha entre graduandos em enfermagem da Faculdade de Educação e Meio Ambiente. Revista Científica da Faculdade de Educação e Meio Ambiente, v. 5, n. 2, p. 156-172, 2014. Disponível em: <http://www.faema.edu.br/revistas/index.php/RevistaFAEMA/article/view/251 >. Acesso em: 12/07/2016.

WECHSLER, $\mathrm{H}$. et al. Trends in college binge drinking during a period of increased prevention efforts: Findings from 4 Harvard School of Public Health College Alcohol Study surveys 1993-2001. J Am Coll Health, v. 50, n. 5, p. 203-217, 2002. Disponível em: < http://archive.sph.harvard.edu/cas/Documents/march02/trends.pdf>. Acesso em: 11/11/2015.

WERNER, M. E. C; SIQUEIRA, M. F. C; LEMES, A. G. Consumo alcoolico entre universitários. Vamos discutir essa ideia? Revista eletrônica da UNIVAR, v. 1, n. 13, p. 4248, $2015 . \quad$ Disponível em: < http://revista.univar.edu.br/index.php/interdisciplinar/article/view/385>. Acesso em: 14/04/16.

WORLD HEALTH ORGANIZATION - WHO. Global status report on alcohol and health. Geneve: WHO, 2011.

WORLD HEALTH ORGANIZATION - WHO. Global status report on alcohol and health. Geneve: WHO, 2014.

WORLD HEALTH ORGANIZATION - WHO. Global status report on alcohol. Geneve: WHO, 2004.

WORLD HEALTH ORGANIZATION - WHO. Global status report on noncommunicable diseases, 2010. Geneve: WHO, 2010.

WORLD HEALTH ORGANIZATION - WHO. Tobacco \& the Rights of the Child. Geneve: WHO, 2001. 62p. Disponívelem: < http:/www.who.int/tobacco/resources/publications/rights_child/en/>. Acesso em29/08/2015.

WORLD HEALTH ORGANIZATION - WHO. WHO report on the global tobacco epidemic, 2011. Warning about the dangers of tobacco. Geneve: WHO, 2011.

WORLD HEALTH ORGANIZATION. Management of substance abuse: The ASSIST screening test version 3.0 and feedback card. 2015. Disponível em: $<$ http://www.who.int/substance_abuse/activities/assist_portuguese.pdf?ua=1>. Acesso em: 20 out. 2015. 


\section{APÊNDICE}

\section{APÊNDICE A - Questionário de investigação do uso de álcool e tabaco}

\section{PERFIL EPIDEMIOLÓGICO}

1) Idade:

2) Semestre em curso:

3) Sexo: $\square$ Masculino $\square$ Feminino

4) Estado civil: $\square$ Solteiro $\square$ Casado $\square$ Divorciado $\square$ Outros

5) Etnia: $\square$ Branco $\square$ Negro $\square$ Pardo $\square$ Amarelo $\square$ Indígena $\square$ Outros

\section{BLOCO 1 - CONSUMO DE ÁLCOOL}

6) Você já usou álcool na vida? Uso recreacional, ocasional e até uso experimental, mesmo tendo sido uma única vez.

$\square \operatorname{Sim} \square$ Não

AS QUESTÕES 7 A 18 NÃO PRECISAM SER RESPONDIDAS SE VOCÊ ASSINALOU "NÃO" NA QUESTÃO ACIMA

7) Atualmente você bebe? $\square$ Não $\square$ Sim

8) Durante os três últimos meses, com que frequência você utilizou álcool?

$\square$ Nunca. Não utilizei nos últimos 3 meses.

1 ou 2 vezes nos últimos 3 meses.

Mensalmente. Ou seja, de 1 a 3 vezes em 1 mês.

Semanalmente. Ou seja, de 1 a 4 vezes na semana.

Diariamente ou quase diariamente. Ou seja, entre 5 e 7 dias por semana.

9) Durante os três últimos meses, com que frequência você teve um forte desejo ou urgência em consumir álcool?

Nunca nos últimos 3 meses.

1 ou 2 vezes nos últimos 3 meses.

Mensalmente. Ou seja, de 1 a 3 vezes em 1 mês.

Semanalmente. Ou seja, de 1 a 4 vezes na semana.

Diariamente ou quase diariamente. Ou seja, entre 5 e 7 dias por semana. 
10) Durante os três últimos meses, com que frequência o seu consumo de álcool resultou em problema de saúde, social, legal ou financeiro? Entenda como: Problema de saúde: qualquer perturbação ou desequilíbrio no organismo (vômitos, queimação, azia, perda de memória, pigarro, tosse, entre outros. Problemas sociais: brigas, discussões, problemas com colegas e familiares, queda no rendimento escolar, entre outros. Problemas legais: multas de trânsito, envolvimento com a polícia, acidentes, entre outros. Problemas financeiros: gasto excessivo com a compra de álcool e consequente redução do orçamento, entre outros.

Nunca nos últimos 3 meses.

1 ou 2 vezes nos últimos 3 meses.

Mensalmente. Ou seja, de 1 a 3 vezes em 1 mês.

Semanalmente. Ou seja, de 1 a 4 vezes na semana.

Diariamente ou quase diariamente. Ou seja, entre 5 e 7 dias por semana.

11) Durante os três últimos meses, com que frequência por causa do uso do álcool você deixou de fazer coisas que eram normalmente esperadas por você? Exemplos: falta à aula ou trabalho, deixou de realizar trabalhos, esquecimento de compromissos importantes, entre outros.

Nunca nos últimos 3 meses.

1 ou 2 vezes nos últimos 3 meses.

Mensalmente. Ou seja, de 1 a 3 vezes em 1 mês.

Semanalmente. Ou seja, de 1 a 4 vezes na semana.

Diariamente ou quase diariamente. Ou seja, entre 5 e 7 dias por semana.

12) Há amigos, parentes ou outra pessoa que tenha demonstrado preocupação com seu uso de álcool? Exemplos: alguém próximo, como algum parente, médico, professor ou chefe já pediu para você parar de usar álcool ou reduzir o seu uso?

Não, nunca.

Sim, mas não nos últimos 3 meses.

Sim, nos últimos 3 meses.

13) Alguma vez você já tentou controlar, diminuir ou parar o uso de álcool e não conseguiu?

Não, nunca.

Sim, mas não nos últimos 3 meses.

Sim, nos últimos 3 meses.

14) Com que idade experimentou o álcool?

$\square$ com menos de 12 anos $\square$ de 12-15 anos $\square$ de 16-18 anos $\square$ com mais de 18 anos

15) O que o (a) motivou a beber? MARQUE APENAS UMA OPÇÃO

$\square$ Influência de amigos $\square$ Curiosidade $\square$ Por estar com problemas pessoais 
$\square$ Propaganda na mídia $\square$ Outros:

16) Por qual bebida você tem ou tinha maior predileção? MARQUE APENAS UMA OPÇÃO

$\square$ Destilados $\square$ Vinho $\square$ Cerveja $\square$ Ice $\square$ Outro:

17) Quantas doses em média você bebe? OBS: NÃO RESPONDA SE PAROU DE BEBER.

(Responda considerando uma dose como: uma latinha de cerveja ou chope de $350 \mathrm{ml}$, uma taça de vinho de 90 $\mathrm{ml}$, uma dose de destilado de $30 \mathrm{ml}$, uma lata ou uma garrafa pequena de qualquer bebida "ice")

$\square$ Até 4 doses $\square$ 5-9 doses $\square 10-15$ doses $\square$ mais de 15 doses

18) Marque um $X$ no(s) quesito(s) que mostra(m) situação(ões) já vivenciada(s) após a ingestão de bebida alcoólica. (Pode marcar mais de uma situação). OBS: RESPONDA MESMO QUE VOCÊ TENHA PARADO DE BEBER.

Envolvimento em alguma briga com emprego de violência física

Envolvimento em algum acidente de trânsito

Faltou à escola ou ao trabalho no dia seguinte

Dirigiu veículo

Nenhuma

Outra:

\section{BLOCO 2 - CONSUMO DE TABACO}

19) Você já usou algum derivado de tabaco na vida? Uso recreacional, ocasional e até uso experimental, mesmo tendo sido uma única vez.

$\square \operatorname{Sim} \square$ Não

\section{AS QUESTÕES 20 A 28 NÃO PRECISAM SER RESPONDIDAS SE VOCÊ ASSINALOU "NÃO" NA QUESTÃO ACIMA}

20) Atualmente você usa algum derivado do tabaco? $\square$ Não $\square$ Sim

21) Durante os três últimos meses, com que frequência você utilizou derivado do tabaco?

Nunca. Não utilizei nos últimos 3 meses.

1 ou 2 vezes nos últimos 3 meses.

Mensalmente. Ou seja, de 1 a 3 vezes em 1 mês.

Semanalmente. Ou seja, de 1 a 4 vezes na semana.

Diariamente ou quase diariamente. Ou seja, entre 5 e 7 dias por semana.

22) Durante os três últimos meses, com que freqüência você teve um forte desejo ou urgência em consumir derivado do tabaco? 
Nunca nos últimos 3 meses.

1 ou 2 vezes nos últimos 3 meses.

Mensalmente. Ou seja, de 1 a 3 vezes em 1 mês.

Semanalmente. Ou seja, de 1 a 4 vezes na semana.

Diariamente ou quase diariamente. Ou seja, entre 5 e 7 dias por semana.

23) Durante os três últimos meses, com que frequência o seu consumo de derivado do tabaco resultou em problema de saúde, social, legal ou financeiro? Entenda como: Problema de saúde: qualquer perturbação ou desequilíbrio no organismo (vômitos, queimação, azia, perda de memória, pigarro, tosse, entre outros. Problemas sociais: brigas, discussões, problemas com colegas e familiares, queda no rendimento escolar, entre outros. Problemas legais: multas de trânsito, envolvimento com a polícia, acidentes, entre outros. Problemas financeiros: gasto excessivo com a compra de álcool e consequente redução do orçamento, entre outros.

Nunca nos últimos 3 meses.

1 ou 2 vezes nos últimos 3 meses.

Mensalmente. Ou seja, de 1 a 3 vezes em 1 mês.

Semanalmente. Ou seja, de 1 a 4 vezes na semana.

Diariamente ou quase diariamente. Ou seja, entre 5 e 7 dias por semana.

24) Há amigos, parentes ou outra pessoa que tenha demonstrado preocupação com seu uso de derivado de tabaco? Exemplos: alguém próximo, como algum parente, médico, professor ou chefe já pediu para você parar de usar tabaco ou reduzir o seu uso?

Não, nunca.

Sim, mas não nos últimos 3 meses.

Sim, nos últimos 3 meses.

25) Alguma vez você já tentou controlar, diminuir ou parar o uso de derivado do tabaco e não conseguiu?

Não, nunca.

Sim, mas não nos últimos 3 meses. $\square$ Sim, nos últimos 3 meses.

26) Com que idade experimentou derivado do tabaco?

$\square$ com menos de 12 anos $\square$ de 12-15 anos $\square$ de 16-18 anos $\square$ com mais de 18 anos

27) O que o (a) motivou a utilizar derivado do tabaco? MARQUE APENAS UMA OPÇÃO

$\square$ Influência de amigos $\square$ Curiosidade $\square$ Problemas pessoais $\square$ Outro motivo: 
28) Qual derivado do tabaco você tem ou tinha maior predileção? MARQUE APENAS UMA OPÇÃ̃O

$\square$ Cigarro comum $\square$ Charuto $\square$ Cigarretes $\square$ Narguilé $\square$ Outro:

Assinatura do Pesquisador:

Brasília, de de 2016. 


\section{ANEXOS}

\section{ANEXO A - Questionário ASSIST - Versão Original - Entrevista}

Nome:

\section{Entrevistador:}

\section{ASSIST - OMS}

\begin{tabular}{|l|c|c|}
\hline $\begin{array}{l}\text { 1. Na sua vida qual(is) } \\
\text { dessa(s) substâncias } \\
\text { você já usou? } \\
\text { (somente uso nâo } \\
\text { prescrito pelo médico) }\end{array}$ & NÃo & SIM \\
\hline a. derivados do tabaco & 0 & 3 \\
\hline b. bebidas alcoólicas & 0 & 3 \\
\hline c. maconha & 0 & 3 \\
\hline d. cocaína, crack & 0 & 3 \\
\hline e. anfetaminas ou êxtase & 0 & 3 \\
\hline f. inalantes & 0 & 3 \\
\hline q.hipnóticos/sedativos & 0 & 3 \\
\hline h. alucinógenos & 0 & 3 \\
\hline i. opióides & 0 & 3 \\
\hline j. outras, especificar & 0 & 3 \\
\hline
\end{tabular}

- $\mathrm{SE}$ "NAO" em todos os itens investigue:

Nem mesmo quando estava na escola?

- Se "NAO" em todos os itens, pare a entrevista

- Se "SIM" para alguma droga, continue com as demais questões

\begin{tabular}{|c|c|c|c|c|c|}
\hline $\begin{array}{l}\text { 3. Durante os três últimos } \\
\text { mesess, com que } \\
\text { freqüência você teve um } \\
\text { forte desejo ou urgência } \\
\text { em consumir? } \\
\text { (primeira droga, segunda } \\
\text { droga, etc)) }\end{array}$ & $\frac{\mathbb{d}}{2}$ & 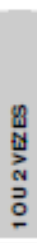 & 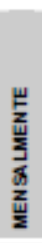 & 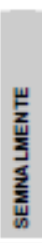 & 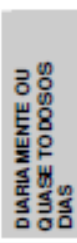 \\
\hline a. derivados do tabaco & 0 & 3 & 4 & 5 & 6 \\
\hline b. bebidas alcoólicas & 0 & 3 & 4 & 5 & 6 \\
\hline c. maconha & 0 & 3 & 4 & 5 & 6 \\
\hline d. cocaína. crack & 0 & 3 & 4 & 5 & 6 \\
\hline e. anfetaminas ou êxtase & 0 & 3 & 4 & 5 & 6 \\
\hline f. inalantes & 0 & 3 & 4 & 5 & 6 \\
\hline g.hipnóticos/sedativos & 0 & 3 & 4 & 5 & 6 \\
\hline h. alucinógenos & 0 & 3 & 4 & 5 & 6 \\
\hline i. opióides & 0 & 3 & 4 & 5 & 6 \\
\hline j. outras, especificar & 0 & 3 & 4 & 5 & 6 \\
\hline
\end{tabular}

Registro

\section{QUESTIONÁRIO PARA TRIAGEM DO USO DE ÁLCOOL, TABACO E OUTRAS SUBSTÂNCIAS.}

\begin{tabular}{|c|c|c|c|c|c|}
\hline $\begin{array}{l}\text { 2. Durante os três últimos } \\
\text { meses, com que } \\
\text { frequência você utilizou } \\
\text { essa(s) substância(s) } \\
\text { que mencionou? } \\
\text { (primeira droga, depois a } \\
\text { segunda droga, etc) }\end{array}$ & $\frac{\delta}{2}$ & 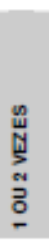 & 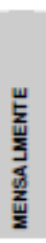 & 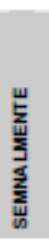 & 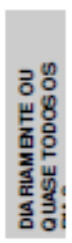 \\
\hline a. derivados do tabaco & 0 & 2 & 3 & 4 & 6 \\
\hline b. bebidas alcoólicas & 0 & 2 & 3 & 4 & 6 \\
\hline c. maconha & 0 & 2 & 3 & 4 & 6 \\
\hline d. cocaína, crack & 0 & 2 & 3 & 4 & 6 \\
\hline e. anfetaminas ou êxtase & 0 & 2 & 3 & 4 & 6 \\
\hline f. inalantes & 0 & 2 & 3 & 4 & 6 \\
\hline g.hipnóticos/sedativos & 0 & 2 & 3 & 4 & 6 \\
\hline h. alucinógenos & 0 & 2 & 3 & 4 & 6 \\
\hline i. opióides & 0 & 2 & 3 & 4 & 6 \\
\hline j. outras, especificar & 0 & 2 & 3 & 4 & \\
\hline
\end{tabular}

- $\quad$ Se "NUNCA" em todos os itens da questão 2 pule para a questão 6 , com outras respostas continue com as demais questões
4. Durante os três últimos meses, com que frequêencia o seu consumo de (primeira droga, depois a segunda droga, etc) resultou em problema de saúde, social, legal ou financeiro?

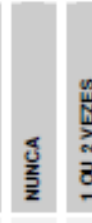

\begin{tabular}{|l|l|l|l|l|l|}
\hline a. derivados do tabaco & 0 & 4 & 5 & 6 & 7 \\
\hline b. bebidas alcoólicas & 0 & 4 & 5 & 6 & 7 \\
\hline c. maconha & 0 & 4 & 5 & 6 & 7 \\
\hline d. cocaína, crack & 0 & 4 & 5 & 6 & 7 \\
\hline e. anfetaminas ou êxtase & 0 & 4 & 5 & 6 & 7 \\
\hline f. inalantes & 0 & 4 & 5 & 6 & 7 \\
\hline g.hipnóticos/sedativos & 0 & 4 & 5 & 6 & 7 \\
\hline h. alucinógenos & 0 & 4 & 5 & 6 & 7 \\
\hline i. opióides & 0 & 4 & 5 & 6 & 7 \\
\hline j. outras, especificar & 0 & 4 & 5 & 6 & 7 \\
\hline
\end{tabular}

\section{NOMES POPULARES OU COMERCIAIS DAS DROGAS}


5. Durante os três últimos meses, com que freqüência, por causa do seu uso de (primeira droga, depois a segunda droga, etc), você deixou de fazer coisas que eram normalmente esperadas de você?

a. derivados do tabaco

b. bebidas alcoólicas

c. maconha

d. cocaína, crack

e. anfetaminas ou êxtase

f. inalantes

g.hipnóticos/sedativos

h. alucinógenos

i. opióides

j. outras, especificar

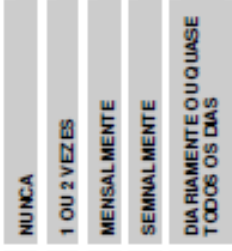

$\begin{array}{lllll}0 & 5 & 6 & 7 & 8\end{array}$

\begin{tabular}{l|l|l|l|l|}
0 & 5 & 6 & 7 & 8 \\
\hline
\end{tabular}

$\begin{array}{lllll}0 & 5 & 6 & 7 & 8\end{array}$

\begin{tabular}{l|l|l|l|l}
0 & 5 & 6 & 7 & 8
\end{tabular}

$\begin{array}{lllll}0 & 5 & 6 & 7 & 8\end{array}$

\begin{tabular}{l|l|l|l|l}
0 & 5 & 6 & 7 & 8
\end{tabular}

$\begin{array}{lllll}0 & 5 & 6 & 7 & 8\end{array}$

\begin{tabular}{l|l|l|l|l|}
0 & 5 & 6 & 7 & 8
\end{tabular}

$\begin{array}{lllll}0 & 5 & 6 & 7 & 8\end{array}$

\begin{tabular}{l|l|l|l|l}
0 & 5 & 6 & 7 & 8
\end{tabular}
- FACA as questões 6 e 7 para todas as substâncias mencionadas na questão 1

6. Há amigos, parentes ou outra pessoa que tenha demonstrado preocupaçāo com seu uso de (primeira droga, depois a segunda droga, etc...)?

a. derivados do tabaco

b. bebidas alcoólicas

c. maconha

d. cocaína, crack

e. anfetaminas ou êxtase

f. inalantes

g.hipnóticos/sedativos

h. alucinógenos

i. opióides

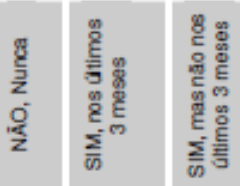

j. outras, especificar

Nota Importante: Pacientes que tenham usado drogas injetáveis nos últimos 3 meses devem ser perguntados sobre seu padrâo de uso injetável durante este periodo, para determinar seus niveis de

risco $\theta$ a melhor forma de intervençáa.

Al ((primeira droga, depois a segunda droga, etc...) e nāo consequiu?
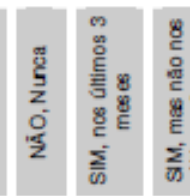

a. derivados do tabaco

b. bebidas alcoólicas

c. maconha

d. cocaína, crack

e. anfetaminas ou êxtase

f. inalantes

g.hipnóticos/sedativos

h. alucinógenos

i. opióides

j. outras, especificar

\begin{tabular}{|l}
\hline 3 \\
\hline 3 \\
\hline 3 \\
\hline 3 \\
\hline 3 \\
\hline 3 \\
\hline 3 \\
\hline 3 \\
\hline 3 \\
\hline 3 \\
\hline 0
\end{tabular}

\begin{tabular}{|c|c|c|}
\hline \multicolumn{3}{|c|}{$\begin{array}{l}\text { 8- Alguma vez você já usou drogas por injeção? } \\
\text { (Apenas uso nāo médico) }\end{array}$} \\
\hline $\begin{array}{l}\mathrm{NAO}, \\
\text { nunca }\end{array}$ & $\begin{array}{c}\mathrm{SIM}, \text { nos } \\
\text { últimos } 3 \text { meses }\end{array}$ & $\begin{array}{c}\text { SIM, mas não nos } \\
\text { últimos } 3 \text { meses }\end{array}$ \\
\hline
\end{tabular}

Guia de Intervenção para Padrão de uso injetável

\begin{tabular}{|l|l|}
\hline $\begin{array}{l}\text { Uma vez por semana ou menos } \\
\text { Ou menos de três dias seguidos }\end{array}$ & $\begin{array}{l}\text { Intervençào Breve incluindo cartáo de } \\
\text { "riscos associados com o uso } \\
\text { injetável" }\end{array}$ \\
\hline
\end{tabular}

\begin{tabular}{|c|c|c|c|c|}
\hline & $\begin{array}{l}\text { s do que uma } \\
\text { mais do que tre }\end{array}$ & $\begin{array}{l}z \text { por semana } \\
\text { dias seguidos }\end{array}$ & Intervençao mais aprofundada $\theta$ \\
\hline & $\begin{array}{l}\text { Anote a pontuação para cada droga. SOME } \\
\text { SOMENTE das Questøes } 2,3,4,5,6 \text { e } 7\end{array}$ & $\begin{array}{l}\text { Nenhuma } \\
\text { intervençäo }\end{array}$ & $\begin{array}{c}\text { Receber } \\
\text { Intervençäo Breve }\end{array}$ & $\begin{array}{l}\text { Encaminhar para tratamento } \\
\text { mais intensivo }\end{array}$ \\
\hline Tabaco & & $0-3$ & $4-26$ & 27 ou mais \\
\hline Alcool & & $0-10$ & $11-26$ & 27 ou mais \\
\hline Maconha & & $0-3$ & $4-26$ & 27 ou mais \\
\hline Cocaina & & $0-3$ & $4-26$ & 27 ou mais \\
\hline Anfetaminas & & $0-3$ & $4-26$ & 27 ou mais \\
\hline Inalantes & & $0-3$ & $4-26$ & 27 ou mais \\
\hline Hipnóticos/sedativos & & $0-3$ & $4-26$ & 27 ou mais \\
\hline Alucinógenos & & $0-3$ & $4-26$ & 27 ou mais \\
\hline Opioides & & $0-3$ & $4-26$ & 27 ou mais \\
\hline
\end{tabular}

Cálculo do escore de envolvimento com uma substância especifica.

Para cada substância (de 'a' a 'j') some os escores obtidos nas questoes 2 a 7 (inclusive).

Nao inclua os resultados das questoes 1 e 8 aqui.

Por exemplo, um escore para maconha deverá ser calculado do seguinte modo: $02 c+Q 3 c+Q 4 c+Q 5 c+Q 6 c+Q 7 c$

Note que Q5 para tabaco nâo é codificada, sendo a pontuaçăo para tabaco = Q2a + Q3a + Q4a + Q6a + Q7a 


\section{ANEXO B - Questionário ASSIST - Versão Adaptada - Autopreenchimento}

Instruções de preenchimento. Leia atentamente antes de preencher:

1. Este questionário avalia o seu envolvimento com álcool, tabaco e outras substâncias, identificando seu nível de uso ou problemas associados.

2. Todas as respostas são confidenciais e o preenchimento é individual. Não coloque seu nome no questionário.

3.A sua sinceridade nas respostas é muito importante.

4.Só responda depois de ler com bastante atenção as perguntas e as alternativas dadas. Se não souber responder uma questão ou se não se sentir a vontade em respondê-la, deixe-a em branco.

5. Todas as questões trazem instruções de preenchimento.

6. Algumas das perguntas serão sobre suas experiências nos últimos 3 meses e outras serão sobre a vida toda.

7. As substâncias podem ter sido fumadas, aspiradas, cheiradas, injetadas, ingeridas ou tomadas em pílulas ou comprimidos.

8. Algumas das substâncias podem ter sido receitadas pelo seu médico (como sedativos ou ansiolíticos, medicamentos para emagrecer, medicamentos para dor, etc.). Por favor, quando a medicação tiver sido receitada pelo seu médico não registre nada. Entretanto, se você tomou essas medicações por outros motivos diferentes daquele pelo qual foi receitado, ou estiver usando mais freqüentemente ou em doses maiores do que as receitadas, ai então, registre o uso destas substâncias.

9. Existem algumas perguntas sobre o uso de drogas ilícitas. Entretanto, qualquer informação que você nos forneça será tratada como confidencial.

10. Ao finalizar o preenchimento deposite o questionário no envelope e o entregue ao instrutor.

11. Sua contribuição é muito importante para essa pesquisa. Agradecemos a sua colaboração!

\section{Por favor, marque uma resposta para cada substância usada}

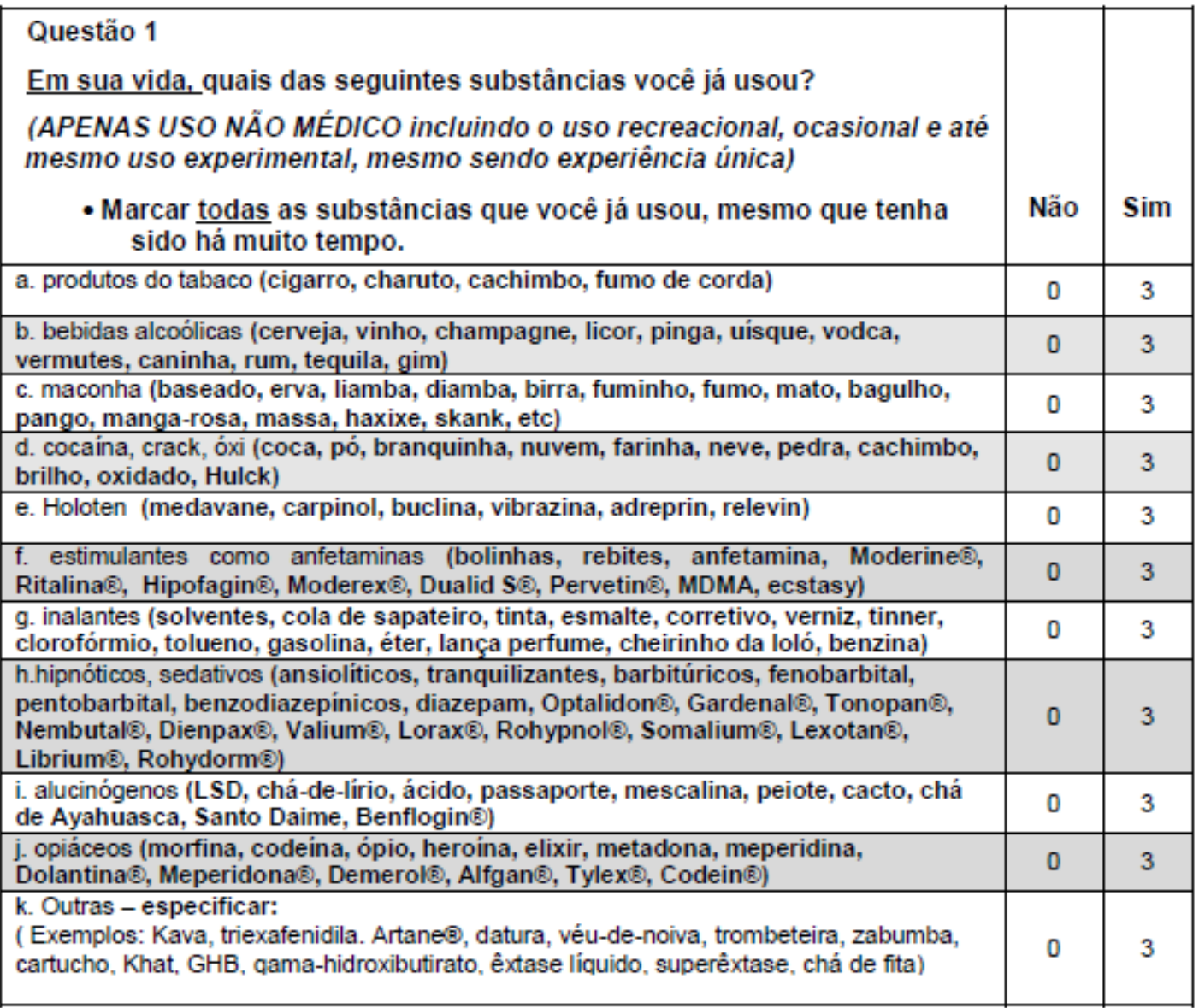


Se você respondeu "Näo" para todas as substâncias da Questão 1 (i.e. NUNCA experimentou qualquer uma destas substâncias) não precisa continuar respondendo, mas por favor devolva esse questionário.

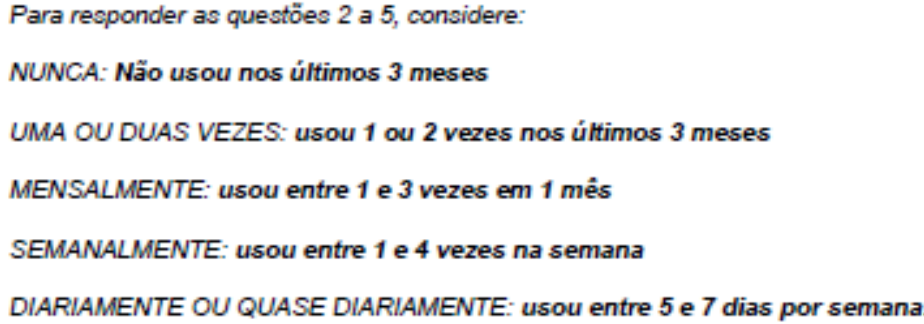

\begin{tabular}{|c|c|c|c|c|c|}
\hline $\begin{array}{l}\text { Questão } 2 \\
\text { Nos últimos três meses, com que freqüência você usou as } \\
\text { substâncias que vocề marcou na questão } 1 \text { (responda essa } \\
\text { questão para todas as drogas assinaladas na questão 1)? }\end{array}$ & 焉 & 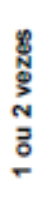 & 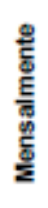 & 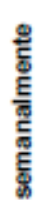 & 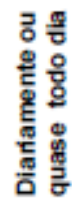 \\
\hline a. produtos do tabaco (cigarro, charuto, cachimbo, fumo de corda) & 0 & 2 & 3 & 4 & 6 \\
\hline $\begin{array}{l}\text { b. bebidas alcoólicas (cerveja, vinho, champagne, licor, pinga, uisque, } \\
\text { vodca, vermutes, caninha, rum, tequila, gim) }\end{array}$ & 0 & 2 & 3 & 4 & 6 \\
\hline $\begin{array}{l}\text { c. maconha (baseado, erva, liamba, diamba, birra, fuminho, fumo, mato, } \\
\text { bagulho, pango, manga-rosa, massa, haxixe, skank, etc) }\end{array}$ & 0 & 2 & 3 & 4 & 6 \\
\hline $\begin{array}{l}\text { d. cocaína, crack, óxi (coca, pó, branquinha, nuvem, farinha, neve, pedra, } \\
\text { cachimbo, brilho, oxidado, Hulck) }\end{array}$ & 0 & 2 & 3 & 4 & 6 \\
\hline e. Holoten (medavane, carpinol, buclina, vibrazina, adreprin, relevin) & 0 & 2 & 3 & 4 & 6 \\
\hline 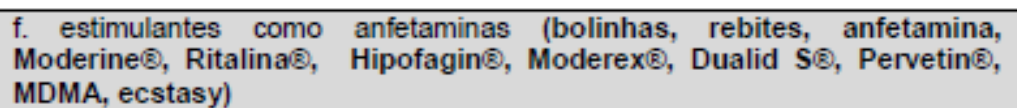 & 0 & 2 & 3 & 4 & 6 \\
\hline $\begin{array}{l}\text { g. inalantes (solventes, cola de sapateiro, tinta, esmalte, corretivo, } \\
\text { verniz, tinner, clorofórmio, tolueno, gasolina, éter, lança perfume, } \\
\text { cheirinho da loló, benzina) }\end{array}$ & 0 & 2 & 3 & 4 & 6 \\
\hline 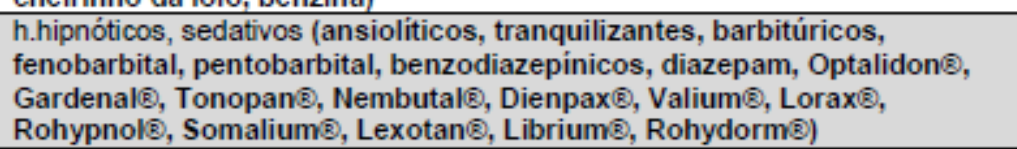 & 0 & 2 & 3 & 4 & 6 \\
\hline $\begin{array}{l}\text { i. alucinógenos (LSD, chá-de-lírio, ácido, passaporte, mescalina, peiote, } \\
\text { cacto, chá de Ayahuasca, Santo Daime, Benflogin@) }\end{array}$ & 0 & 2 & 3 & 4 & 6 \\
\hline 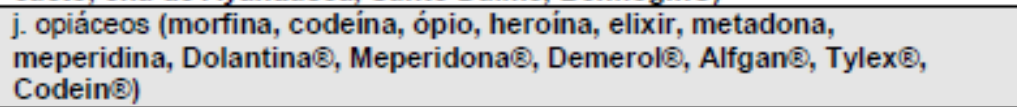 & 0 & 2 & 3 & 4 & 6 \\
\hline $\begin{array}{l}\text { k. Outras - especificar: } \\
\text { ( Exemplos: Kava, triexafenidila. Artane@, datura, véu-de-noiva, trombeteira, } \\
\text { zabumba, cartucho, Khat, GHB, gama-hidroxibutirato, êxtase liquido, } \\
\text { superêxtase, chá de fita) }\end{array}$ & 0 & 2 & 3 & 4 & 6 \\
\hline
\end{tabular}

\section{Se respondeu "Nunca" para todos os itens da Questão 2, pule para a Questão 6.}

Se qualquer uma das substâncias marcadas na Questão 2 foi usada nos três meses anteriores, continue respondendo as Questôes 3, 4 e 5 para cada substância usada. 
Por favor, marque uma resposta para cada substância usada nos últimos 3 meses

\begin{tabular}{|c|c|c|c|c|c|}
\hline $\begin{array}{l}\text { Questão } 3 \\
\text { Durante os três últimos meses, com que frequência você teve } \\
\text { um forte desejo ou urgência ou uma vontade incontrolável em } \\
\text { consumir? } \\
\text { DESEJO = craving ou fissura } \\
\text { (responda essa questão para todas as drogas assinaladas na } \\
\text { questão 2) }\end{array}$ & 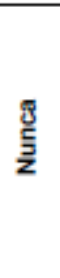 & 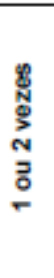 & 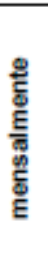 & 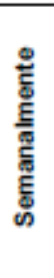 & 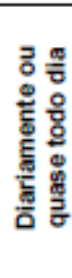 \\
\hline a. produtos do tabaco (cigarro, charuto, cachimbo, fumo de corda) & 0 & 3 & 4 & 5 & 6 \\
\hline $\begin{array}{l}\text { b. bebidas alcoólicas (cerveja, vinho, champagne, licor, pinga, uísque, } \\
\text { vodca, vermutes, caninha, rum, tequila, gim) }\end{array}$ & 0 & 3 & 4 & 5 & 6 \\
\hline $\begin{array}{l}\text { c. maconha (baseado, erva, liamba, diamba, birra, fuminho, fumo, mato, } \\
\text { bagulho, pango, manga-rosa, massa, haxixe, skank, etc) }\end{array}$ & 0 & 3 & 4 & 5 & 6 \\
\hline $\begin{array}{l}\text { d. cocaína, crack, óxi (coca, pó, branquinha, nuvem, farinha, neve, pedra, } \\
\text { cachimbo, brilho, oxidado, Hulck) }\end{array}$ & 0 & 3 & 4 & 5 & 6 \\
\hline e. Holoten (medavane, carpinol, buclina, vibrazina, adreprin, relevin) & 0 & 3 & 4 & 5 & 6 \\
\hline $\begin{array}{l}\text { f. estimulantes como anfetaminas (bolinhas, rebites, anfetamina, } \\
\text { Moderine } 8 \text {, Ritalina } 8 \text {, Hipofagin } 8 \text {, Moderex(B), Dualid S } 8 \text {, Pervetin } 8 \text {, } \\
\text { MDMA, ecstasy) }\end{array}$ & 0 & 3 & 4 & 5 & 6 \\
\hline $\begin{array}{l}\text { g. inalantes (solventes, cola de sapateiro, tinta, esmalte, corretivo, } \\
\text { verniz, tinner, clorofórmio, tolueno, gasolina, éter, lança perfume, } \\
\text { cheirinho da loló, benzina) }\end{array}$ & 0 & 3 & 4 & 5 & 6 \\
\hline 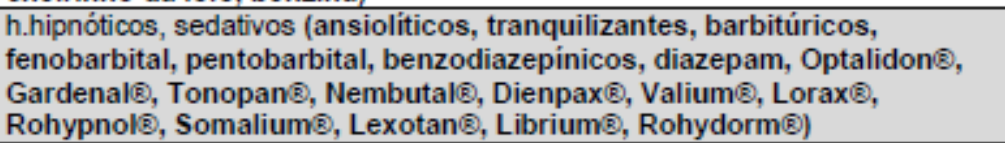 & 0 & 3 & 4 & 5 & 6 \\
\hline $\begin{array}{l}\text { i. alucinógenos (LSD, chá-de-lírio, ácido, passaporte, mescalina, peiote, } \\
\text { cacto, chá de Ayahuasca, Santo Daime, Benflogin @) }\end{array}$ & 0 & 3 & 4 & 5 & 6 \\
\hline 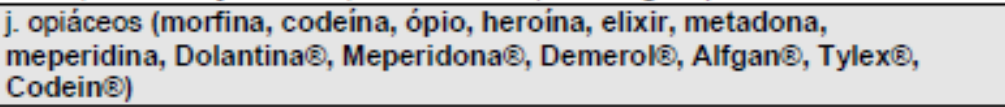 & 0 & 3 & 4 & 5 & 6 \\
\hline $\begin{array}{l}\text { l. Outras - especificar: } \\
\text { ( Exemplos: Kava, triexafenidila. Artane@, datura, véu-de-noiva, trombeteira, } \\
\text { zabumba, cartucho, Khat, GHB, gama-hidroxibutirato, êxtase liquido, } \\
\text { superêxtase, chá de fita) }\end{array}$ & 0 & 3 & 4 & 5 & 6 \\
\hline
\end{tabular}


Por favor, marque uma resposta para cada substância usada nos últimos 3 meses

\begin{tabular}{|c|c|c|c|c|c|}
\hline 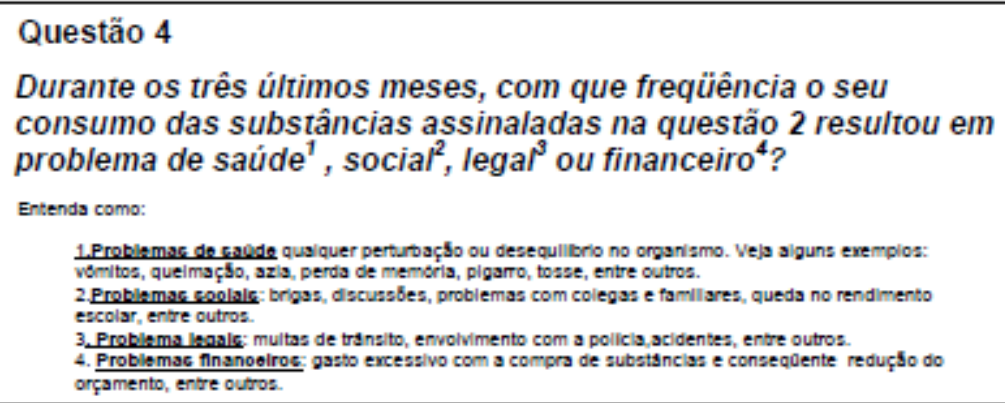 & 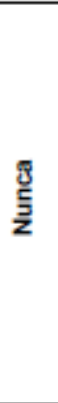 & 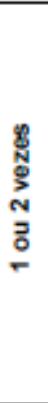 & 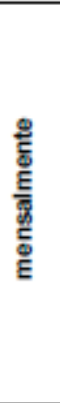 & 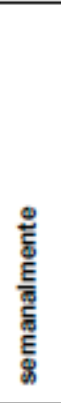 & 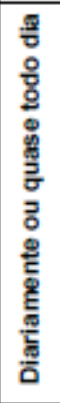 \\
\hline a. produtos do tabaco (cigarro, charuto, cachimbo, fumo de corda) & 0 & 4 & 5 & 6 & 7 \\
\hline $\begin{array}{l}\text { b. bebidas alcoólicas (cerveja, vinho, champagne, licor, pinga, uísque, } \\
\text { vodca, vermutes, caninha, rum, tequila, gim) }\end{array}$ & 0 & 4 & 5 & 6 & 7 \\
\hline $\begin{array}{l}\text { c. maconha (baseado, erva, liamba, diamba, birra, fuminho, fumo, mato, } \\
\text { bagulho, pango, manga-rosa, massa, haxixe, skank, etc) }\end{array}$ & 0 & 4 & 5 & 6 & 7 \\
\hline $\begin{array}{l}\text { d. cocaína, crack, óxi (coca, pó, branquinha, nuvem, farinha, neve, pedra, } \\
\text { cachimbo, brilho, oxidado, Hulck) }\end{array}$ & 0 & 4 & 5 & 6 & 7 \\
\hline e. Holoten (medavane, carpinol, buclina, vibrazina, adreprin, relevin) & 0 & 4 & 5 & 6 & 7 \\
\hline $\begin{array}{ll}\text { f. estimulantes como anfetaminas (bolinhas, rebites, anfetamina, } \\
\text { Moderine } 8 \text {, Ritalina } 8 \text {, Hipofagin }(8 \text {, Moderex } 8 \text {, Dualid } \mathbf{S} 8 \text {, Pervetin } \otimes \text {, } \\
\text { MDMA, ecstasy) }\end{array}$ & 0 & 4 & 5 & 6 & 7 \\
\hline $\begin{array}{l}\text { g. inalantes (solventes, cola de sapateiro, tinta, esmalte, corretivo, } \\
\text { verniz, tinner, clorofórmio, tolueno, gasolina, éter, lança perfume, } \\
\text { cheirinho da loló, benzina) }\end{array}$ & 0 & 4 & 5 & 6 & 7 \\
\hline 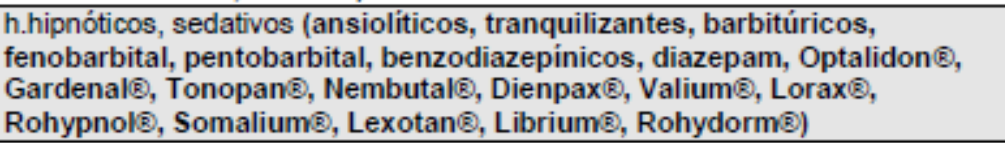 & 0 & 4 & 5 & 6 & 7 \\
\hline $\begin{array}{l}\text { i. alucinógenos (LSD, chá-de-lírio, ácido, passaporte, mescalina, peiote, } \\
\text { cacto, chá de Ayahuasca, Santo Daime, Benflogin@) }\end{array}$ & 0 & 4 & 5 & 6 & 7 \\
\hline $\begin{array}{l}\text { j. opiáceos (morfina, codeína, ópio, heroína, elixir, metadona, } \\
\text { meperidina, Dolantina®, Meperidona®, Demerol@, Alfgan®, Tylex®, } \\
\text { Codein®) }\end{array}$ & 0 & 4 & 5 & 6 & 7 \\
\hline $\begin{array}{l}\text { k. Outras - especificar: } \\
\text { ( Exemplos: Kava, triexafenidila. Artane@, datura, véu-de-noiva, trombeteira, } \\
\text { zabumba, cartucho, Khat, GHB, gama-hidroxibutirato, êxtase líquido, } \\
\text { superêxtase, chá de fita) }\end{array}$ & 0 & 4 & 5 & 6 & 7 \\
\hline
\end{tabular}


Por favor, marque uma resposta para cada substância usada nos últimos 3 meses

\begin{tabular}{|c|c|c|c|c|c|}
\hline $\begin{array}{l}\text { Questão } 5 \\
\text { Durante os três últimos meses, com que freqüência você deixou } \\
\text { de fazer coisas que eram normalmente esperadas de você } \\
\text { devido ao consumo das substâncias assinaladas na questão } \\
\text { 2? } \\
\text { Exemploc: Falta ac aulac, đelxou do rosllzar trabalhoc, osquocimento de oompromiscoc importantoc, ontro } \\
\text { outroc. }\end{array}$ & 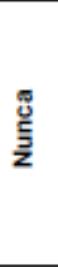 & 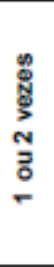 & 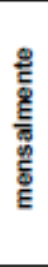 & 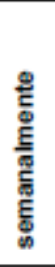 & 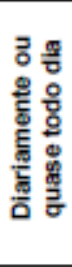 \\
\hline a. produtos do tabaco (cigarro, charuto, cachimbo, fumo de corda) & 0 & 5 & 6 & 7 & 8 \\
\hline $\begin{array}{l}\text { b. bebidas alcoólicas (cerveja, vinho, champagne, licor, pinga, uísque, } \\
\text { vodca, vermutes, caninha, rum, tequila, gim) }\end{array}$ & 0 & 5 & 6 & 7 & 8 \\
\hline $\begin{array}{l}\text { c. maconha (baseado, erva, liamba, diamba, birra, fuminho, fumo, mato, } \\
\text { bagulho, pango, manga-rosa, massa, haxixe, skank, etc) }\end{array}$ & 0 & 5 & 6 & 7 & 8 \\
\hline $\begin{array}{l}\text { d. cocaína, crack, óxi (coca, pó, branquinha, nuvem, farinha, neve, pedra, } \\
\text { cachimbo, brilho, oxidado, Hulck) }\end{array}$ & 0 & 5 & 6 & 7 & 8 \\
\hline e. Holoten (medavane, carpinol, buclina, vibrazina, adreprin, relevin) & 0 & 5 & 6 & 7 & 8 \\
\hline 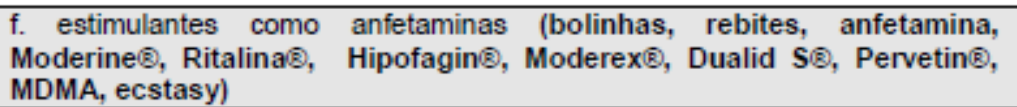 & 0 & 5 & 6 & 7 & 8 \\
\hline $\begin{array}{l}\text { g. inalantes (solventes, cola de sapateiro, tinta, esmalte, corretivo, } \\
\text { verniz, tinner, clorofórmio, tolueno, gasolina, éter, lança perfume, } \\
\text { cheirinho da loló, benzina) }\end{array}$ & 0 & 5 & 6 & 7 & 8 \\
\hline 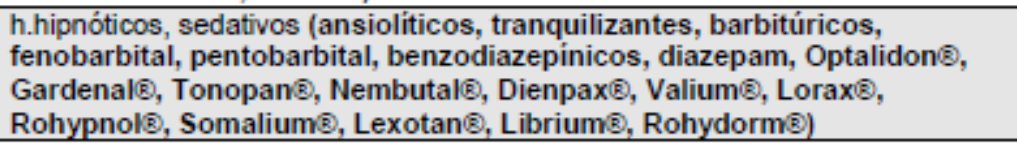 & 0 & 5 & 6 & 7 & 8 \\
\hline $\begin{array}{l}\text { i. alucinógenos (LSD, chá-de-lírio, ácido, passaporte, mescalina, peiote, } \\
\text { cacto, chá de Ayahuasca, Santo Daime, Benflogin@) }\end{array}$ & 0 & 5 & 6 & 7 & 8 \\
\hline 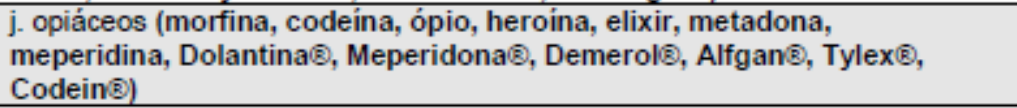 & 0 & 5 & 6 & 7 & 8 \\
\hline $\begin{array}{l}\text { k. Outras: especificar } \\
\text { ( Exemplos: Kava, triexafenidila. Artane@, datura, véu-de-noiva, trombeteira, } \\
\text { zabumba, cartucho, Khat, GHB, gama-hidroxibutirato, êxtase líquido, } \\
\text { superêxtase, chá de fita) }\end{array}$ & 0 & 5 & 6 & 7 & 8 \\
\hline
\end{tabular}


Questões 6 e 7 - Por favor marque uma resposta para cada substância usada na sua vida (aquelas assinaladas na questão 1)

\begin{tabular}{|c|c|c|c|}
\hline 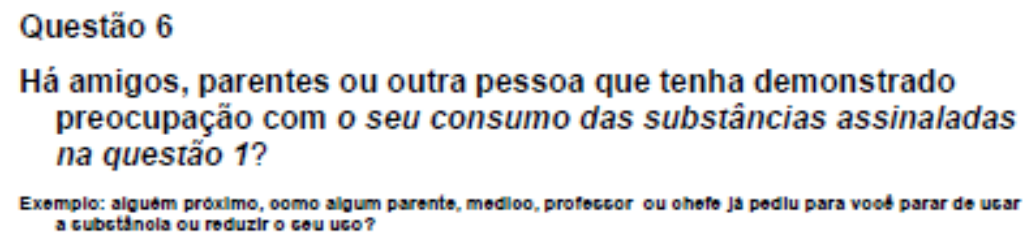 & 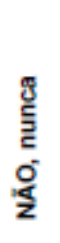 & 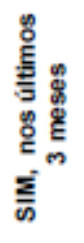 & 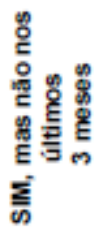 \\
\hline a. produtos do tabaco (cigarro, charuto, cachimbo, fumo de corda) & 0 & 6 & 3 \\
\hline $\begin{array}{l}\text { b. bebidas alcoólicas (cerveja, vinho, champagne, licor, pinga, uísque, } \\
\text { vodca, vermutes, caninha, rum, tequila, gim) }\end{array}$ & 0 & 6 & 3 \\
\hline $\begin{array}{l}\text { c. maconha (baseado, erva, liamba, diamba, birra, fuminho, fumo, mato, } \\
\text { bagulho, pango, manga-rosa, massa, haxixe, skank, etc) }\end{array}$ & 0 & 6 & 3 \\
\hline $\begin{array}{l}\text { d. cocaína, crack, óxi (coca, pó, branquinha, nuvem, farinha, neve, pedra, } \\
\text { cachimbo, brilho, oxidado, Hulck) }\end{array}$ & 0 & 6 & 3 \\
\hline e. Holoten (medavane, carpinol, buclina, vibrazina, adreprin, relevin) & 0 & 6 & 3 \\
\hline $\begin{array}{l}\text { f. estimulantes como anfetaminas (bolinhas, rebites, anfetamina, Moderine } ₫ \text {, } \\
\text { Ritalina } \otimes \text {, Hipofagin }(\text {, Moderex }(8 \text {, Dualid } S \otimes, \text { Pervetin } 8 \text {, MDMA, ecstasy) }\end{array}$ & 0 & 6 & 3 \\
\hline $\begin{array}{l}\text { g. inalantes (solventes, cola de sapateiro, tinta, esmalte, corretivo, verniz, } \\
\text { tinner, clorofórmio, tolueno, gasolina, éter, lança perfume, cheirinho da } \\
\text { loló, benzina) }\end{array}$ & 0 & 6 & 3 \\
\hline 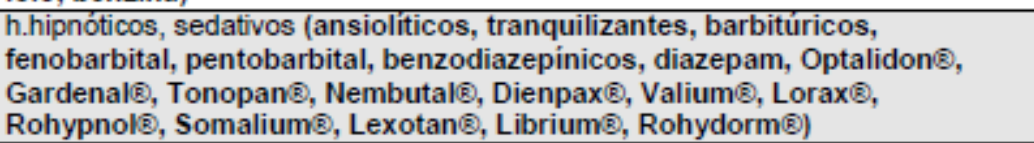 & 0 & 6 & 3 \\
\hline $\begin{array}{l}\text { i. alucinógenos (LSD, chá-de-lírio, ácido, passaporte, mescalina, peiote, } \\
\text { cacto, chá de Ayahuasca, Santo Daime, Benflogin@) }\end{array}$ & 0 & 6 & 3 \\
\hline 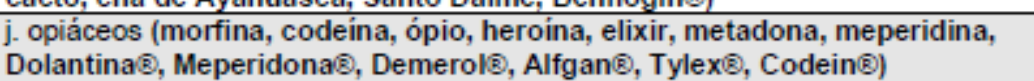 & 0 & 6 & 3 \\
\hline $\begin{array}{l}\text { k. Outras. especificar: } \\
\text { (Exemplos: Kava, triexafenidila. Artane@, datura, véu-de-noiva, trombeteira, } \\
\text { zabumba, cartucho, Khat, GHB, gama-hidroxibutirato, êxtase líquido, } \\
\text { superêxtase, chá de fita) }\end{array}$ & 0 & 6 & 3 \\
\hline
\end{tabular}




\begin{tabular}{|c|c|c|c|c|}
\hline \multicolumn{2}{|c|}{$\begin{array}{l}\text { Questão } 7 \\
\text { Alguma vez você já tentou controlar, diminuir ou parar o uso das } \\
\text { substâncias assinaladas na questão } 1 \text { e não conseguiu? }\end{array}$} & 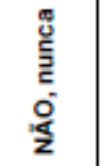 & 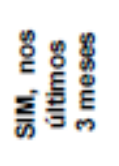 & 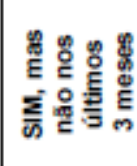 \\
\hline \multicolumn{2}{|l|}{ a. produtos do tabaco (cigarro, charuto, cachimbo, fumo de corda) } & 0 & 6 & 3 \\
\hline \multicolumn{2}{|l|}{$\begin{array}{l}\text { b. bebidas alcoólicas (cerveja, vinho, champagne, licor, pinga, uisque, } \\
\text { vodca, vermutes, caninha, rum, tequila, gim) }\end{array}$} & 0 & 6 & 3 \\
\hline \multicolumn{2}{|l|}{$\begin{array}{l}\text { c. maconha (baseado, erva, liamba, diamba, birra, fuminho, fumo, mato, } \\
\text { bagulho, pango, manga-rosa, massa, haxixe, skank, etc) }\end{array}$} & 0 & 6 & 3 \\
\hline \multicolumn{2}{|l|}{$\begin{array}{l}\text { d. cocaína, crack, óxi (coca, pó, branquinha, nuvem, farinha, neve, pedra, } \\
\text { cachimbo, brilho, oxidado, Hulck) }\end{array}$} & 0 & 6 & 3 \\
\hline \multicolumn{2}{|l|}{ e. Holoten (medavane, carpinol, buclina, vibrazina, adreprin, relevin) } & 0 & 6 & 3 \\
\hline \multicolumn{2}{|c|}{ 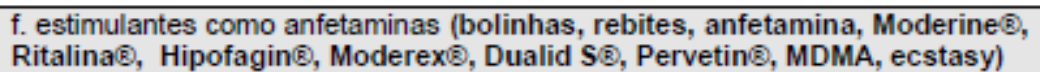 } & 0 & 6 & 3 \\
\hline \multicolumn{2}{|c|}{$\begin{array}{l}\text { g. inalantes (solventes, cola de sapateiro, tinta, esmalte, corretivo, verniz, } \\
\text { tinner, clorofórmio, tolueno, gasolina, éter, lança perfume, cheirinho da } \\
\text { loló, benzina) }\end{array}$} & 0 & 6 & 3 \\
\hline \multicolumn{2}{|c|}{ 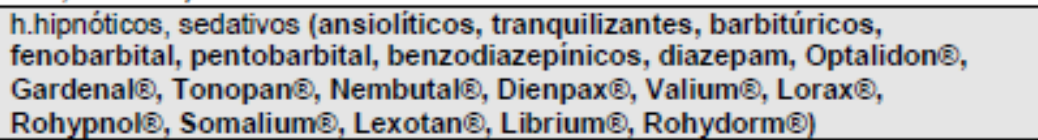 } & 0 & 6 & 3 \\
\hline \multicolumn{2}{|c|}{$\begin{array}{l}\text { i. alucinógenos (LSD, chá-de-lírio, ácido, passaporte, mescalina, peiote, } \\
\text { cacto, chá de Ayahuasca, Santo Daime, Benflogin@) }\end{array}$} & 0 & 6 & 3 \\
\hline \multicolumn{2}{|c|}{ 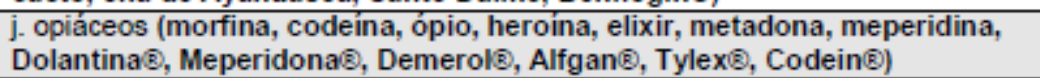 } & 0 & 6 & 3 \\
\hline \multicolumn{2}{|c|}{$\begin{array}{l}\text { k. Outras.especificar: } \\
\text { ( Exemplos: Kava, triexafenidila. Artane@, datura, véu-de-noiva, trombeteira, } \\
\text { zabumba, cartucho, Khat, GHB, gama-hidroxibutirato, êxtase líquido, } \\
\text { superêxtase, chá de fita) }\end{array}$} & 0 & 6 & 3 \\
\hline \multirow[t]{2}{*}{$\begin{array}{l}\text { Questão } 8 \text { - Alguma vez você já usou drogas por injeção? } \\
\text { (Apenas uso não- médico) }\end{array}$} & $\begin{array}{l}\text { NÃO, } \\
\text { nunca }\end{array}$ & $\begin{array}{l}\text { SIM, nos } \\
\text { últimos } \\
3 \text { meses }\end{array}$ & \multicolumn{2}{|c|}{$\begin{array}{l}\text { SIM, mas não } \\
\text { nos últimos } 3 \\
\text { meses }\end{array}$} \\
\hline & 0 & & & \\
\hline
\end{tabular}


ANEXO C - Tabela de Pontuação da Versão Adaptada para Autopreenchimento do ASSIST

PONTUAÇÃO PARA CADA DROGA

Some os números assinalados nas questões $2,3,4,5,6$ e 7 para cada droga. $O$ resultado indicará a faixa de risco do seu padrão de consumo. Para ficar mais claro o seu nível de risco com o uso da droga recomendamos que você assinale, no quadro abaixo, a faixa de risco correspondente à pontuação obtida para cada droga:

\begin{tabular}{|l|c|}
\hline & $\begin{array}{c}\text { Soma dos } \\
\text { números } \\
\text { assinalados nas } \\
\text { questöes 2, 3, 4, } \\
5,6 \text { e 7 para } \\
\text { cada droga }\end{array}$ \\
\hline Tabaco & \\
\hline Allcool & \\
\hline Maconha & \\
\hline Cocaína & \\
\hline Estimulantes tipo anfetamina & \\
\hline Inalantes \\
\hline Hipnóticos/sedatives \\
\hline Alucinógenos \\
\hline Opióides \\
\hline
\end{tabular}
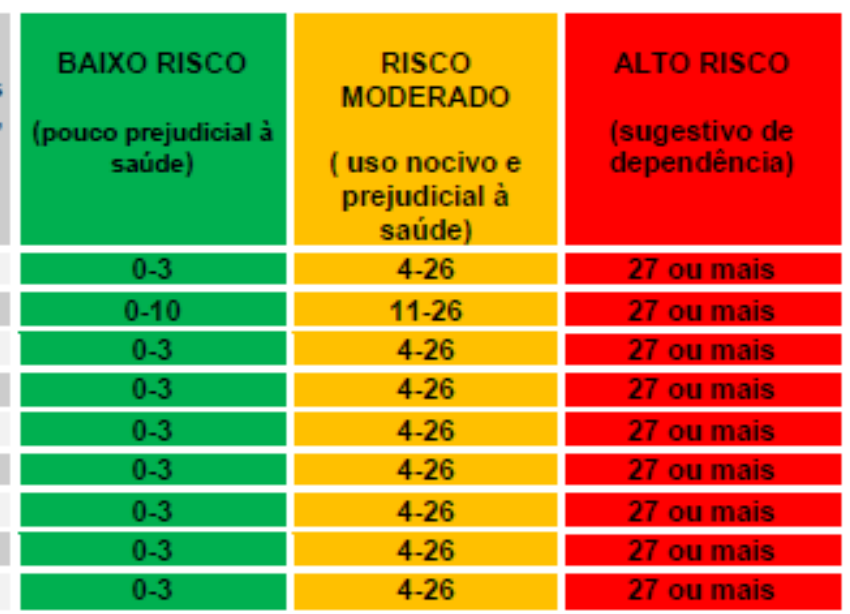

\section{SIGNIFICADO DAS DIFERENTES FAIXAS DE RISCO}

BAIXO RISCO - Se você atingiu esse escore você apresenta baixo risco de estar atualmente experimentando algum dos problemas relacionados ao uso de substâncias (problemas de saúde, problemas sociais, financeiros e legais). Você também possui um baixo risco de desenvolver problemas futuros SE ESSE PADRÃO DE USO FOR MANTIDO.

RISCO MODERADO - indivíduo que atinge esse escore já pode estar apresentando alguns problemas, inclusive problemas de saúde. Caso ainda não apresente, se continuar com esse padrão de uso, provavelmente terá problemas futuros de saúde e outros problemas, incluindo a possibilidade de desenvolver dependência. Para evitar problemas futuros e amenizar problemas atuais é recomendado reduzir o consumo da substância ou até mesmo parar o seu uso.

ALTO RISCO - indivíduo que atinge esse escore provavelmente já está apresentando problemas relacionados ao uso de substância, podendo ser problemas de saúde, social, financeiro, legal ou de relacionamento. Como essa faixa de risco é uma faixa sugestiva de dependência recomenda-se procurar atendimento especializado para auxiliar na resolução dos problemas. Você pode procurar um médico de sua confiança ou então procurar a Unidade Básica de Saúde mais próxima de sua residência onde você será avaliado pelo médico que fará os encaminhamentos necessários. 
ANEXO D - Parecer do Comitê de Ética em Pesquisa

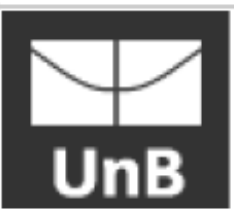

\section{FACULDADE DE CIÊNCIAS DA SAÚDE DA UNIVERSIDADE DE BRASÍLIA - CEP/FS-UNB}

\section{PARECER CONSUBSTANCIADO DO CEP}

\section{DADOS DO PROJETO DE PESQUISA}

Título da Pesquisa: Prevalência do uso de álcool e de tabaco entre alunos do Curso de Enfermagem em duas Faculdades Privadas do Distrito Federal

Pesquisador: Samuel Rios Teixeira

Área Temática:

Versão: 2

CAAE: 52136415.8 .0000 .0030

Instituição Proponente: Programa de Pós Graduação em Enfermagem - Mestrado - Universidade de Patrocinador Principal: Financiamento Próprio

DADOS DO PARECER

Número do Parecer: 1.429 .776

Situação do Parecer:

Aprovado

Necessita Apreciação da CONEP:

Não

BRASILIA, 29 de Fevereiro de 2016

\footnotetext{
Assinado por:

Keila Elizabeth Fontana

(Coordenador)
} 


\section{ANEXO E - Termo de Consentimento Livre e Esclarecido - TCLE}

Convidamos o(a) Senhor(a) a participar do projeto de pesquisa Prevalência do uso de álcool e de tabaco entre alunos do curso de enfermagem em duas faculdades privadas do Distrito Federal, sob a responsabilidade do pesquisador Samuel Rios Teixeira. O projeto envolverá alunos matriculados nos cursos de enfermagem de duas faculdades privadas do Distrito Federal com o objetivo de conhecer a magnitude e o perfil de risco do consumo de álcool e de tabaco por estudantes de enfermagem dessas instituições de ensino.

A sua participação é sigilosa e se dará por meio do preenchimento de um questionário fechado e anônimo a ser respondido nas dependências de sua faculdade no primeiro semestre letivo de 2016 com um tempo estimado de 5 minutos para sua realização. Os riscos desta participação estão relacionados à exposição de informações pessoais relativas ao consumo de tabaco e álcool, no entanto, o pesquisador se compromete e se responsabiliza pela confidencialidade dos seus dados. Se você aceitar participar, estará contribuindo para produzir informações a serem disponibilizadas às autoridades sanitárias, políticas e instituições de ensino superior como forma de subsidiar a adoção de programas, políticas de prevenção e/ou eliminação do consumo de álcool e tabaco entre os acadêmicos de enfermagem, futuros educadores em saúde.

$\mathrm{O}$ (a) Senhor(a) pode se recusar a responder (ou participar de qualquer procedimento) qualquer questão que lhe traga constrangimento, podendo desistir de participar da pesquisa em qualquer momento sem sofrer qualquer prejuízo. Sua participação é voluntária, isto é, não há pagamento por sua colaboração. Você não terá qualquer despesa para participar desta pesquisa.

Caso haja algum dano direto ou indireto decorrente de sua participação na pesquisa, você poderá ser indenizado, obedecendo-se as disposições legais vigentes no Brasil.

Os resultados da pesquisa serão divulgados na Universidade de Brasília e nas Faculdades onde foram coletados os dados, podendo ser publicados posteriormente. Os dados e materiais serão utilizados somente para esta pesquisa e ficarão sob a guarda do pesquisador por um período de cinco anos e, após este período, serão destruídos.

Havendo qualquer dúvida em relação à pesquisa, o contato poderá ser feito diretamente com o pesquisador Samuel Rios Teixeira no telefone (61) 82021766 inclusive por ligação a cobrar e sem restrição de horário ou pelo e-mail (ppgenf@unb.br).

Este projeto foi Aprovado pelo Comitê de Ética em Pesquisa da Faculdade de Ciências da Saúde (CEP/FS) da Universidade de Brasília. O CEP é composto por profissionais de diferentes áreas cuja função é defender os interesses dos participantes da pesquisa em sua integridade e dignidade e contribuir no desenvolvimento da pesquisa dentro de padrões éticos. As dúvidas com relação à assinatura do TCLE ou os direitos do participante da pesquisa podem ser esclarecidos pelo telefone (61) 3107-1947 ou do e-mail cepfs@unb.br ou cepfsunb@gmail.com, horário de atendimento de 10:00hs às 12:00hs e de 13:30hs às 15:30hs, de segunda a sexta-feira. O CEP/FS se localiza na Faculdade de Ciências da Saúde, Campus Universitário Darcy Ribeiro, Universidade de Brasília, Asa Norte.

Este documento tem duas vias. Uma ficará com você e a outra com o pesquisador.

Nome / assinatura do participante

Nome / assinatura do Pesquisador Responsável

Brasília, de de 